\title{
Study of Chemical States, Composition and Adsorption Behavior of Iron Coated Granular Activated Carbon (Fe-GAC) for Selenate Removal and Feasible Adsorbent Modifications
}

Ning Zhang

West Virginia University

Follow this and additional works at: https://researchrepository.wvu.edu/etd

\section{Recommended Citation}

Zhang, Ning, "Study of Chemical States, Composition and Adsorption Behavior of Iron Coated Granular Activated Carbon (Fe-GAC) for Selenate Removal and Feasible Adsorbent Modifications" (2012). Graduate Theses, Dissertations, and Problem Reports. 481.

https://researchrepository.wvu.edu/etd/481

This Dissertation is protected by copyright and/or related rights. It has been brought to you by the The Research Repository @ WVU with permission from the rights-holder(s). You are free to use this Dissertation in any way that is permitted by the copyright and related rights legislation that applies to your use. For other uses you must obtain permission from the rights-holder(s) directly, unless additional rights are indicated by a Creative Commons license in the record and/ or on the work itself. This Dissertation has been accepted for inclusion in WVU Graduate Theses, Dissertations, and Problem Reports collection by an authorized administrator of The Research Repository @ WVU.

For more information, please contact researchrepository@mail.wvu.edu. 


\title{
Study of Chemical States, Composition and Adsorption Behavior of Iron Coated Granular Activated Carbon (Fe-GAC) for Selenate Removal and Feasible Adsorbent Modifications
}

\author{
Ning Zhang \\ Dissertation submitted to the \\ College of Engineering and Mineral Resources \\ at West Virginia University \\ in partial fulfillment of the requirements \\ for the degree of
}

Doctor of Philosophy

In

Civil and Environmental Engineering

\author{
Approved by \\ Lian-Shin Lin, Ph.D., Chair \\ Dianchen Gang, Ph.D. \\ Nianqiang Wu, Ph.D. \\ Louis McDonald, Ph.D. \\ Paul Ziemkiewicz, Ph.D. \\ Jennifer Weidhaas, Ph.D.
}

Department of Civil and Environmental Engineering

\author{
Morgantown, West Virginia \\ 2012
}

Keywords: selenate removal, iron-coated GAC, adsorption isotherm, adsorption kinetics

Copyright 2012 Ning Zhang 


\title{
ABSTRACT \\ Study of Chemical States, Composition and Adsorption Behavior of Iron Coated Granular Activated Carbon (Fe-GAC) for Selenate Removal and Feasible Adsorbent Modifications
}

\author{
Ning Zhang
}

This study examined the adsorptive removal of selenate using iron coated granular activated carbon (Fe-GAC) and further investigated its complexation mechanisms and coordination structures using spectroscopic techniques. Adsorption kinetics and equilibrium experiments with initial selenium concentration of $1 \mathrm{mg} / \mathrm{L}$ were conducted under three different ionic strengths to study selenate adsorption behavior. Selenate adsorption reached equilibrium within 48 hours with more than $85 \%$ of the equilibrium capacities being obtained within the first 6 hours. High removal efficiency (i.e., $>75 \%$ ) was achieved for $\mathrm{pH}$ range 2 - 5. Pseudo-second-order kinetic model characterized selenate adsorption kinetics well $\left(\mathrm{R}^{2}=0.999\right)$ and the rate constant decreased with ionic strength. Adsorption capacity decreased significantly with increasing ionic strength, which was not observed in selenite adsorption with the same adsorbent. Competitive adsorption with other four oxy-anions $\left(\mathrm{SiO}_{3}{ }^{2-}, \mathrm{SO}_{4}{ }^{2-}, \mathrm{PO}_{4}{ }^{3-}\right.$ and $\mathrm{CO}_{3}{ }^{2-}$ ) showed that selenate removal efficiency was reduced to various degrees in the presence of each individual anion. Competitive adsorption of binary adsorbates (selenite and selenate) showed that the Fe-GAC had higher adsorption affinity for selenite over selenate and the adsorption preference increased with ionic strength. Sheindorf-Rebuhn-Sheintuch (SRS) multi-adsorbate competitive adsorption model was applied to quantify the binary competitive adsorption between selenate and selenite.

Acid-base titration experiments were carried out under three ionic strengths (i.e., 0.001, 0.01 and $0.1 \mathrm{M})$ and showed point of zero charge $\left(\mathrm{pH}_{\mathrm{pzc}}\right)$ at $\mathrm{pH} 7.8$ for the tested Fe-GAC. It indicates a preferred positively charged surface for anions under acidic conditions. Raman spectroscope was used to determine the type of surface complex and the coordination state of adsorbed selenate at different $\mathrm{pH}$ with $0.1 \mathrm{M}$ ionic strength. The results showed that inner-sphere and outer-sphere complexes were formed at $\mathrm{pH} 5$ and 8 , respectively. Additionally, mixture of mono-dentate and bi-dentate binding was observed at $\mathrm{pH} 5$ with selenate. In comparison, selenite was only observed to form bi-dentate inner sphere bindings with surface sites.

Three electrolytes ( $\mathrm{LiCl}, \mathrm{NaCl}$ and $\mathrm{KCl}$ ) were used as background electrolytes in this study to investigate their effects on selenate adsorption. Adsorption isotherms carried out under three ionic strengths $(0.01,0.05$ and $0.1 \mathrm{M})$ were all well fitted with the Freundlich isotherm $\left(\mathrm{R}^{2}>0.97\right)$. The results suggested that as ionic strength increased, selenate adsorption decreased to various degrees in the presence of all three electrolytes, which followed the order: $\mathrm{KCl}<\mathrm{NaCl}<\mathrm{LiCl}$. Additionally, under the same ionic strength controlled by three background electrolytes, Kruskal - Wallis Statistical Test showed increasing difference among selenate adsorption as ionic strengths increased from 0.01 to $0.1 \mathrm{M}$. This result can be attributed to the variations of cation radius. 
X-ray photoelectron spectroscope (XPS) was used to investigate the chemical state and composition of coated iron on GAC surface. The multiplet peak fitting results for high resolution XPS spectra for $\mathrm{O} 1 \mathrm{~s}$ and $\mathrm{Fe} 2 \mathrm{p} 3 / 2$ indicated that $\mathrm{Fe}(\mathrm{III})$ was formed after coated with $0.1 \mathrm{M}$ ferrous chloride, and $\alpha$-FeOOH was the possible chemical composition. Furthermore, the suspension of Fe-GAC in $\mathrm{NaCl}$ electrolytes at studied $\mathrm{pH}$ range (3 - 8) did not cause appreciable changes of iron chemical states and composition. Raman spectra for selenate loaded Fe-GAC indicated the formation of bidentate inner sphere complex at $\mathrm{pH}$ lower than 7 and a mixture of outer sphere and monodentate inner sphere complex at $\mathrm{pH}$ 8. Theses results explained the low selenate adsorption under alkaline conditions. Two modification methods of Fe-GAC preparation were proposed based on the XPS and Raman results: (1) binary coating with other metal oxides in order to increase the point of zero charge $\left(\mathrm{pH}_{\mathrm{zpc}}\right)$; and (2) ferrous iron coating to reduce selenate first followed by high adsorption removal of selenite. 


\section{ACKNOWLEDEMENT}

My greatest gratitude goes to my advisor, Dr. Lian-Shin Lin. He showed great patience and undertook tremendous responsibility of supervising me during my study and dissertation writing. Whenever I came up with any questions or problems, he was always there offering help and advices. His strictness with science and industrious attitude set an extraordinary example for me and my future career. His broad knowledge and great idea enlightened me a lot in my research work. It was with his encouragement and help that I could be confident in completing the whole research project.

My thanks are also extended to my entire Ph.D. committees: Drs. Dianchen Gang, Louis McDonald, Paul Ziemkiewicz, Jennifer Weidhaas and Nianqiang Wu. I cordially appreciate their times for serving in my committees and their advices on my research development and dissertation completion. I specially thank Dr. McDonald for his ICPOES supply for my analytical testing. Drs. Wu and Dr. McDonald also provided numerous help in Raman and XPS analysis and results interpretations. Special thanks also go to Dr. Gang for his suggestions on experimental design and implementation. I greatly appreciate the help of Drs. Ziemkiewicz and Weidhaas for my dissertation writing. Their nice personality gave me much encouragement for the project.

The same thanks go to my parents and my husband. During the period of my study at WVU, they devoted their love, care and generosity to me. Their supports always encourage me toward accomplishing my study. In addition, I would like to thank my friends and fellow students: Donglin Huang, Ming Li, Yushun Chen and his wife Jinyan Sun, Hang Li and her husband Yuncheng Wang, Chenjie Wu, Lina Cui, Isabel Cardona and Dongyang Deng who were always ready to help when I had difficulties in conducting my research.

Last but not least, my thanks go to all the other faculties and staffs in the Civil and Environmental Engineering, WVU: Drs. Xinchao Wei, Hoil Park, Karen Buzby, and Research Assistant Will Ravenscroft. Their help and assistance allowed me to finish my research smoothly. I would also like to express my thanks to the staff in WVU Shared 
Research Facilities (SRFs) for their kindness in providing training and technical support for instrument operation and maintenance. Additionally, my thanks go to Center of Advanced Separation Technologies (CAST) and WV Department of Energy for their funding support of this study. 


\section{TABLE OF CONTENTS}

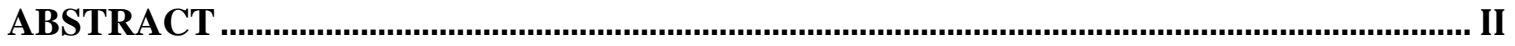

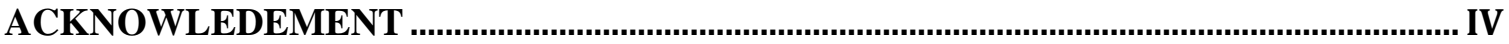

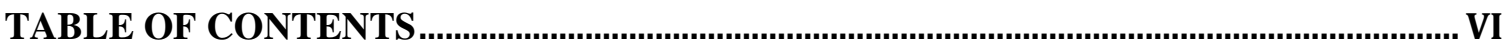

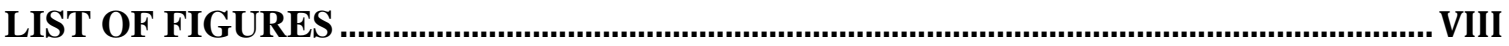

LIST OF TABLES

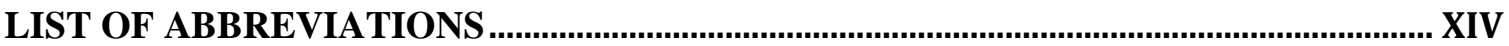

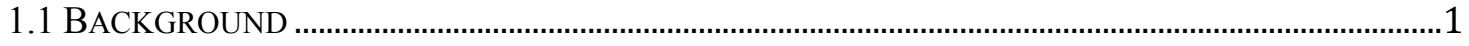

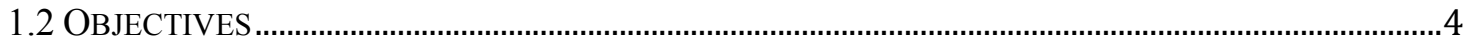

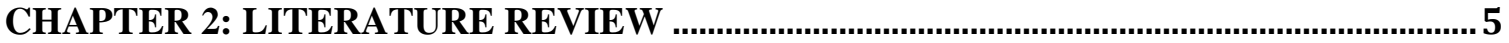

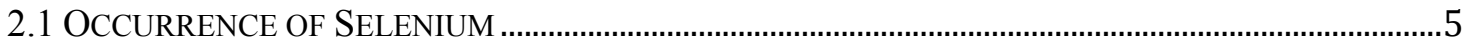

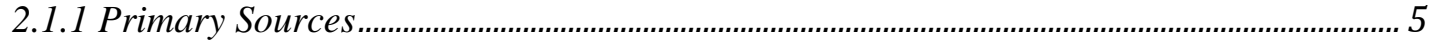

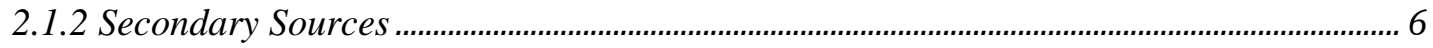

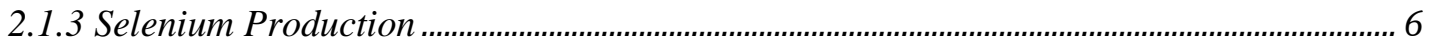

2.2 CHEMICAL SPECIES AND TRANSFORMATION OF SELENIUM.........................................................6

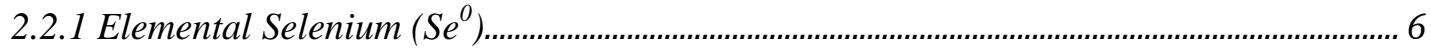

2.2.2 Selenide $\left(\mathrm{Se}^{2-}\right)$.......................................................................................................................... 7

2.2.3 Selenite $\left(\mathrm{SeO}_{3}{ }^{2-}\right)$...................................................................................................................... 7

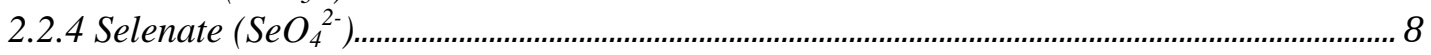

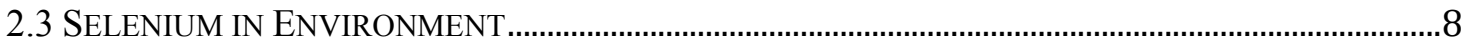

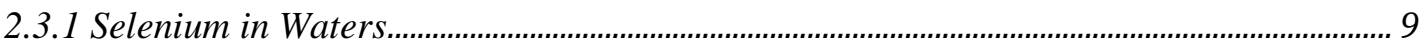

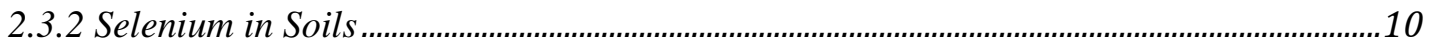

2.3.3 Selenium in Atmosphere

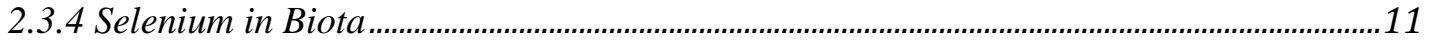

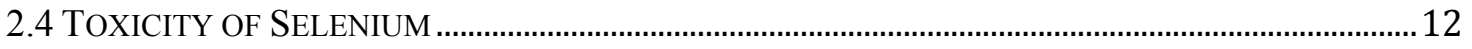

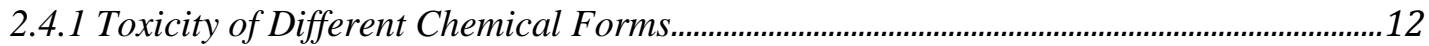

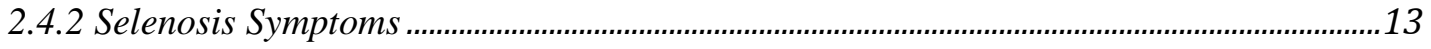

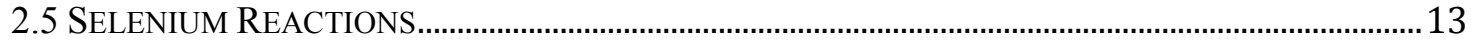

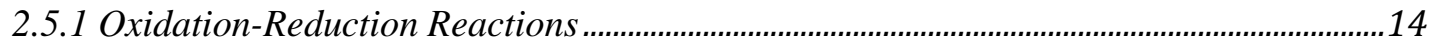

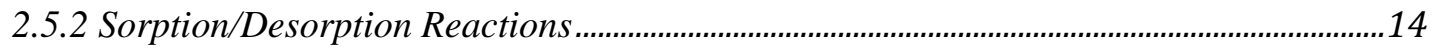

2.5.3 Complexation Reactions .................................................................................................

2.5.4 Precipitation Reaction .................................................................................................................

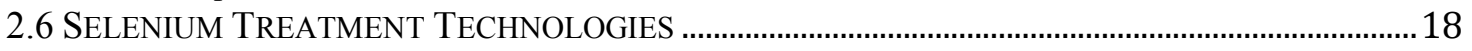

2.6.1 Traditional Treatment Technologies ................................................................................19

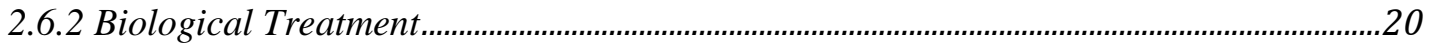

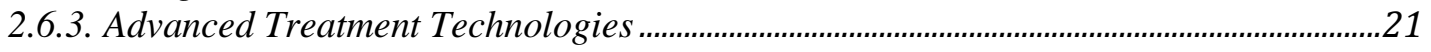

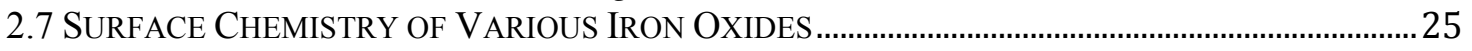

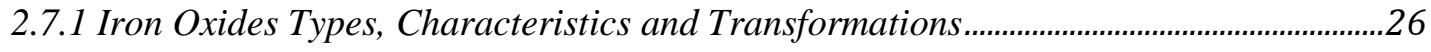

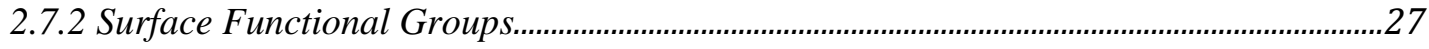

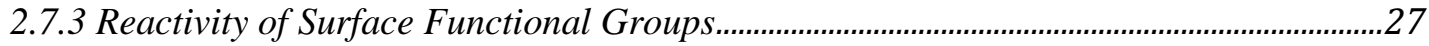


2.8 SELENATE ADSORPTION MECHANISMS.

2.9 CHARACTERIZATION OF SELENATE ADSORPTION MECHANISM AND OXIDATION STATES.30

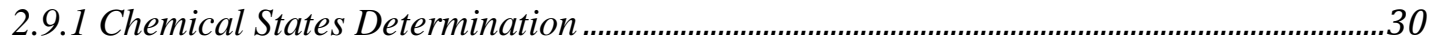

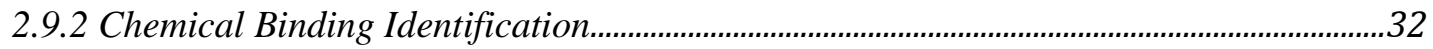

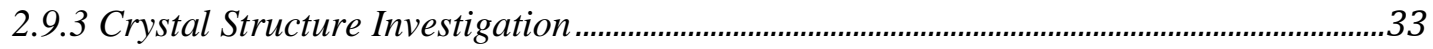

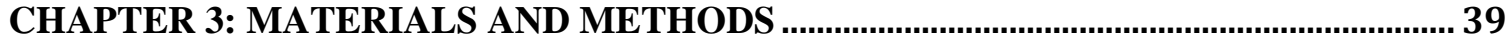

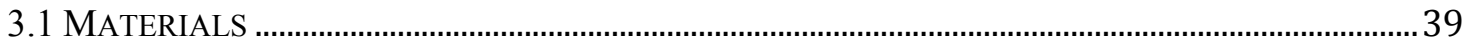

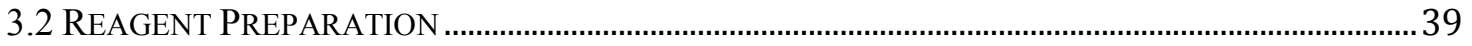

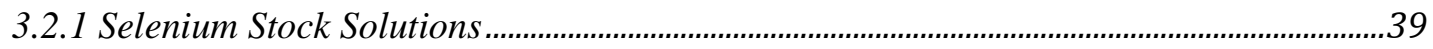

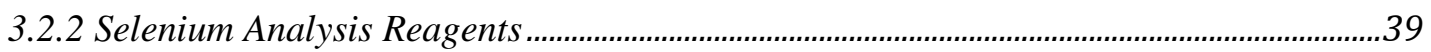

3.2.3 Iron Extraction Reagents............................................................................................................. 40

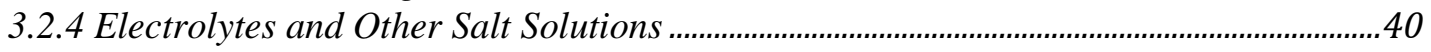

3.3 ADSORBENT PREPARATION AND CHARACTERIZATION.................................................................. 40

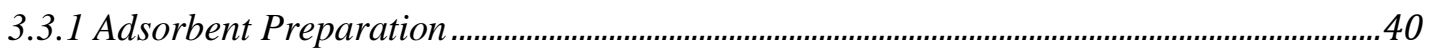

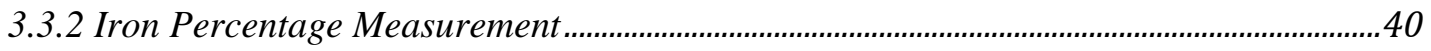

3.3.3 Iron Composition Analysis................................................................................................. 41

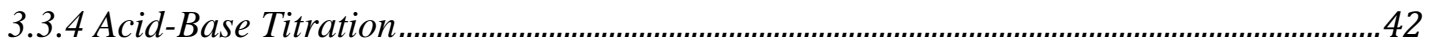

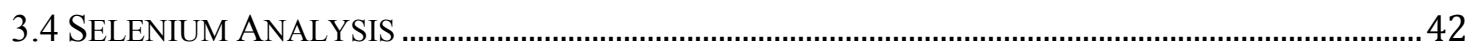

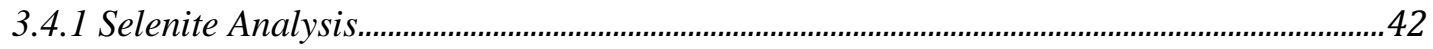

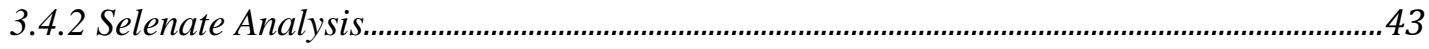

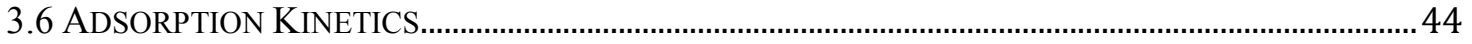

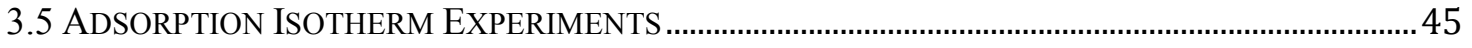

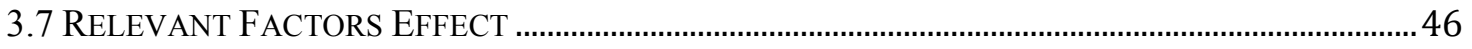

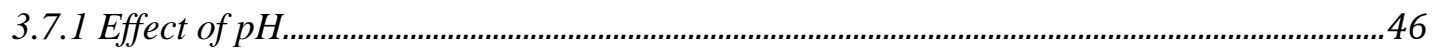

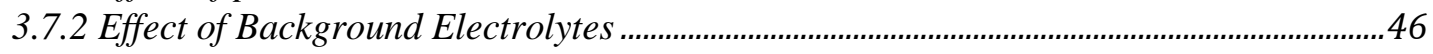

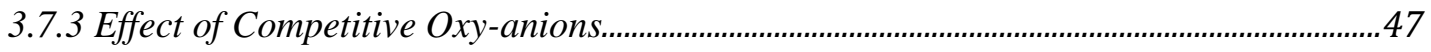

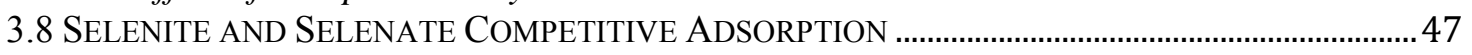

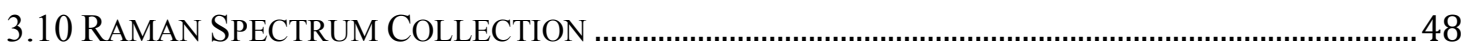

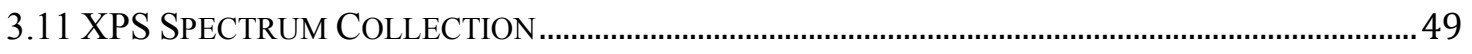

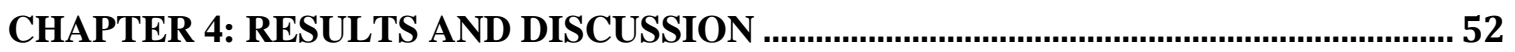

4.1 INVESTIGATION OF IRON CHEMICAL STATES AND COMPOSITION ON FE-GAC ......................52

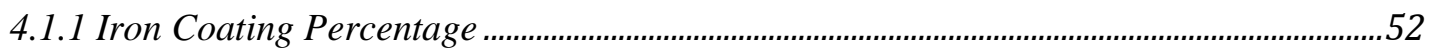

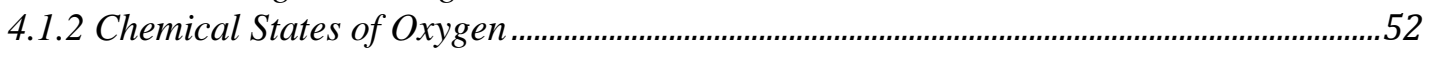

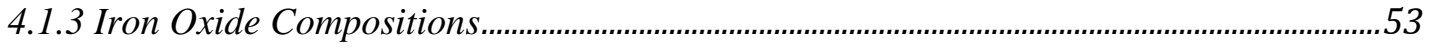

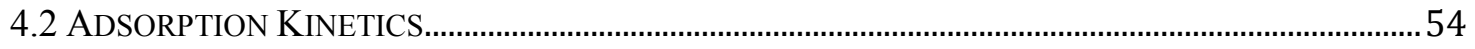

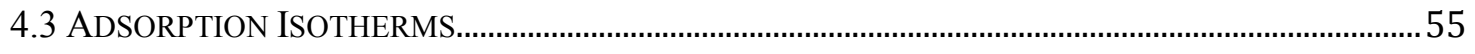

4.4 INVESTIGATION OF RELEVANT FACTORS EFFECT ON SELENATE ADSORPTION.......................56

4.4.1 pH effect

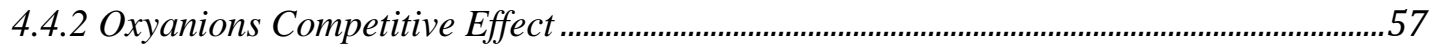

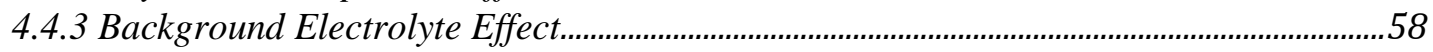

4.5 COMPETITIVE ADSORPTION BETWEEN SELENITE AND SELENATE............................................59

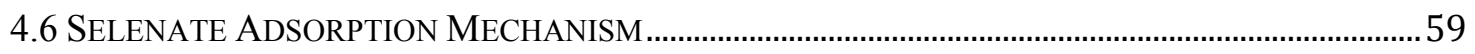

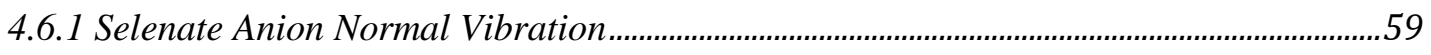

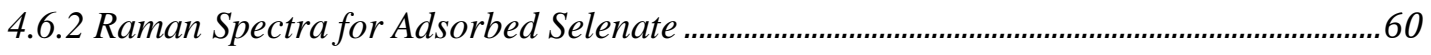

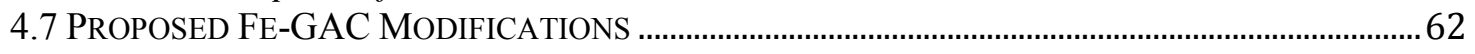

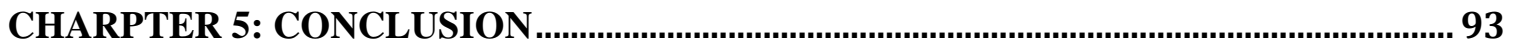

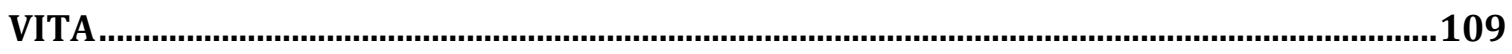




\section{LIST OF FIGURES}

Figure 1. Selenium production usage in each industry. .................................................................. 35

Figure 2. Species fraction diagram for Se (IV) as a function of $\mathrm{pH}$............................................36

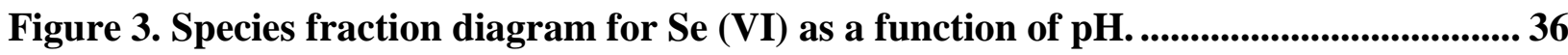

Figure 4. Selenium potential-pH diagram at $25^{\circ} \mathrm{C}$ for a dissolved selenium activity of 10-7 mol/L (Séby, et al., 1998).................................................................................................... 37

Figure 5. Structures of singly, doubly and triply coordinated surface hydroxyl groups on iron oxides (Cornell, 2003)............................................................................................ 37

Figure 6. Illustration of FeGAC preparation procedure. .................................................................50

Figure 7. Illustration of batch adsorption experiments incubated in a reciprocating

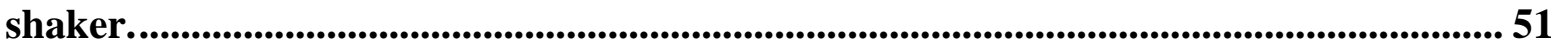

Figure 8. XPS survey scan for Virgin GAC (Darco 12X20)....................................................... 68

Figure 9. XPS survey scan for 0.1 M iron coated Fe-GAC (Darco 12X20)............................. 69

Figure 10. XPS spectrum with multiplet peak fittings (solid lines) for O1s on virgin GAC. Summation of the peak fittings is shown as bold solid line. Experimental data are indicated by solid dots. 70

Figure 11. XPS spectrum with multiplet peak fittings (solid lines) for O1s on $0.1 \mathrm{M}$ iron coated Fe-GAC. Summation of the peak fittings is shown as bold solid line. Experimental data are indicated by solid dots......................................................................... 71 
Figure 12. XPS spectrum with multiplet peak fittings (solid lines) for O1s on $0.1 \mathrm{M}$ iron coated Fe-GAC suspended in $0.1 \mathrm{M} \mathrm{NaCl}$. Summation of the peak fittings is shown as bold solid line. Experimental data are indicated by solid dots......................... 72

Figure 13. XPS spectrum for Fe2p on $0.1 \mathrm{M}$ iron coated Fe-GAC. 73

Figure 14. XPS spectrum for $\mathrm{Fe}_{2} \mathrm{p}_{3 / 2}$ on $0.1 \mathrm{M}$ iron coated $\mathrm{Fe}-\mathrm{GAC}$ with multiplet peak fittings (solid lines). Summation of the peak fittings is shown as bold solid line. Experimental data is indicated by solid dots. Center of gravity at $711.3 \mathrm{eV}$ for spectrum is indicated by arrow. 74

Figure 15. XPS spectrum with multiplet peak fittings (solid lines) for Fe2 $\mathrm{p}_{3 / 2}$ on 0.1 $\mathrm{M}$ iron coated Fe-GAC suspended in $0.1 \mathrm{M} \mathrm{NaCl}$. Summation of the peak fittings is shown as bold solid line. Experimental data is indicated by solid dots. Center of gravity at $711.3 \mathrm{eV}$ for spectrum is indicated by arrow 75

Figure 16. Selenate adsorption kinetics for initial Se concentration of $1 \mathrm{mg} / \mathrm{L}$ at $\mathrm{pH} 5$ and $0.01 \mathrm{M}$ ionic strength in the presence of $3.5 \mathrm{~g} / \mathrm{L}$ Fe-GAC. The pseudosecond order kinetic model is indicated by the curve. 76

Figure 17. Selenate adsorption kinetics for initial Se concentration of $1 \mathrm{mg} / \mathrm{L}$ at pH 5 and $0.05 \mathrm{M}$ ionic strength in the presence of $3.5 \mathrm{~g} / \mathrm{L}$ Fe-GAC. The pseudosecond order kinetic model is indicated by the curve 77

Figure 18. Selenate adsorption kinetics for initial Se concentration of $1 \mathrm{mg} / \mathrm{L}$ at $\mathbf{p H} 5$ and $0.1 \mathrm{M}$ ionic strength in the presence of $3.5 \mathrm{~g} / \mathrm{L} \mathrm{Fe}-\mathrm{GAC}$. The pseudo-second order kinetic model is indicated by the curve. 78 
Figure 19. Adsorption isotherms of the Fe-GAC for selenate (initial Se concentration $=1 \mathrm{mg} / \mathrm{L}$ ) at $\mathrm{pH} 5$ and $25^{\circ} \mathrm{C}$. The Freundlich models are indicated by the curves.

Figure 20. Adsorptive removal of selenate (initial Se concentration $=1 \mathrm{mg} / \mathrm{L}$ ) as a function of pH under ionic strength $0.05 \mathrm{M}$ and $25^{\circ} \mathrm{C}$. 80

Figure 21. Acid base titration curves for the Fe-GAC (loading rate $=2 \mathrm{~g} / \mathrm{L}$ ) under ionic strengths $0.01,0.05$ and $0.1 \mathrm{M}$. 81

Figure 22. Oxy-anion competitive adsorption against selenate (initial Se concentration $=1 \mathrm{mg} / \mathrm{L}$ ) under ionic strengths $0.05 \mathrm{M}, \mathrm{pH}$, and $25{ }^{\circ} \mathrm{C}$ after 24 hours. 82

Figure 23. Adsorption isotherms of the Fe-GAC for selenate (initial Se concentration $=1 \mathrm{mg} / \mathrm{L})$ with the presence of different background electrolytes $(\mathrm{LiCl}, \mathrm{NaCl}$, and $\mathrm{KCl}$ ) at $\mathrm{pH} \mathrm{5,0.01} \mathrm{M}$ ionic strength and $25{ }^{\circ} \mathrm{C}$. The Freundlich models are indicated by the curves.

Figure 24. Adsorption isotherms of the Fe-GAC for selenate (initial Se concentration $=1 \mathrm{mg} / \mathrm{L})$ with the presence of different background electrolytes $(\mathrm{LiCl}, \mathrm{NaCl}$, and $\mathrm{KCl}$ ) at $\mathrm{pH} \mathrm{5,} \mathrm{0.05} \mathrm{M}$ ionic strength and $25^{\circ} \mathrm{C}$. The Freundlich models are indicated by the curves. 84

Figure 25. Adsorption isotherms of the Fe-GAC for selenate (initial Se concentration $=1 \mathrm{mg} / \mathrm{L})$ with the presence of different background electrolytes $(\mathrm{LiCl}, \mathrm{NaCl}$, and $\mathrm{KCl}$ ) at $\mathrm{pH}$ 5, $0.1 \mathrm{M}$ ionic strength and $25^{\circ} \mathrm{C}$. The Freundlich models are indicated by the curves. 85 
Figure 26. Competitive adsorption isotherms of the Fe-GAC for selenite and selenate (initial Se concentration $1 \mathrm{mg} / \mathrm{L}$ for each) under ionic strength of $0.1 \mathrm{M}$, pH 5 and $25^{\circ} \mathrm{C}$. Pairs of the same symbols represent selenate/selenite concentrations in the same batch reactor. $\times: 0.5 \mathrm{~g} / \mathrm{L} ; \square: 1.0 \mathrm{~g} / \mathrm{L} ;+$; $1.5 \mathrm{~g} / \mathrm{L} ; \bigcirc$ :

$2.0 \mathrm{~g} / \mathrm{L} ; *: 2.5 \mathrm{~g} / \mathrm{L} ; \Delta: 3.0 \mathrm{~g} / \mathrm{L}$ and $\diamond: 3.5 \mathrm{~g} / \mathrm{L}$ 86

Figure 27. Competitive adsorption isotherms of the Fe-GAC for selenite and selenate (initial Se concentration $1 \mathrm{mg} / \mathrm{L}$ for each) under ionic strength of 0.05 $\mathrm{M}$, pH 5 and $25^{\circ} \mathrm{C}$. Pairs of the same symbols represent selenate/selenite concentrations in the same batch reactor. $\times: 0.5 \mathrm{~g} / \mathrm{L} ; \square: 1.0 \mathrm{~g} / \mathrm{L} ;+: 1.5 \mathrm{~g} / \mathrm{L} ; \bigcirc$ :

$2.0 \mathrm{~g} / \mathrm{L} ; *: 2.5 \mathrm{~g} / \mathrm{L} ; \Delta: 3.0 \mathrm{~g} / \mathrm{L}$ and $\diamond: 3.5 \mathrm{~g} / \mathrm{L}$ 87

Figure 28. Competitive adsorption isotherms of the Fe-GAC for selenite and selenate (initial Se concentration $1 \mathrm{mg} / \mathrm{L}$ for each) under ionic strength of 0.05 $\mathrm{M}, \mathrm{pH} 5$ and $25^{\circ} \mathrm{C}$. Pairs of the same symbols represent selenate/selenite concentrations in the same batch reactor. $\times: 0.5 \mathrm{~g} / \mathrm{L} ; \square: 1.0 \mathrm{~g} / \mathrm{L} ;+: 1.5 \mathrm{~g} / \mathrm{L} ; \bigcirc$ : $2.0 \mathrm{~g} / \mathrm{L} ; *: 2.5 \mathrm{~g} / \mathrm{L} ; \Delta: 3.0 \mathrm{~g} / \mathrm{L}$ and $\diamond: 3.5 \mathrm{~g} / \mathrm{L}$ 88

Figure 29. Raman spectra of $\mathrm{Na}_{2} \mathrm{SeO}_{4}$ solutions $(0.1 \mathrm{M})$ at $\mathrm{pH}$ (a) 3 ; (b) 5 ; and (c) 8 .......... 89

Figure 30. Raman spectra for adsorbed selenate with $0.1 \mathrm{M}$ initial selenate concentration at pH (a) 7; (b) 6; (c) 5; (d) 4; and (e) 3 . 90

Figure 31. Raman spectra for adsorbed selenate with $0.1 \mathrm{M}$ initial selenate concentration at $\mathbf{p H}=7$ under excitation of laser power (a) $50 \mathrm{~mW}$; and (b) 10 mW. 91

Figure 32. Raman spectra for adsorbed selenate with $0.1 \mathrm{M}$ initial selenate concentration at $\mathrm{pH}$ (a) 8 and (b) 7 . 92 


\section{LIST OF TABLES}

Table 1. Standard thermodynamic data used to establish the potential-pH diagram

(Séby, et al., 1998).

Table 2. Total and amorphous iron on GAC surface coated with four initial ferrous

iron conentrations.

Table 3. Percentage of iron dissolved in aqueous solutions at different $\mathbf{p H}$. 64

Table 4. Parameters values of Gauss - Lorentz multiplet peak fittings for $\mathrm{Fe}_{2} \mathrm{p}_{3 / 2}$ and O1s XPS spectra. 65

Table 5. Second-order adsorption rate constants $(k)$ and adsorption capacities $\left(q_{e}\right)$ of Fe-GAC (loading rate $=3.5 \mathrm{~g} / \mathrm{L})$ for selenate $($ initial Se concentration $=1$ $\mathrm{mg} / \mathrm{L})$ at $\mathrm{pH} 5$ and $25^{\circ} \mathrm{C}$. 66

Table 6. Parameter values of the Freundlich model for selenate and selenite adsorption.

Table 7. Parameter values of the Freundlich model and the Langmuir model for selenate adsorption under two ionic strengths and AIC comparison results for the two models. 66

Table 8. Parameter values of the Freundlich model for selenate adsorption in presence of different background electrolytes and Kruskal - Wallis testing values (q)

Table 9. Adsorption capacities (mg-Se/g-adsorbent) of the Fe-GAC (loading rate = 1

g/L) for selenite and selenate in a binary adsorbate system (initial Se

concentration $=1 \mathrm{mg} / \mathrm{L}$ for each) and single-adsorbate system (initial Se 
concentration $=1 \mathrm{mg} / \mathrm{L}$ ) at $\mathrm{pH} 5$ and $25^{\circ} \mathrm{C}$. SRS model parameter values: $a_{12}$ competition coefficient of selenate against selenite, and vice versa for $a_{21} \ldots \ldots . . . . . . . . . . . . . .667$ 


\section{LIST OF ABBREVIATIONS}

1. GAC - Granular activated carbon

2. SEM - Scanning electron microscopy

3. EDS - Energy dispersion spectrometer

4. BET - Brunauer-Emmett-Teller

5. DAN - 2, 3-diaminonaphthalene

6. MCL - Maximum contaminant level

7. MCLG - Maximum Contaminant Level Goals

8. EPA - Environmental Protection Agency

9. ZVI - Zero Valent Iron

10. BDAT - Best demonstrated available technology

11. BASBR - Baffled anaerobic solids bed reactors

12. BSeR - Biological selenium reduction

13. HFO - Hydrous ferric oxide 


\section{CHAPTER 1: INTRODUCTION}

\subsection{Background}

Selenium (Se) is both beneficial and toxic to animals, plants, and humans. However, it was not until the 1930s that selenium widely drew attention as a result of health and reproduction problems in livestock and poultry caused by seleniferous areas in South Dakota (Moxon and Rhian, 1943). The narrow gap between necessary (i.e., 0.04 to $0.1 \mathrm{mg} / \mathrm{L}$ in normal dietary) and toxic (i.e., $4 \mathrm{mg} / \mathrm{L}$ in food) concentrations of Se makes it imperative to understand the processes controlling the distribution of this element in the environment (Eisler, 1985).

Selenium can accumulate in some selenium tolerant plants (e.g., Astragalus, Stanleya, and etc.) to a level as high as thousands mg-Se/kg-dry weight (Terry et al., 2000). In humans, selenium is a trace element which functions as a cofactor for reduction of antioxidant enzymes such as glutathione peroxidases and thioredoxin reductase (Venardos et. al., 2004). Accumulation of selenium in soils, aquifer sediments and drinking water through various pathways has threatened the health of wildlife and humans (Lakin, 1973). It degrades water quality and may accumulate in fishes and birds. Even though selenium contamination does not result in sudden fish kills, it causes deterioration and deformity in fish and wildlife over time. In some contaminated areas, high levels of selenium accumulation in plants, high rates of mortality and deformity in birds have been observed (Bowen, 1966; Ohlendorf, 1989).

Selenium is widely used in industrial processes including the photovoltaic cells, glass and ceramic manufacture. It is also one of the strongly enriched elements in coal, being present as an organoselenium compound, a chelated species, or as an adsorbed element (USEPA, 2006). Coleman et al. (1993) reviewed the selenium data from 9,000 coal samples throughout the U.S. and found the highest concentrations of selenium in coal were in Texas and Mississippi. Neuzil et al. (2007) reported a wide content range of selenium in coal bearing strata in West Virginia (i.e., 0 - $6800 \mu \mathrm{g} / \mathrm{kg}$ ). Mountaintop removal and excess spoil valley fills were found to have impacts on the nearby 
waterways (WVGES, 2006). In 2002, USEPA conducted a study of the stream chemistry associated with sites classified as mined, unmined, filled, and filled/residence. Of the streams samples, selenium concentrations were found to exceed EPA's water quality criterion $(5 \mu \mathrm{g} / \mathrm{L})$ at most (13 out of 15) sites in the filled category (USEPA, 2003). Other main contamination sources of selenium are listed below (USDA, 2002):

- Coal, gold, silver, nickel, and phosphate mining

- Metal smelting

- Municipal landfills

- Oil transport, refining, and utilization

- Agricultural irrigation

Selenium is chemically and structurally similar to sulfur, a group VI non-metal, which forms oxyacids of strengths similar to those of sulfur (Ghosh et al., 1994). In the environment, selenium exists in different oxidation states, selenide $\left(\mathrm{Se}^{2-}\right)$, elemental selenium $\left(\mathrm{Se}^{0}\right)$, selenite $\left(\mathrm{SeO}_{3}{ }^{2-}\right)$ and selenate $\left(\mathrm{SeO}_{4}{ }^{2-}\right)$ (Tamari, 1998). It can also be present as various organically bound $\mathrm{Se}^{2-}$; these compounds are analogous to those of sulfur and include seleno-amino acids (i.e. selenocysteine and selenomethionine) and methyl selenides (i.e., dimethylselenide and dimethyldiselenide) (Séby et al., 1998). Selenite and selenate are thermodynamically stable under the neutral pH (e.g., 4 - 8) and mildly redox conditions. They are the predominant chemical forms in aqueous media (Jacobs, 1989). Selenite is present in mildly oxidizing, neutral $\mathrm{pH}$ environments and typical humid regions, while selenate is the predominant form under ordinary alkaline and oxidized conditions (Goh and Lim, 2004).

Most of the selenium research conducted currently has focused on either agricultural drainage water or western U.S. coal mines wastewaters (Vesper et al., 2004). A variety of treatment technologies have been reported in the literature for selenium removal (Mari as and Selleck, 1992; Gallup, 1996; Frankenberger Jr. et al., 2004; Mavrov et al., 2006). Examples include ion-exchange, reverse osmosis, nanofiltration, solar ponds, chemical reduction with iron, microalgal-bacterial treatment and biological treatment. While these approaches can remove selenium to a level below $5 \mu \mathrm{g} / \mathrm{L}$ under optimal conditions, most of these systems are expensive and are not suitable for mining 
wastewater with high sulfate concentrations. Therefore, there is a need to develop a treatment method suitable for removing selenium originating from mining activities. Adsorption of Se by metal oxides such as iron oxides and aluminum oxide has been demonstrated by several researchers (Ghosh et al., 1994; Parida et al., 1997; Su and Suarez, 2000; Monteil-Rivera et al., 2000), but theses adsorbents can be difficult to use in continuous flow systems due to their small particle size. To overcome this difficulty several researchers have combined iron oxides with more traditional adsorbents (e.g., sand and granular activated carbon) (Lo and Chen, 1997; Kuan et al., 1998; Namasivayam and Prathap, 2006; Zhang, et al., 2008). Granular activated carbon (GAC) is one of the most promising adsorbents.

It is well understood that there are several functional groups distributed on the surface of GAC, such as carboxyl, hydroxyl, phenol, and quinone. The structure of GAC can be described as a combination of carbon particles connected with a random distribution of these surface functional groups (Pakula et al., 1998). Fe (III) was reported to form stronger complexes with carboxyl and phenol ligands than Fe (II), therefore, ferric iron were more effective than ferrous iron in the formation of complexes (Gu et al., 2005). Iron coated GAC compared to other adsorbents is expected to achieve higher metal removal and as well as removal of organics simultaneously. It is also easy to be compacted into column and applied to continuous heavy metals treatment (Vaughan Jr. and Reed, 2005). Gu et al. (2005) has successfully used Fe-GAC to remove arsenate from drinking water.

Iron coated granular activated carbon (Fe-GAC) was developed by the oxidation of ferrous iron to form ferric iron followed by its precipitation onto GAC porous surface (Gu et al., 2005). Fe-GAC successfully removed arsenic and various other oxyanions from aqueous solutions through adsorption process. As a result of the chemical similarity between selenium and arsenic, Fe-GAC was applied to remove selenite from aqueous solution (Zhang et al., 2008). Slightly lower adsorption was often reported for selenate than that for selenite with different adsorbents used (e.g., goethite, hematite). Therefore, there is a need for the detailed investigation of the physical and chemical properties of synthesized adsorbents in terms of its chemical composition and stabilities at different 
pHs, so that some modifications can be proposed in order to obtain an improvement of selenate adsorption.

\subsection{Objectives}

This study aimed to develop effective adsorbents to remove selenate from aqueous solutions and further examined its complexation mechanisms and coordination structures by using spectroscopic techniques. The major goals were to:

- Study the chemical states and chemical compositions of coated iron on GAC surfaces using X-Ray photoelectron spectroscopy (XPS)

- Evaluate the adsorptive removal of selenate using Fe-GAC through benchscale experiments

- Investigate the effects of relevant factors (e.g., $\mathrm{pH}$, ionic strength and presence of other oxy-anions) on selenate adsorption

- Determine the type of surface complex and the coordination state of adsorbed selenate under different conditions using Raman spectroscopy.

- Propose feasible methods for adsorbent modification in order to improve the selenate adsorption 


\section{CHAPTER 2: LITERATURE REVIEW}

\subsection{Occurrence of Selenium}

Selenium was discovered by Jon Jakob Berzelius in 1817. It has an atomic number of 34 and an electronic configuration of $[A r] 3 d^{10} 4 s^{2} 4 p^{4}$. It is located in the oxygen group of the periodic table between nonmetallic sulfur (S) and metallic tellurium (Te). It was found that there are several naturally occurring isotopes for Se $\left[{ }^{74} \mathrm{Se}\right.$ $(0.87 \%),{ }^{76} \mathrm{Se}(9.02 \%),{ }^{77} \mathrm{Se}(7.58 \%),{ }^{78} \mathrm{Se}(23.52 \%),{ }^{80} \mathrm{Se}(49.82 \%)$ and $\left.{ }^{82} \mathrm{Se}(9.19 \%)\right]$ (McNeal and Balistrieri, 1989).

Selenium occurs naturally in the environment. Though it is among the rare elements on the surface of the earth, selenium is widely dispersed in nature with a $1.3 \times 10^{-5} \%$ concentration in the earth's crust (Todini and Co s.p.a., 2006). The primary sources of selenium are volcanic emanations and metallic sulfides associated with igneous activity. Biological sinks were reported as the secondary sources of selenium (Lakin, 1973). Black shales, coal and petroleum were found to have 10 - 20 times more abundant in selenium than the earth's crust.

\subsubsection{Primary Sources}

Wells (1967) reported high selenium content in volcanic ash flows. Selenium is dispersed with the gases emitted from volcanes and has been deposited on the earth for ages. Rankama and Sahama (1950) estimated that selenium produced by volcanic emissions amounted to $0.1 \mathrm{~g}-\mathrm{Se} / \mathrm{cm}^{2}$-earth surface. Reuter (1975) also revealed that selenium is released as high temperature volatile gases during volcanic eruption. Reuter (1975) further concluded that igneous rocks generally have low selenium concentration due to their ignition. Selenium in volcanic sulfur was found as high as $5.18 \%$ (Palache et al., 1944).

Additionally, it was found that selenium was present in coals up to 300 times as much as in other geologic materials (Coleman et al., 1993). Vesper et al. (2008) concluded that sulfur and total organic carbon (TOC) have been used as predictors of selenium concentration in coals. Coleman et al. (1993) reported a significant relationship existing between total sulfur and selenium concentrations in Powder River Basin coals. 


\subsubsection{Secondary Sources}

Organic selenium substitutes for sulfur in simple amino acids. Selenium distributed by erosion of igneous rocks or by volcanic emanations is locally concentrated in carbonaceous deposits, which are generally present in black shales. Additionally, black shales were reported containing higher selenium than limestones or sandstone as selenium is often present as organo-selenium and iron adsorbed species. Concentrations ranging from 1 to $300 \mathrm{mg}-\mathrm{Se} / \mathrm{kg}$ were reported in the Cretaceous black shales in Wyoming (NAS-NRC, 1983).

\subsubsection{Selenium Production}

Production of selenium in 1985 was reported to be 429,515 pounds (USEPA, 2006). Selenium is most commonly produced from selenide in many sulfide ores, such as those of copper, silver, or lead. It is obtained as a byproduct of the processing of these ores, from the anode mud of copper refineries and the mud from the lead chambers of sulfuric acid plants. These muds can be processed by a number of means to obtain free selenium. There are around 40 known selenium-containing minerals, some of which can have as much as $30 \%$ selenium - but all are rare. The main selenium producing countries are Canada, USA, Bolivia and Russia. Global industrial production of selenium is around 1.5 million $\mathrm{kg}$ a year and about 0.15 million $\mathrm{kg}$ of selenium are recycled from industrial waste and reclaimed from old photocopiers (Lenntech, 2007). Selenium main application in industry includes electronic and photocopier components, gas manufacturing, chemicals and pigments. Figure 1 illustrates the percentage of each industrial usage.

\subsection{Chemical Species and Transformation of Selenium}

Several factors can affect the selenium speciation, including $\mathrm{pH}$, redox conditions, solubilities of its salts and availability of complexation ligands. The sections below discuss the predominant species of selenium under various environmental conditions.

\subsubsection{Elemental Selenium $\left(\mathrm{Se}^{0}\right)$}

Generally, elemental selenium is stable in reducing environments. The crystalline forms of elemental selenium are alpha-monoclinic and beta-monoclinic Se, which are 
commonly known as red crystalline selenium. The amorphous forms of selenium are red amorphous and glassy or black varieties (Vokal-Borek, 1979). Elemental selenium is very insoluble in water, although, certain microorganisms can oxidize elemental selenium to selenite and small amounts of selenate (Sarathchandra and Watkinson, 1981).

\subsubsection{Selenide $\left(\mathrm{Se}^{2-}\right)$}

Selenide is chemically similar to sulfide. It usually exists in reducing conditions as hydrogen selenide $\left(\mathrm{H}_{2} \mathrm{Se}\right)$ and metal selenides. Hydrogen selenide gas has a strong odor and is extremely toxic to animals. Excess exposure to hydrogen selenide may result in hepatotoxicity (Spallholz and Hoffman, 2002). When dissolved in water, hydrogen selenide is a weak acid with $p K_{a l}$ less than 4 . Aqueous $\mathrm{H}_{2} \mathrm{Se}$ also shows high toxicity and can be easily oxidized to form elemental Se. Metal selenides are usually formed by replacing sulfur in metal sulfide ores (e.g., $\mathrm{Fe}, \mathrm{Cu}$, and $\mathrm{Pb}$ ). Most metal selenides have very low solubilities (Elrashidi et al., 1987). It has also been reported that volatile methylated derivatives of selenium and dissolved organic selenide compounds can be produced by microbial activity (Chau et al., 1976 and Cutter and Bruland, 1984).

\subsubsection{Selenite $\left(\mathrm{SeO}_{3}{ }^{2-}\right)$}

Selenite is usually present in mildly oxidizing environments. Selenous acid $\left(\mathrm{H}_{2} \mathrm{SeO}_{3}\right)$ is a weak acid. Figure 2 illustrates the species fraction of Se (IV) at different $\mathrm{pH}$. The fully deprotonated form $\left(\mathrm{SeO}_{3}{ }^{2-}\right)$ exists under alkaline conditions, while singly protonated form $\left(\mathrm{HSeO}_{3}{ }^{-}\right)$predominates under acidic conditions. When $\mathrm{pH}$ is lower than 3, selenous acid is dominant. Generally, selenite salts show low solubility (e.g., $\left.\mathrm{Ag}_{2} \mathrm{SeO}_{3}\right)$.

Selenite can be reduced to elemental selenium via chemical reduction under acidic conditions (e.g., elemental iron reduction). Also, several microbial genera (e.g., Acinetobacter, Aeromonas, Bacillus, Candida and etc.) were reported to reduce selenite into insoluble elemental selenium and selenide (Maiers et al., 1988). Scott and Morgan (1996) reported the oxidation of Se (IV) to Se (VI) at pH 4 using synthetic birnessite $(\delta$ $\left.\mathrm{MnO}_{2}\right)$. 


\subsubsection{Selenate $\left(\mathrm{SeO}_{4}{ }^{2-}\right)$}

Selenate is the fully oxidation form of selenium. It is fairly stable in well oxidized environments. Unlike selenous acid, selenic acid $\left(\mathrm{H}_{2} \mathrm{SeO}_{4}\right)$ is a strong acid with a negative $p K_{a l}$ value. Therefore, the fully protonated form is barely present and singly protonated form exists only at low $\mathrm{pH}$. The deprotonated forms predominate over the entire $\mathrm{pH}$ range (Figure 3 ). Selenate salts are generally more soluble than corresponding selenite salts (McNeal and Balistrieri, 1989), and thus less likely to be adsorbed by minerals oxides (e.g., iron oxides and aluminum oxides). Therefore, selenate readily migrates with natural water in environment. Additionally, selenate is the most plant available species among all selenium forms (Sors et al., 2005), and therefore selenate is more likely to accumulate in plants.

Zero valent iron (ZVI) is widely applied in selenate reduction. Both elemental selenium and selenide was reported to be produced under different reaction conditions. Microbial activities can also result in the reduction of selenate under both aerobic and anaerobic conditions (Oremland et al., 1989).

\subsection{Selenium in Environment}

Selenium typically can be found in almost all the materials on earth (McNeal and Balistrieri, 1989). Moreover, human activities such as fossil fuel combustion, agricultural irrigations, and mining, increasingly released selenium to environment (Nriagu and Pacyna, 1988). Engberg and Sylvester (1990) reported the detectable amounts of selenium existing in the samples of water, bottom sediment, and biota in the 20 investigated areas in western US. Maximum selenium concentration was reported in seleniferous soils, with the concentrations commonly found within $1-1200 \mathrm{mg}-\mathrm{Se} / \mathrm{kg}$ soils (Trelease, 1945; Fleming, 1962). From 1987 to 1993, according to the Toxics Release Inventory published by USEPA (2006), total selenium released to land and water had exceeded over a half million kilograms. These releases were primarily from copper smelting industries. It was also reported that two of largest selenium releasing states were Utah and Indiana (USEPA, 2006). 


\subsubsection{Selenium in Waters}

Selenite and selenate are the two predominant chemical forms of selenium in aqueous systems due to their relatively high solubility and may readily transport with surface and ground water. Additionally, selenium content in surface water is greatly influenced by $\mathrm{pH}$, presenting high in both acidic $(\mathrm{pH}<3.0)$ and alkaline waters $(\mathrm{pH}>$ 7.5). Selenite in surface water can precipitate in the presence of ferric at $\mathrm{pH}$ range 6.3 6.7 (Lakin, 1973). When $\mathrm{pH}$ greater than 8 , selenite salts may be oxidized to form selenate which shows relatively high solubility, therefore result in an increase of Se concentrations. It was found that average selenium concentrations in Colorado River and its major tributaries were in the range 1 - $4 \mu \mathrm{g} / \mathrm{L}$ (Engberg, 1999), however, a maximum of higher than $400 \mu \mathrm{g} / \mathrm{L}$ was found in this area also (NAS, 1976). In the Lake Michigan, selenium concentrations were reported in the range of $0.8-10 \mu \mathrm{g} / \mathrm{L}$ (Jacobs, 1989). Dissolved concentrations of selenium in San Francisco Bay was found to be $0.1-0.2$ $\mu \mathrm{g} / \mathrm{L}$ (Cutter, 1989).

Lindberg (1968) reported the selenium concentration ranging from 0.06 to 0.15 $\mu \mathrm{g} / \mathrm{L}$ in eight ground and surface waters in Sweden. Selenium contents in 43 samples from surface water in Colorado were found from 1 - $400 \mu \mathrm{g} / \mathrm{L}$ (Scott and Vodgeli, 1961). Among these 43 samples, 11 were reported to exceed the drinking water criteria (i.e., 10 $\mu \mathrm{g} / \mathrm{L})$.

Trace levels of selenium ranging from $0-10 \mu \mathrm{g} / \mathrm{L}$ are commonly found in community drinking water in USA and $10 \mu \mathrm{g} / \mathrm{L}$ is suggested as the upper limit concentration of Se for safety concern (Lakin, 1973). The USEPA regulated selenium concentration in drinking water at $50 \mu \mathrm{g} / \mathrm{L}$ for both MCLG and MCL (US EPA, 2006). The USEPA set the national water quality chronic criterion for selenium at $5 \mu \mathrm{g} / \mathrm{L}$ (USEPA, 1987). However, a controversy has risen, as more adverse effects were found for unaffected areas, regarding to set lower selenium environmental standards (e.g., $<2$ $\mu \mathrm{g} / \mathrm{L}$ ) for the protection of aquatic birds and mammals (Hamilton and Lemly, 1999). 


\subsubsection{Selenium in Soils}

Selenium concentrations in soils are generally between 0.01 to $2 \mu \mathrm{g}-\mathrm{Se} / \mathrm{g}$, though it can be as high as $1200 \mu \mathrm{g}-\mathrm{Se} / \mathrm{g}$ in seleniferous areas (Mayland et al., 1989). A concentration of $38 \mathrm{mg}-\mathrm{Se} / \mathrm{kg}$ as water soluble selenate has been reported in seleniferous areas (Lakin, 1948; Swaine, 1955). It was reported soils developed from the Cretaceous shales in some middle US states (e.g., South Dakota, Montana, Wyoming, Nebraska and etc.) presented high selenium concentrations (i.e., $>10 \mu$ g-Se/g) (Reeves, 2006). Concentration of selenium in some Hawaiian surface soils was also found at high level (i.e., $1-20 \mu \mathrm{g}-\mathrm{Se} / \mathrm{g}$ ), but they are not readily available for vegetation due to the formation of complexation with Fe and Al minerals (Anderson et al., 1961; Rosenfeld and Beath, 1964).

It was found that selenium in soils is present in several chemical forms which differ widely in their solubility and availability to plants (Anderson and Scarf, 1983). Redox potential and $\mathrm{pH}$ play an important role in the chemical forms of Se existing in soils and sediments (van Dorst and Peterson, 1984). Inorganic selenium exists predominately as the oxyanions (i.e., selenite and selenate) in the aqueous solutions of well aerated alkaline soils. In poorly aerated acid soils, inorganic selenium occurs as the relatively insoluble selenide and elemental forms.

Moreover, soils derived from parent materials containing high selenium content under alkaline conditions also present high biologically available selenium. Plants growing on these soils will have sufficient selenium $(0.1 \mu \mathrm{g}-\mathrm{Se} / \mathrm{g}$ forage $)$ for animal benefits (Kubota et al., 1967). However, natural selenium toxicosis was reported when selenium level was higher than $10 \mu \mathrm{g}-\mathrm{Se} / \mathrm{g}$ in soils (Mayland et al., 1989).

\subsubsection{Selenium in Atmosphere}

Selenium compounds are commonly released to the air during the combustion of coal and petroleum fuels, and also from the smelting and refining of other metals. Therefore, selenium concentrations in air are tremendously influenced by industrial activities. Volatile selenium can also be released via non-accumulative plants (e.g., dimethyl diselenide volatilized from Astragalus racemosus). Shrift (1961) revealed that 
dimethyl selenide can be given off by certain microorganisms and is exhaled by animals fed on seleniferous diets.

Lakin and Byers (1941) found selenium concentrations in atmospheric dust of $0.05-10 \mathrm{mg} / \mathrm{L}$ in 10 US cities. Hashimoto and Winchester (1967) reported an average of $0.09 \mu \mathrm{g}-\mathrm{Se} / 100-\mathrm{m}^{3}$ air during the summer of 1965 in Cambridge, MA. Lakin (1973) suggested that selenium is commonly present in air in industrial areas.

\subsubsection{Selenium in Biota}

Selenium is found widely exist in plants, waterfowls, fishes and mammals. Biomagnify of selenium concentrations was observed by Holland (1979): $2 \mu \mathrm{g} / \mathrm{L}$ in water, $23-25 \mu \mathrm{g} / \mathrm{g}$ in plankton, $26-31 \mu \mathrm{g} / \mathrm{g}$ in benthic invertebrates, and $18-47 \mu \mathrm{g} / \mathrm{g}$ in three fish species. Eisler (1985) suggested that selenium concentrations tended to be higher when collected from locales showing the following characteristics, including highly seleniferous soils or sediments, high human population densities, heavy accumulations of selenium laden wastes and selenium contaminated subsurface irrigation drain water.

Selenium in terrestrial plants was found to tend to accumulate in Aster, Astragalus, Oonopsis and several other genera (Eisler, 1985). These plants are classified as selenium accumulator and typically require 1 to $50 \mu \mathrm{g} / \mathrm{g}$ selenium in either soil or water for growth (Eisler, 1985). Primary selenium accumulator plants (e.g., Astragalus, Oonopsis, Stanelya, and etc.) and secondary selenium accumulator plants (e.g., Astor, Gutierrezia and etc.) may contain selenium in the range of $100-10,000$ and $25-100 \mu \mathrm{g} / \mathrm{g}$, respectively. Selenium nonaccumulator plants generally contain $1-25 \mu \mathrm{g} / \mathrm{g}$-freshweight when growing on seleniferous soil. Chau and Riley (1970) and Lunde (1970) reported the selenium concentrations in marine algae and marcro-phytes ranged from 0.04 to $0.24 \mu \mathrm{g} / \mathrm{g}$-dry-weight, selenium in edible seaweeds was found at the level of 0.14 to $0.39 \mu \mathrm{g} / \mathrm{g}$-dry-weight.

High selenium level (e.g., $>12 \mu \mathrm{g} / \mathrm{g}$-wet-weight) was found in liver and kidney tissues of marine and coastal vertebrates (e.g., fishes, birds, and mammals). May and McKinney (1981) reported selenium concentrations in freshwater fishes in US ranging from 0.05 to $2.9 \mu \mathrm{g} / \mathrm{g}$-fresh-weight (whole fish) and averaged about $0.6 \mu \mathrm{g} / \mathrm{g}$. Harr (1978) reported that selenium concentrations in tissues from animals maintained on high 
selenium feeds generally contain 3 - $5 \mu \mathrm{g}$-Se/g-fresh-weight, comparing with the concentration of $20 \mu \mathrm{g}-\mathrm{Se} / \mathrm{g}$ that resulted animal death from selenium poisoning.

\subsection{Toxicity of Selenium}

The recommended daily intake of selenium for the reference adult North American male and female are 70 and $55 \mu \mathrm{g}$ /day, respectively (NAS, 1989). It may increase to 65 and $75 \mu \mathrm{g} /$ day for female during pregnancy and lactation period, respectively. The Food and Nutrition Board-Institute of Medicine (2000) recommended upper selenium intake level as $400 \mu \mathrm{g} /$ day. Excess selenium can cause selenosis with clinical signs, such as growth retardation, decreased fertility, embryo toxicity, fetotoxicity and teratogenic effects in animals (IRIS, 1991) It has been observed that concentrations of selenate $\left(\mathrm{SeO}_{4}{ }^{2-}, \mathrm{Se}(\mathrm{VI})\right)$ as low as $10 \mu \mathrm{g} / \mathrm{L}$ in water can cause death and birth deformities in waterfowl (Letey et al., 1986). The U.S. EPA defined selenium intake level of $1262 \mu \mathrm{g} / \mathrm{day}$ for human as the element intake at which clinical selenosis appeared, which was related to a whole blood selenium level of $1350 \mu \mathrm{g} / \mathrm{L}$ (Navarro-Alarcon and Cabrera-Vique, 2008). Also, a dietary of $2 \mathrm{mg}-\mathrm{Se} / \mathrm{kg}$ on a continuous basis has been suggested as a maximum tolerable level for all species (NAS-NRC, 1980). However, carcinogenic effects were not found for diets containing up to $8 \mathrm{mg}-\mathrm{Se} / \mathrm{kg}$ (Tinsley et al., 1967; Harr et al., 1967).

\subsubsection{Toxicity of Different Chemical Forms}

Combs and Combs (1986) suggested that sodium selenite, sodium selenate, selenomethionine and selenoglutathione are among the more toxic species. In alkaline soils and oxidizing conditions, selenium may be oxidized sufficiently to maintain the availability of its biologically active form, and cause plant uptake of the metal to be increased. In acidic or neutral soils, it tends to remain relatively insoluble and the amount of biologically available selenium should steadily decrease. Selenium volatilizes from soils when converted to volatile selenium compounds (e.g., dimethyl selenide) by microorganisms (FRTR, 2002). Elemental selenium and most metallic selenides have relatively low toxicities because of their low bioavailability. By contrast, selenate and 
selenite are very toxic, and have modes of action similar to that of arsenic (Swinden, 2007). Hydrogen selenide is an extremely toxic and corrosive gas. Selenium also occurs in organic compounds such as dimethyl selenide, selenomethionine and selenocysteine, all of which have high bioavailability and are toxic in large doses. Selenium dioxide is the primary source of problems from industrial exposures since the dioxide forms selenious acid with water or sweat, and the acid is an irritant.

\subsubsection{Selenosis Symptoms}

Selenium toxicity is classified into three types: acute selenosis, subacute selenosis and chronic selenosis (IRIS, 1991). Consuming relatively high amounts of selenium within a short time can cause acute selenosis (IRIS, 1991). Some noticeable symptoms are unsteady walking, labored breathing and finally may result in death. Pathological findings of acute selenosis are inclusive of liver congestion, endocarditis and myocarditis, degeneration of gastrointestinal tract and long bones erosion (Francke and Moxon, 1936).Subacute selenosis is caused by exposure to a large dose of selenium over a longer time. It may result in neurological dysfunction and respiratory distress. It commonly occurred among grazing livestock continuous fed by selenium accumulating plants (Rosenfeld and Beath, 1964). Chronic selenium toxicity to humans is selenosis (Goldhaber, 2003). Some major symptoms of selenosis include hair and fingernail loss, skin rash (e.g., alopecia), hoof necrosis and loss, garlic breath and abnormal functioning of the nervous system (Navarro-Alarcon and Cabrera-Vique, 2008).

\subsection{Selenium Reactions}

Selenium reactions are complex to understand its general behavior. Several parameters (i.e. $\mathrm{pH}$, redox potential, microbial activity and presence of complexing and

precipitation agents) affect its predominant species, motility and toxicity (Séby, et al., 1998). To identify the presence and reactivity for each species, a brief review of their reactions under different conditions is necessary. 


\subsubsection{Oxidation-Reduction Reactions}

Selenium exists on the earth in several valences status, oxidation - reduction reactions are important processes that can affect both the chemical speciation and the stability of selenium in natural environment; these reactions are strongly influenced by the potential and $\mathrm{pH}$ (Séby, et al., 1998). In aqueous medium, a potential-pH diagram as Figure 4 for a selenium activity of $10^{-7} \mathrm{~mol} / \mathrm{L}$ can provide information on the chemical stability and the redox chemistry of this element as a function of these parameters.

At high redox potential values, $\mathrm{Se}(\mathrm{VI})$ is predominant in a wide $\mathrm{pH}$ range under the $\mathrm{SeO}_{4}{ }^{2-}$ form. In the moderate potential values, $\mathrm{Se}$ (IV) is stable and according to the $\mathrm{pH}$, can be present as $\mathrm{H}_{2} \mathrm{SeO}_{3}, \mathrm{HSeO}_{3}{ }^{-}$or $\mathrm{SeO}_{3}{ }^{2-}$. In reducing environment, elemental selenium can exist in a wide $\mathrm{pH}$ range. Under more reducing conditions, Se (-II) is predominant with $\mathrm{HSe}^{-}$as major Se species in solution. However, these observations based on thermodynamic considerations are often misleading when applied to natural waters particularly at trace levels (Abdullab, 1995). An accurate interpretation of the selenium behavior requires in situ speciation determinations (Devereln et al., 1994; Séby et al. 1997; Fio and Fujii, 1990).

\subsubsection{Sorption/Desorption Reactions}

In oxidized to moderately reduced environment, the selenium distribution between solid and aqueous phases depends mainly on sorption/desorption reactions, particularly at trace levels (Neal et al., 1987a). These reactions can occur on different solid surfaces such as inorganic solids and organic matter (Öhman, 1988), as described below.

\subsubsection{Sorption Reactions on Inorganic Materials}

On the surfaces of inorganic materials (i.e. minerals, soils, iron oxides, alumina, etc.), selenium adsorption behavior depends on its oxidation state: selenate sorption is generally much lower than selenite sorption (Ahlrichs and Hossner, 1987; Balistrieri and Chao, 1987; Saeki et al., 1995). For Se (IV), different studies have shown a strong affinity to materials rich in metallic oxides or/and hydroxides (iron, manganese, aluminium, etc). The sorption mechanism of Se (IV) was broadly studied and involved very often a ligand exchange reaction with formation of an inner-sphere surface complex 
(Monteil-Rivera et al., 2000; Namasivayam and Prathap, 2006). Previous studies also indicated that the selenite adsorption was significantly $\mathrm{pH}$ dependent. It showed a lower affinity when it was sorbed by Al and Fe oxides or clays (Parida et al., 1997). The mechanism for the sorption was commonly accepted as surface complexation involving the $\mathrm{SeO}_{3}{ }^{2-}$ and $\mathrm{HSeO}_{3}{ }^{-}$sorbed onto the surface sites by ligand exchange (Monteil-Rivera et al., 2000).

The adsorbed Se (IV) amounts as a function of time show a two steps behavior: the first part of the curve indicate a fast and linear retention which becomes slower with time (Balistrieri and Chao, 1987; Papelis et al., 1995; Papelis et al., 1995; Del Debbio, 1997). Two general kinetic models had been applied to the selenite adsorption: (1) pseudo-first-order kinetic model and (2) pseudo-second-order kinetic model. The equations are listed below (Azizian, 2004):

$$
\begin{aligned}
& \frac{d q}{d t}=k_{1}\left(q_{e}-q\right) \\
& \frac{d q}{d t}=k_{2}\left(q_{e}-q\right)^{2}
\end{aligned}
$$

Where $q_{e}$ and $q$ are solute sorbed per gram of sorbent at equilibrium and time $\mathrm{t} ; k_{1}$ and $k_{2}$ are pseudo first order and pseudo second order rate constants. Integrate the equations above, gives the following linear forms

$$
\begin{gathered}
\log \left(q_{e}-q\right)=\log q_{e}-\frac{k_{1} t}{2.303} \\
\frac{t}{q}=\frac{1}{k_{2} q_{e}^{2}}+\frac{t}{q_{e}}
\end{gathered}
$$

Previous studies indicated that selenite adsorption kinetics could be characterized better by the pseudo-second-order kinetic model (Kuan et al., 1998; Namasivayam and Prathap, 2006). Goh and Lim (2004) reported that selenite adsorption can be described by Elovich rate law, the rate of selenite adsorption decreased exponentially with the increasing selenium coverage on the surface of adsorbents when tropical soils were utilized to remove selenium. The linear form of the Elovich equation can be expressed as:

$$
q=\frac{1}{\alpha} \ln (a \alpha)+\frac{1}{\alpha} \ln \left(t+\frac{1}{a \alpha}\right)
$$


where, $a$ and $\alpha$ are Elovich kinetic constants. In other works, it was assumed that adsorption rate is controlled by an intraparticulate mass transfer in the solid (Papelis et al., 1995; Papelis et al., 1995).

For adsorption equilibrium, the Langmuir model and the Freundlich model were widely used. The Langmuir model is used to reveal the equilibrium between surface and solution as a reversible chemical equilibrium between species. It suggests a monolayer sorption, with no lateral interaction between the adsorbed molecules. Equation for Langmuir model can be expressed as follow (Crittenden et al., 2005):

$$
q_{e}=\frac{q_{\max } C_{e}}{b+C_{e}}
$$

where $C_{e}(\mathrm{mg} / \mathrm{L})$, the equilibrium concentration in the solution; $q_{\max }(\mathrm{mg}-\mathrm{Se} / \mathrm{g}$-adsorbent), represents the maximum adsorption capacity; adsorption constant $b(\mathrm{~L} / \mathrm{mg})$, is related to the energy of adsorption, it is both temperature-dependent and related to the Gibbs free energy and hence to the enthalpy change for the adsorption process.

The Freundlich model, originally proposed as an empirical equation, is used to describe the data for heterogeneous adsorbents such as activated carbon. The model can be expressed as follows (Crittenden et al., 2005):

$$
q_{e}=K_{f} C_{e}^{1 / n}
$$

Where $K_{f}$ and $1 / n$ are parameters of the Freundlich isotherm. $K_{f}(m g / g)(L / m g)^{\frac{1}{n}}$, reveals the adsorption capacity and $1 / n$ unitless, the intensity of adsorption.

Kuan et al. (1998) reported that when applied the aluminum-oxide coated sand to the selenite adsorption, the adsorption capacity could reach $1.08 \mathrm{mg}$-Se (IV)/g-adsorbent with the coefficient of linear regression $\left(R^{2}\right)$ for Langmuir model calculated to be 0.98 at pH 4.6. Lo and Chen (1997) obtained the adsorption capacity value of 0.017 mmol-Se (IV)/g-adsorbent at $\mathrm{pH} 4.0$, as iron-coated sand was used.

The weaker sorption of selenate compared to selenite was observed on different solid surfaces (Masscheleyn and Patrick, 1993; White and Dubrovsky, 1994; Balishtrieri, 1987) and could be explain by the formation of an outersphere complex at the solid surface (Saeki et al., 1995; Davis and Leckie, 1980). Adsorption of Se (VI) is also 
strongly affected by the $\mathrm{pH}$ with a similar behavior to Se (IV) (Ahlrichs and Hossner, 1987; Saeki et al., 1995; Vuori et al., 1994).

\subsubsection{Sorption Reactions on Organic Matter}

Interactions between selenium and organic matter such as humic substances were reported for Se (IV) (Gustafsson and Johnsson, 1994). From iron oxyhydroxide coated with sodium humate, it was observed a more important immobilization of Se (IV) compared to the mineral alone. In order to clarify the association between selenite and humic substances, some authors have assigned the retention of $\mathrm{Se}$ (IV) to a microbial reductive incorporation on soils and aquatic systems and this reaction would occur mainly in the low molecular-weight-fraction of the humic substances (fulvic acids) (Gustafsson and Johnsson, 1994). The mechanism of selenite sorption on organic matter is not yet well understood and incorporation or adsorption reactions could occur alone or in a simultaneous way.

\subsubsection{Complexation Reactions}

In aqueous phase, selenium can exist in the form of complexes mainly as ion pairs that are in association with inorganic cations (White and Dubrovsky, 1994; Elrashidi et al., 1987; Reddy et al., 1995). A number of works has experimentally shown the presence of these Se compounds. Only a study on Se speciation in groundwater samples has shown the occurrence of $\mathrm{MgSeO}_{4(\mathrm{aq})}$ by using the specific adsorption properties of the divalent $\mathrm{Se}(\mathrm{IV})$ and $\mathrm{Se}(\mathrm{VI})$ species on $\mathrm{CuO}$ solid particles (Reddy et al., 1995).

Equilibrium thermodynamic calculations for a groundwater at $\mathrm{pH}=7$ containing a total selenium concentration of $300 \mathrm{mg} / \mathrm{L}$ have shown that under oxidizing conditions $(E>$ $400 \mathrm{mV}$ ), $\mathrm{SeO}_{4}{ }^{2-}$ and $\mathrm{CaSeO}_{4(\mathrm{aq})}$ are the predominant species in aqueous solution. For potentials ranging from 0 to $400 \mathrm{mV}$, the most stable species are $\mathrm{CaSeO}_{3(\mathrm{aq})}$ and $\mathrm{SeO}_{3}{ }^{2-}$ and, under more reducing conditions $(E<0 \mathrm{mV})$, only $\mathrm{HSe}^{-}$is present in solution (White and Dubrovsky, 1994). A similar study was carried out in soil solutions and none of the 27 complexes studied were found to contribute significantly to the total soluble selenium concentration. Only the $\mathrm{SeO}_{4}{ }^{2-}, \mathrm{HSeO}_{3}{ }^{-}, \mathrm{SeO}_{3}{ }^{2-}, \mathrm{H}_{2} \mathrm{Se}$ and $\mathrm{HSe}^{-}$dissolved forms predominate according to the $\mathrm{pH}$ and potential conditions (Elrashidi et al., 1987). 


\subsubsection{Precipitation Reaction}

Inorganic Se with the oxidation states of $-2,+4$ and +6 can react with metal cations (e.g, $\mathrm{Ag}^{+}, \mathrm{Fe}^{3+}, \mathrm{Al}^{3+}$ ) and be immobilized via precipitation. Generally, selenide has very low solubility with most of the metal cations. Selenate salts show higher solubility than corresponding selenite salts.

\subsubsection{Selenite Precipitation}

Selenite anions can only exist at trace level with most of the cations (e.g., $\mathrm{Fe}^{3+}$, $\left.\mathrm{Al}^{3+}\right)$ due to the formation of precipitates. Fairly low solubility product $\left(K_{s p}\right)$ (i.e., $10^{-30 \sim-}$ ${ }^{33}$ ) for ferric selenite $\left(\mathrm{Fe}_{2}\left(\mathrm{SeO}_{3}\right)_{3}\right)$ was reported by several researchers (Chukhlantsev and Tomashevsky, 1957; Geering et al., 1968). $\mathrm{Al}^{3+}$ was also found to have similar magnitude solubility product with ferric (Essington, 1988). Essington (1988) reported higher solubility for ferrous selenite $\left(K_{s p}=10^{-9.99}\right)$ than that for ferric selenite. Comparing with that, selenite can dissolve more when it combines with sodium $\left(K_{s p}=10^{-3.51}\right)$, potassium $\left(K_{s p}=10^{-1.48}\right)$ and calcium $\left(K_{s p}=10^{-5.6}\right)$.

\subsubsection{Selenate Precipitation}

Solubilities of metal selenate salts were less studied than that of metal selenite salts. Similar with selenite, ferric $\left(K_{s p}=10^{-23.19}\right)$ and aluminum $\left(K_{s p}=10^{-21.46}\right)$ selenate were found to dissolve at trace level. And potassium selenate $\left(K_{s p}=10^{0.6}\right)$ and sodium selenate $\left(K_{s p}=10^{-0.89}\right)$ were found easier to dissolve in water.

\subsection{Selenium Treatment Technologies}

A variety of treatment technologies have been reported to remove selenium from contaminated waters (Marinas and Selleck, 1992; Gallup, 1996; Frankenberger et al., 2004; Mavrov et al., 2006). Traditional treatment methods (e.g., coagulation, lime softening and sand filtration) are not effective (Kapoor et al., 1995). Some advanced techniques (e.g., ion-exchange, reverse osmosis, nanofiltration) are not economically feasible in treating large volume of selenium containing water and meeting EPA's high criteria (i.e., $5 \mu \mathrm{g} / \mathrm{L}$ ) (Zhang et al., 2005). Zerovalent iron reduction and adsorption onto 
iron oxide/hydroxides are two major widely used and promising options in removing selenium.

\subsubsection{Traditional Treatment Technologies}

Since selenium first drove significant public concern in early 80 s because of its bioaccumulation in birds at California's Kesterson Reservoir in the San Joaquin Valley (SJV), several treatment technologies were developed for selenium removal from agricultural drainage and industrial wastewater. These conventional treatment technologies include physical, chemical and biological methods. Although much has been learned, the goal of finding practical, cost-effective technology for treating selenium contaminated water has not yet been accomplished (Losi and Frankenberger Jr., 1997). An integrated, multiphased approach to the problem will most likely prove necessary and feasible.

\subsubsection{Coagulation}

Coagulation involves the agglomeration of colloidal particles to form larger particles which can be easily separated from solution by sedimentation and /or filtration (Kapoor et al., 1995). Cherkinski et al. (1970) reported removal efficiency of 50-70\% for initial selenium concentration of $2-10 \mathrm{mg} / \mathrm{L}$ using alum coagulation, sedimentation and filtration in the pilot scale studies. However, the effluent still can not meet the EPA criteria. A laboratory jar test study on the spiked water samples collected from the Ohio River with selenium concentration of $0.1 \mathrm{mg} / \mathrm{L}$ was conducted (Logsdon et al., 1974). The results indicated that coagulation using alum and ferric sulfate was ineffective for selenate removal. The removal was found to be less than $10 \%$ at any $\mathrm{pH}$ and high coagulant dosages. The results also showed that removal of selenite in well water collected from Glendale, Ohio reached $80 \%$ at $\mathrm{pH} 6$ but dropped dramatically to $20 \%$ at $\mathrm{pH}$ 8. It was also found that selenite removal was not significantly increased as the coagulant dose increased.

Logsdon et al. (1974) also conducted the pilot scale studies to remove selenium from the same water sources. The pilot plant treatment consisted of rapid mix flocculation, settling and filtration. The detention times used in the pilot study for rapid mixing, flocculation and settling were 2 minutes, 1 hour and 6.5 hours, respectively. The 
results of pilot plant showed similar removal efficiency of with jar tests, which was $60 \%$ for selenite at $\mathrm{pH} 6.5$ and 10\% for selenate at $\mathrm{pH} 8.5$ (Sorg and Logsdon, 1976).

\subsubsection{Precipitation}

Selenite was reported to be significantly removed by precipitation with iron hydroxide (80-95\%). Comparing with this, removal of selenate via precipitation was reported to be less than $15 \%$ (Yodnane et al., 1992). To reduce the concentration of selenium from fly ash leachate from 0.1 to $0.01 \mathrm{mg} / \mathrm{L}$ required an iron dosage of $28 \mathrm{mg} / \mathrm{L}$. The continuous iron coprecipitation process consisted of a rapid mix tank for chemical feed, a flocculation tank and a sedimentation tank.

Merrill et al. (1986) evaluated the technical and economic feasibility of precipitation with iron oxyhydroxide in removing selenium from ash pond effluent containing $40-60 \mu \mathrm{g} / \mathrm{L}$ selenium. A pilot scale study was conducted consisting of rapid mix, flocculation and sedimentation. The results indicated that high removal efficiency (e.g., $56-80 \%$ ) was achieved at $\mathrm{pH} 6.2$ and below. However, precipitation processes were found to be feasible only if the selenite form was the predominant species.

\subsubsection{Lime Softening}

Lime softening was also investigated by researchers to remove selenium from wastewater. A removal efficiency of $40-50 \%$ at $\mathrm{pH} 9.0-11.5$ was reported (Logsdon et al., 1974). Percentage removals did not vary with the change in the initial concentration of selenium from 0.05 to $10 \mathrm{mg} / \mathrm{L}$ at $\mathrm{pH} 11.3$. It was also found that lime precipitation did not remove selenate effectively (e.g., <10\%) (Kapoor et al., 1995), it is due to relatively high solubility of calcium selenate $\left(K_{s p}=10^{-3.09 \sim-4.77}\right.$ for $\left.\mathrm{CaSeO}_{4}\right)$.

\subsubsection{Biological Treatment}

Biological treatment for selenium removal is a viable alternative to the physciochemical treatment (Kapoor et al., 1995). Selenate and selenite can be reduced readily in most systems through interactions with organic matter or via microbiological processes. Activities of microorganisms drive the formation of elemental selenium in order to immobilize and remove aqueous predominant species (i.e., selenite and selenate) by providing reducing conditions and overcoming kinetic barriers to selenium reduction 
(Kenward et al., 2006). Many studies have shown that Se-reducing bacteria can effectively catalyze the reduction of selenate into elemental selenium. Other strains of bacteria may further reduce elemental selenium to selenide or oxidize selenide to form elemental selenium (Doran et al., 1977). Most of these microbe-mediated processes actively reduce selenate to elemental selenium by utilizing selenate as a terminal electron acceptor during the respiration of organic carbon. For example, in agricultural drainage water of the San Joaquin Valley, CA, selenate was effectively reduced to elemental selenium by Enterobacter taylorae (Zhang and Frankenberger, 2003) using this pathway.

Biological treatment technology has been applied in industry (MSE Technology Applications, Inc., 2001). Applied Biosciences Corporation developed the BSeR ${ }^{\mathrm{TM}}$ process using BASBR. Selenium (selenate and selenite) was reduced to elemental selenium by specially developed biofilms containing specific proprietary microorganisms. This process produces a precipitate of elemental selenium. As the elemental selenium formed in biological treatment, it may precipitate and block the microbes carrying media (e.g., biofilms and biosolids). Therefore, biological processes need to be coupled with back flushing procedure and increase the capital costs (Golder Associates Inc., 2009).

Gerhardt et al. (1991) studied a biological treatment process using algal-bacteria system (ABSRS) to remove selenium and nitrate from agricultural drainage water. The system was comprised of algal growth ponds, anoxic reduction unit and solid-liquid separation tank. The average alga concentration used in this system was $178 \pm 99 \mathrm{mg} / \mathrm{L}$. The results showed a marginal removal in soluble selenium species for initial selenium concentration of $200-400 \mu \mathrm{g} / \mathrm{L}$. It was found that selenate was completely reduced to selenite by selenium reducing bacteria in the anoxic units. However, it was reported that a sufficient growth of algal was difficult to achieve and the reduction was highly temperature dependent (Golder Associates Inc., 2009).

\subsubsection{Advanced Treatment Technologies}

As discussed above, most of the conventional treatment options were reported ineffective in removing selenium from wastewater, especially with for existence of selenate as predominant form. Therefore, development of feasible and cost-effective techniques is in need for large scale industrial applications. 


\subsubsection{Ion Exchange}

Ion exchange involves the exchange of an undesirable dissolved constituent for a more desirable solute electrostatically attached to an ion exchange material (Frankenberger Jr. et al., 2004). Ion exchange is a very simple process to operate and is suitable for intermittent flow. Resin for the ion exchange process is often synthetic. Research indicates that resins work effectively for removing arsenic, selenium and other ionic constituents.

It was found that ion exchange is more effective in removing selenite rather than selenate (Mavrov et al., 2006), which is due to the interference from sulfate. When large amount of sulfate present in wastewater (e.g., acid mine drainage) along with selenate, competition from sulfate inhibits the removal of selenate. Nishimura and Hashimoto (2007) studied the selenate removal by an ion exchange process using Polyamine-type weakly basic resin. They reported a strong adsorption of selenate anions (initial $\mathrm{Se}$ concentration of $30-240 \mathrm{mg} / \mathrm{L}$ ) by the resin over a wide $\mathrm{pH}$ range from 3 to 12 . However, a tremendous decrease was revealed in the presence of elevated sulfate concentrations. Furthermore, they suggested small amount of $\mathrm{HCl}(1 \mathrm{M})$ was effective in eluting selenate anions off from resin.

The cost for selective ion exchange is generally less than that for reverse osmosis (Frankenberger et al., 2004). But the high chemical regeneration cost for the resin makes this technology unattractive, particularly for the wastewater with the high total dissolved solids (i.e. a few hundred $\mathrm{mg} / \mathrm{L}$ ) because of the quick saturation rates.

\subsubsection{Reverse Osmosis}

Reverse osmosis (RO) is the process of separating dissolved ions and other species from water by overcoming the osmotic pressure and forcing water through a semipermeable membrane from the stronger solution (Kapoor et al., 1995). Sorg and Logsdon (1976) studied the selenium removal by RO process using cellulose acetate membrane. The investigated water sources were Cincinnati tap water with $\mathrm{pH}$ value at 7.13 and spiked by a selenite concentration to $0.1 \mathrm{mg} / \mathrm{L}$. The operation conditions for cellulose acetate membrane were reported at flow rate of $1.3 \mathrm{~L} / \mathrm{min}$ and operating 
pressure of $190 \mathrm{psi}$. The results showed that selenite removal was greater than $97 \%$. It was also found that selenate could achieve similar removal level.

\subsubsection{Chemical Reduction with Zero-Valent Iron}

Elemental iron is commonly referred to as zerovalent iron (ZVI). As a transition metal, ZVI is used as a catalyst for chemical synthesis in industry. In contaminant remediation, ZVI serves as both a catalyst and an electron donor in which ZVI immobilizes soluble trace element contaminants (e.g., selenium, chromium and uranium) by surface reduction and precipitation (Huang et al., 1998; Farrell et al., 1999; Qiu et al., 2000). Selenium can be reduced to selenite, elemental $\operatorname{Se}[\operatorname{Se}(0)]$, and selenide depending upon $\mathrm{pH}$ and $\mathrm{O}_{2}$ in water. Low $\mathrm{pH}$ and low oxygen favors the more reduced forms of selenium. The corrosion of ZVI is an electrochemical process during which iron is oxidized to soluble ferrous ion $\left(\mathrm{Fe}^{2+}\right)$. Ferrous ion could react with $\mathrm{OH}^{-}$to form $\mathrm{Fe}(\mathrm{OH})_{3}$ and then further oxidized to form green rust I. The green rust can also serve as a reducing agent to abiotically reduce $\mathrm{Se}(\mathrm{IV})$ to $\mathrm{Se}(\mathrm{IV})$ and $\mathrm{Se}(0)$ (Myneni et al., 1997). The advantage of zerovalent iron is to reduce the concentration of selenium to very low concentrations and might be useful as a polishing step following microbial treatments (Frankenberger et al., 2004). Besides its low cost, the secondary and ternary reaction products, such as $\mathrm{Fe}(\mathrm{II})$ and $\mathrm{Fe}(\mathrm{III})$ compounds, impose no harm to the environment (Qiu et al., 2000). However, the waste and sludge (e.g., elemental selenium) need to be removed from the treatment systems and further properly handled which may increase the cost of treatment.

Murphy (1988) studied the chemical process when using treatment systems containing finely divided iron to remove selenate. It was revealed that ZVI had to be converted into ferrous first in order to have the selenate reduction occur. The existence of oxygen was necessary for the transformation of ZVI. The reaction is described as:

$$
2 \mathrm{Fe}+\mathrm{O}_{2}+2 \mathrm{H}_{2} \mathrm{O} \rightarrow 2 \mathrm{Fe}(\mathrm{OH})_{2}
$$

However, extra oxygen will cause a decrease in selenate removal due to the further oxidation of ferrous hydroxide to ferric precipitates:

$$
2 \mathrm{Fe}+\frac{3}{2} \mathrm{O}_{2}+3 \mathrm{H}_{2} \mathrm{O} \rightarrow 2 \mathrm{Fe}(\mathrm{OH})_{3}
$$


Selenate reduction reactions are also proposed as follow:

$$
\begin{aligned}
\mathrm{Na}_{2} \mathrm{SeO}_{4}+9 \mathrm{Fe}(\mathrm{OH})_{2} & \rightarrow \mathrm{Se}^{0}+3 \mathrm{Fe}_{3} \mathrm{O}_{4}+2 \mathrm{NaOH}+8 \mathrm{H}_{2} \mathrm{O} \\
\mathrm{Na}_{2} \mathrm{SeO}_{4}+6 \mathrm{Fe}(\mathrm{OH})_{2} & \rightarrow \mathrm{Se}^{0}+3 \mathrm{Fe}_{2} \mathrm{O}_{3}+2 \mathrm{NaOH}+8 \mathrm{H}_{2} \mathrm{O}
\end{aligned}
$$

This suggests that ZVI must be oxidized to ferrous hydroxide first in order to allow the reduction to proceed (Murphy, 1988). It also suggests that a higher ratio of Se (VI) to ferrous result in different formation of iron product. Both reactions (3) and (4) presented above are spontaneous according to free energy calculations (Murphy, 1988). Olegario et al. (2009) reported that selenate could be further reduced to selenide when using ZVI nanoparticle suspensions. However, Se(IV) was barely detected during the reduction of selenate (Murphy, 1988; Olegario et al., 2009).

Selenite also could be removed by ZVI reduction to form $\mathrm{Se}(0)$ or Se (II-) (Loyo et al., 2008). The standard electrode potentials for $\mathrm{HSeO}_{3}{ }^{-} / \mathrm{Se}(0)$ and $\mathrm{Se}(0) / \mathrm{HSe}^{-}$redox couples are more positive than that for the $\mathrm{Fe}(\mathrm{II}) / \mathrm{Fe}(0)$ couple, indicating that $\mathrm{Se}(\mathrm{IV})$ can be reduced to $\mathrm{Se}(\mathrm{II}-)$ by $\mathrm{Fe}(0)$ in a certain $\mathrm{pH}$ range.

\subsubsection{Adsorption by Various Materials}

Kapoor et al. (1995) defined adsorption as the interphase accumulation or concentration of a substance onto the solids surface. Activated carbon is a widely used adsorbent in water/wastewater treatment. Logsdon et al. (1974) investigated the selenium removal efficiency using powdered activated carbon (PAC). The results showed a less than $4 \%$ removal under various $\mathrm{pH}$. A relative increase of selenium removal was observed on the pilot scale studies carried out using granular activated carbon (GAC) for sewage effluent (Linstedt et al., 1971). They reported the removal for selenite was $43 \%$. Linstedt et al. (1971) attributed the increase of selenium removal to the formation of complexation between selenium species and organic matter originally present in wastewater.

Selenium adsorption using activated alumina or aluminum oxide treated materials was estimated by several researchers (Sorg and Logsdon, 1978; Trussell et al., 1980; Novak et al., 1987; Kuan et al., 1998). Studies under various conditions were carried out to examine the optimum adsorption conditions for different adsorbents. The adsorption capacity of activated alumina for selenite was reported about 3 times higher than that for 
selenate (Trussell et al., 1980). Yodnane et al. (1992) evaluated the selenium adsorptive removal for fly ash leachate using activated alumina. Kuan et al. (1998) tested selenite and selenate removal using aluminum oxide coated sand in the presence of $0.1 \mathrm{M} \mathrm{NaCl}$ electrolytes. The results showed $95 \%$ and above removal efficiency for both initial selenite and selenate concentration of $0.8 \mathrm{mM}$ at $\mathrm{pH}$ lower than 8 and 7 , respectively. The results also revealed that both selenite and selenate batch adsorption can reach equilibrium after 100 minutes.

Ferrihydrite precipitation with concurrent adsorption of selenium onto the ferrihydrite surface (ferrihydrite adsorption) is EPA's BDAT for treating seleniumbearing waters (MSE Technology Applications, Inc., 2001). For adsorption of selenium using ferrihydrite to occur, the ferric ion $\left(\mathrm{Fe}^{+3}\right)$ must be present in the water. Selenate $\left(\mathrm{Se}^{+6}\right)$ is most effectively removed from the water at $\mathrm{pH}$ levels below 4 . The chemical reactions for ferrihydrite precipitation of selenium are (MSE Technology Applications, Inc., 2001):

$$
\begin{aligned}
& \mathrm{Fe}^{3+}+3 \mathrm{H}_{2} \mathrm{O} \rightarrow \mathrm{Fe}(\mathrm{OH})_{3(\text { solid })}+3 \mathrm{H}^{+} \\
& \mathrm{SeO}_{4}^{2-}+\mathrm{Fe}(\mathrm{OH})_{3(\text { solid })}+4 \mathrm{H}_{2} \mathrm{O} \rightarrow \mathrm{Fe}(\mathrm{OH})_{3(\text { solid })}+\mathrm{SeO}_{4}^{2-}(\text { ad }) \\
& +8 \mathrm{H}^{+}
\end{aligned}
$$

Parida et al. (1997) investigated the selenite adsorption onto different polymorphic forms of iron oxyhydroxides and amorphous ferrihydrite. $\mathrm{pH}$, initial selenite concentration, adsorbent loading rate, temperature and reaction time were tested to identify the optimum adsorption conditions for each adsorbents. The results indicated the adsorption capacity of selenite removal followed the order of $\beta$-FeOOH $<\alpha-\mathrm{FeOOH}$ $<\gamma$-FeOOH $<\delta$-FeOOH $<$ amorphous ferrihydrite. An adsorption percentage of $80 \%$ was reported using amorphous ferribydrite $(250 \mathrm{mg} / \mathrm{L})$ at $\mathrm{pH}$ lower than 4 for initial selenite concentration of $1.26 \mu \mathrm{m} / \mathrm{L}$ after 2 hours reaction.

\subsection{Surface Chemistry of Various Iron Oxides}

The Fe-GAC adsorbents are found to behave similarly with iron oxides when adsorption is taking place. To understand and predict the Fe-GAC adsorption behavior 
and mechanisms, it is necessary to have a thorough understanding of the surface structure and crystal properties of various iron oxides.

\subsubsection{Iron Oxides Types, Characteristics and Transformations}

Iron oxides are widely present in nature (e.g., in pedosphere, biosphere, lithosphere). There are more than 10 types of iron oxides, with the existing form including oxides (e.g., hematite and maghemite), hydroxides (e.g., Bernalite) or oxyhydroxides (e.g., goethite and lepidocrocite). All the iron oxides were revealed to convert into one or more types under appropriate conditions (Cornell and Schwertmann, 2003). Among these, hematite $\left(\alpha-\mathrm{Fe}_{2} \mathrm{O}_{3}\right)$ and goethite $(\alpha-\mathrm{FeOOH})$ are widely studied and employed in multi-disciplines (e.g., mineralogy, geology, soil science and environmental chemistry) as a result of their high stability under broad environmental conditions. However, all the iron oxides show low solubility in water and some of the Fe atoms might be substituted by other cations, such as Al, Si, Mn. Also, as the very high crystallization energy of iron oxides, only small amount of crystals are formed in both natural environments and industrial products. Moreover, large specific surface areas (i.e., $>100 \mathrm{~m}^{2} / \mathrm{g}$ ) are observed in most iron oxides, therefore, they can be employed as adsorbents to remove dissolved inorganic ions and organic compounds.

Goethite and hematite are found to be the most thermodynamically stable forms under various conditions (Cornell and Schwertmann, 2003). They are often the first oxides to form or the end member of many transformations. The oxy-hydroxides can be dehydroxylated and transformed into their oxide counterparts. This reaction often takes place with the assist of heat or mechanical stress under dry conditions. It was found that hematite is always the end product of dehydroxylation of the pure phase (e.g., goethite, lepidocrocite, akaganeit $(\beta-\mathrm{FeOOH})$, ferrihydrite $\left(\mathrm{Fe}_{5} \mathrm{HO}_{8} \bullet 4 \mathrm{H}_{2} \mathrm{O}\right)$ and etc.) with the formation of other iron oxides as the intermediate forms, such as lepidocrocite $(\gamma-\mathrm{FeOOH})$ and maghemite $\left(\gamma-\mathrm{Fe}_{2} \mathrm{O}_{3}\right)$. Other transformation may occur as the form of dissolution or precipitation under acidic or alkaline conditions, such as lepidocrocite, akaganeite and $\mathrm{Fe}(\mathrm{OH})_{2}$ can be converted into goethite under alkaline conditions; ferrihydrite may also be transformed into goethite in aqueous solution within a broad $\mathrm{pH}$ range $(3-14)$; in the presence of $\mathrm{Cl}$, ferrihydrite can be converted into akaganeite at low $\mathrm{pH}$. 


\subsubsection{Surface Functional Groups}

The surface hydroxyl groups, which typically originate either from adsorption of water or from structural $\mathrm{OH}$, are the functional groups of iron oxides. Generally, hydroxyl groups possess a double pair of electrons together with a dissociable hydrogen atom which enables them to react with both acids and bases (Cornell and Schwertmann, 2003). Hence, iron oxides are typically amphoteric. Crystallographic considerations indicate that the surface hydroxyl groups may be coordinated to one, two or three underlying iron atoms. The structures of these singly, doubly and triply coordinated groups are illustrated in Figure 5. Assuming sixfold coordination for each Fe atom, a charge of $+1 / 2$ could be assigned to each Fe-O bond. Hence, the three of surface $\mathrm{OH}$ groups carry charges of $-1 / 2,0$ and $+1 / 2$.

All three hydroxyl groups are found coexisting on (001) plane, whereas no triply groups are observed on (100) plane; and only singly groups are present on (010) plane. The density of each type of functional group is dependent on the crystal structure and the extent of development of the different crystal faces. It can be measured by various methods, such as acid base titration, BET treatment of water vapour isotherms, $\mathrm{D}_{2} \mathrm{O}$ or tritium exchange and by reaction with adsorbing species (e.g., floride, phosphate and oxalate). Badlani and Wachs (2001) employed methanol adsorption method to determine surface active sites for various oxides including hematite. However, as different methods used, the results often vary with each other. Generally, singly coordinated hydroxyls are reported its density between 3 to $8 \mathrm{OH} / \mathrm{nm}^{2}$ for goethite and hematite. Barr $\mathrm{n}$ and Torrent (1996) reported the densities for singly, doubly and triply functional groups on 101 face of goethite are 3,3 and $9.1 \mathrm{OH} / \mathrm{nm}^{2}$, respectively.

\subsubsection{Reactivity of Surface Functional Groups}

As discussed above, hydroxyl functional groups may vary in structure, charge and acidity. Hence, they typically show different reactivities. Several previous studies (Russel et al., 1974; Lewis and Farmer, 1986; Hiemstra and Van Riemsdijk, 1996) indicated that the doubly coordinated surface hydroxyls on goethite, hematite and lepidocrocite are inert for adsorption over a wide $\mathrm{pH}$ range. Furthermore, Eggleston and Jordan (1998) and Hiemstra and Van Riemsdjik (1999) employed scanning field 
microscopy and acid base titration to investigate the hydroxyl groups on the (001) plane of hematite. They both suggested that doubly coordinated hydroxyl groups are the predominant type on this plane, which make this face unreactive and no charge contribution. Venema et al. (1998) revealed that only singly coordinated hydroxyls on goethite are involved in adsorption of ions on Fe oxides.

\subsection{Selenate Adsorption Mechanisms}

Adsorption of selenate onto iron oxides or hydroxides has been studied for decades. It is generally accepted that selenate anions are adsorbed via ligand exchange process. Surface complexes are formed between selenate anions and surface sites. Surface complexes are defined as a stable molecular entity formed between surface functional groups on the solid surface and the ions or molecules present in the solution (Sparks, 2003).

The surface complexes are classified as inner-sphere complex and outer-sphere complex according to the complexation location. Based on the electric double layer theory, various models were developed to describe the arrangement of adsorbate ions (i.e., triple layer model, stern layer model, generalized two layer model, and etc.). Generally, the surface of the adsorbent is charged and balanced by counterions (i.e., ions of opposite charge to the surface charge) in the adjacent cloud layer, which is known as the diffuse layer with a distance exceeding molecular dimensions. The triple layer model (TLM) developed by Davis and Leckie (1978) suggests the existence of two capacitance layers (i.e., o layer and $\beta$ layer) between the adsorbent surface and diffuse layer. Only proton and hydroxide can be adsorbed on o layer, while adsorption of other ions (e.g., metal cations and ligands) typically occurs on the outersphere layer ( $\beta$ layer) and forms outersphere complexes. Hayes and Leckie (1986) further modified the TLM and suggested that adsorbate ions can enter into inner sphere (o layer) and form chemical bonds with surface sites to form inner-sphere complexes. Eggleston et al. (1998) suggested that main difference between inner and outer sphere complexes lies in the number of water of hydration lost in the coordination of adsorbates and surface sites. Adsorbates lose at least one water molecule to form inner-sphere and retain intervening water of hydration to 
form outer-sphere complexes. Inner sphere complexes can be mono-dentate or bi-dentate. Adsorbates are bound to one oxygen atom to form mono-dentate binds, and bidentate binding is caused by binding with two oxygen atoms. Environmental factors such as $\mathrm{pH}$, surface loading, ionic strength and adsorbent type all affect the type of sorption complex and binding mechanisms.

Various micro-scale spectroscopies were involved to understand the binding formation between selenate ions and surface sites. Harrison and Berkheiser (1982) observed formation of inner-sphere bidentate binuclear complexes of selenate on iron oxides using ex-situ Fourier transform infrared (FTIR). Later studies revealed that drying and vacuum treatment in sample preparation for FTIR analysis could result in the innersphere formation (Johnston and Sposito, 1987). Hays and Leckie (1987) used extended X-ray absorption fine structure (EXAFS) to study selenate adsorption and concluded that selenate was adsorbed via outer-sphere mechanism onto goethite. Zhang and Sparks (1990) applied the triple layer model to selenate adsorption onto goethite and suggested an outer-sphere mechanism for selenate adsorption. Attenuated total reflectance FTIR (ATR-FTIR) and diffuse reflectance (DRIFT) spectroscopy were utilized to study selenate adsorption by Su and Suarez (2000). They found that selenate formed both monodentate and bidentate inner-sphere complexes on the surface of amorphous iron oxides under aqueous conditions but only bidentate inner-sphere complexes existed when samples became dry. Using EXAFS and ATR-FTIR, Peak and Sparks (2002) reported only inner-sphere complexes were formed in selenate adsorption on hematite but both outer- and inner-sphere complexes were formed on goethite and hydrous ferric oxides. Rovira et al. (2008) concluded that adsorption of selenate forms outer-sphere complexes at higher $\mathrm{pH}$ (alkaline conditions) on goethite and inner-sphere complexes at lower $\mathrm{pH}$ (acidic conditions).

Although selenate-iron (hydr)oxide adsorption systems have been studied for decades, controversies about the adsorption mechanisms still exist. In particular, the complexation mechanisms of selenate adsorption under different adsorption conditions (i.e. $\mathrm{pH}$, ionic strength and surface loading) still remain controversial. Exploration of adsorption mechanisms under various conditions is expected to help explain the low adsorption phenomena for selenate. Surface property investigation and molecular 
distribution mapping will promote the understanding of surface site affinity to selenate ions and further improve the adsorbent preparation procedure along with the increase of selenate removal efficiency by adsorptive techniques.

\subsection{Characterization of Selenate Adsorption Mechanism and Oxidation States}

The use of spectroscopic techniques has generated valuable yet controversial information on the structure on adsorbed Se species on iron oxides/hydroxide minerals and synthetic adsorbents. Chemical states of selenium can be determined by spectroscopic analysis and quantitative analytical methods. Various spectroscopes including Attenuated total reflectance-Fourier transform infrared spectroscopy (ATRFTIR), Raman spectroscopy and Extended X-ray absorption fine structure (EXAFS) were used in previous studies to characterize the binding mechanism of selenate sorption (Manceau and Charlet, 1994; Su and Suarez, 2000; Wijnja and Schulthess, 2000; Peak and Sparks, 2002). Atomic scale surface imaging tools (e.g., scanning tunneling microscopy (STM) and high resolution transmission electron microscopy (HRTEM)) are also found to be helpful to provide comprehensive information to identify the crystal structure.

\subsubsection{Chemical States Determination}

X-ray absorption near edge structure (XANES) was widely used in determining the chemical oxidation states. The near-edge structure is characteristic of an environment and valence state. Much chemical information can be extracted from the XANES region: formal valence, coordination environment and subtle geometrical distortions. XANES has been utilized to identify the location, oxidation state and spatial distribution of heavy metal elements in soils and plants.

Olegario et al. (2009) investigated the reaction of Se (VI) with zero-valent iron nanoparticles using X-ray spectroscopic techniques. Initial Se (VI) concentrations used in this study ranged from 0.13 to $3.00 \mathrm{mM}$ with $0.01 \mathrm{M} \mathrm{NaCl}$ in the solution. The

reaction time for batch adsorption experiments lasted for 48 hours. The Se $K$-edge absorption spectra were collected from 12,500-13200 eV. Energy step intervals of 0.2 
$\mathrm{eV}$ from 12,640-12,683 eV (XANES region) were controlled with a $\mathrm{Si}(111)$ monochromator. Energy calibration was performed by assigning the $K$-edge energy $\left(E_{0}\right)$ of $11919 \mathrm{eV}$ to a gold foil which resulted in a measured Se $K$-edge of $12657.4 \mathrm{eV}$ for $\mathrm{Se}(0)$ standard. Olegario et al. (2009) reported values of $E_{0}$ for $\mathrm{Se}(\mathrm{VI}), \mathrm{Se}(\mathrm{IV})$ and $\mathrm{Se}(0)$ as $12664.49,12661.42$ and $12657.51 \mathrm{eV}$, respectively. The measured $E_{0}$ for $\mathrm{Na}_{2} \mathrm{Se}$ was $12656.17 \mathrm{eV}$, which makes the $\mathrm{Se}^{2-}$ distinctly different from Se (VI), Se (IV) and $\mathrm{Se}(0)$ and thus are usefull as a fingerprint for $\mathrm{Se}^{2-}$ the oxidation state.

The results of XANES spectrum analysis of Se (VI)-adsorbed nano $\mathrm{Fe}^{0}$ suggested that Se (VI) had been fully reduced and no evidence for the existence of Se (VI) in final product was shown. The results also indicated that the oxidation state of Se was clearly $\mathrm{Se}^{2-}$, however, it was also possible that poorly ordered domains of $\mathrm{Se}(0)$ could be present as part of the $\mathrm{Fe}$ corrosion layer, especially for the more oxidizing environmental conditions or partial reduction of Se (VI) occurred.

X-Ray Photoelectron Spectroscopy (XPS) is another widely used surface technique for surface elemental composition and chemical oxidation state studies. The working principle of XPS is that the core electron of a target atom receives sufficient energy from an incoming X-ray source and escapes from the atom and emits out to the surface. The kinetic energy $\left(E_{k}\right)$ of the emitted electrons is measured by XPS energy analyzer. The binding energy of the core electron is then calculated by the difference between adsorbed energy and kinetic energy. Qiu et al. (2000) studied the oxidation state of Se after reduction by ZVI reduction using XPS. A Se (VI) concentration of $10 \mathrm{mM}$ was prepared in $1 \mathrm{mM} \mathrm{NaCl}$ solution. $\mathrm{pH}$ was controlled at $8-8.5$ to simulate field conditions. Qiu et al. (2000) indicated that for Se (0) deposited on clean iron foil in the absence of oxygen, the $3 \mathrm{p}_{3 / 2}$ binding energy is $161.0 \mathrm{eV}$. For the standard $\mathrm{Se}(\mathrm{VI})$ powder, the $2 p_{3 / 2}$ binding energy is $169.7 \mathrm{eV}$. The $3 \mathrm{p}_{3 / 2}$ binding energy is $166.0 \mathrm{eV}$ for $\mathrm{Se}$ collected from iron substrate reacted in $0.5 \mathrm{~mL}$ of a $10 \mathrm{mM} \mathrm{Na}_{2} \mathrm{SO}_{4}$ solution without $\mathrm{N}_{2}$ purging. The results showed that peak collected without $\mathrm{N}_{2}$ purging lied between elemental Se and Se (VI), which indicated the presence of partially reduced form $\mathrm{Se}(\mathrm{IV})$. 


\subsubsection{Chemical Binding Identification}

Harrison and Berkheiser (1982) observed formation of inner-sphere bidentate binuclear complexes of selenate on iron oxides using ex-situ Fourier transform infrared (FTIR). Watanabe et al. (1994) suggested that conclusions of several earlier FTIR studies of selenate and sulfate adsorption are often equivocal because samples were dried before spectroscopic study. Later studies revealed that drying and vacuum treatment in sample preparation for FTIR analysis could result in the inner-sphere formation (Johnston and Sposito, 1987). Parfitt and Russell (1977) also suggested a transition from outersphere to inner-sphere complex upon air drying for nitrate and chloride ions. Hence, an in situ study is more precise to analyze the interfacial structure of selenate.

Attenuated total reflectance FTIR (ATR-FTIR) spectroscopy was utilized to investigate selenate and selenite sorption onto amorphous $\mathrm{Fe}$ oxide $\left[\mathrm{am}-\mathrm{Fe}(\mathrm{OH})_{3}\right]$ by $\mathrm{Su}$ and Suarez (2000). They reported the spectra of free selenite, selenate and selenate, selenite sorbent suspensions recorded in the range of $4000-700 \mathrm{~cm}^{-1}$. Bands at 850,825 and $731 \mathrm{~cm}^{-1}$ were observed for free selenite anions in solution at $\mathrm{pH} 5$, and bands at 872 $\mathrm{cm}^{-1}$, assigned to $v_{3}$ (asymmetric stretching of Se-O bond), was identified for free selenate anions in solution at $\mathrm{pH} 8$. Su and Suarez (2000) suggested that the coordination of selenate with metal cations could cause the decrease of selenate symmetry resulting in a splitting of the $v_{3}$ band. They concluded based on the data provided by Harrison and Berkheiser (1982) that two bands will appear at $C_{3 v}$ symmetry if a monodentate complex forms, three bands are present at $\mathrm{C}_{2 v}$ symmetry if a bidentate complex forms. Su and Suarez (2000) determined the spectra of selenate complexes at the solid-aqueous solution interface by subtracting the bulk solution IR absorption from the spectrum of the corresponding sorbent suspension. The results for am- $\mathrm{Fe}(\mathrm{OH})_{3}$ reacted with 0.05 and 0.1 M selenate at pH 5.0 showed two bands at 895 and $885 \mathrm{~cm}^{-1}$ indicating a reduction in symmetry.

Wijnja and Schulthess (2000) studied coordination and speciation of selenate on goethite surfaces using Raman spectroscopy. The Raman spectra for $0.1 \mathrm{M}$ selenate solution at $\mathrm{pH} 0.8$ and 7.5 were reported. According to value of $p K_{a 2}$ of selenate, $\mathrm{HSeO}_{4}{ }^{-}$ is the predominant species at $\mathrm{pH} 0.8$ and $\mathrm{SeO}_{4}{ }^{2-}$ is the only species in solution at $\mathrm{pH}$ 7.5. Four bands were identified for selenate at $\mathrm{pH} 7.5: 349,417,837$ and $873 \mathrm{~cm}^{-1}$ assigned to 
doubly degenerate $v_{2} \mathrm{OSeO}$ bending, triply degenerate $v_{4} \mathrm{OSeO}$ bending, nondegenerate $v_{1}$ symmetric $\mathrm{SeO}$ stretching and $v_{3}$ asymmetric $\mathrm{SeO}$ stretching, respectively. It was suggested that stretching vibrations are much more intense than the bending vibrations (Wijnja and Schulthess, 2000). Spectra for selenate (0.004 M) adsorbed at various $\mathrm{pH}$ on goethite ( $\mathrm{I}=0.004$ to $0.006 \mathrm{M})$ and $\mathrm{Al}$ oxide $(\mathrm{I}=0.008$ to $0.014 \mathrm{M})$ were compared with spectra for adsorbents only. Results showed that bands at 875 and $900 \mathrm{~cm}^{-1}$ became clear and sharp as the decrease of $\mathrm{pH}$ from 7.2 to 4.2 . A shoulder band at $835 \mathrm{~cm}^{-1}$ was also observed to disappear as $\mathrm{pH}$ decreased. A shift of $v_{1}$ band for adsorbed selenate $\left(848 \mathrm{~cm}^{-}\right.$ $\left.{ }^{1}\right)$ from selenate in solution $\left(837 \mathrm{~cm}^{-1}\right)$ was also observed. The shift of $v_{1}$ and split of $v_{3}$ indicated the direct coordination of $\mathrm{SeO}_{4}$ to the goethite surface (i.e., monodentate innersphere surface complex). The fade of the shoulder band also indicated that a fraction of the adsorbed $\mathrm{SeO}_{4}$ exists as an outer-sphere complex.

Peak and Sparks (2002) employed extended X-ray absorption fine structure (EXAFS) to determine the selenate bonding mechanism on goethite. It was found that the hydrated radius for $\mathrm{SeO}_{4}{ }^{2-}$ and $\mathrm{HSeO}_{4}{ }^{-}$are $\sim 4 \AA$ (Stumm and Morgan, 1996). The $k^{3}$ weighted $\chi$ function spectra and radial structure functions (RSF) spectra were presented for selenate solution and selenate on various iron oxides by Peak and Sparks (2002). They also fit the spectra with theoretical scattering paths using FEFF7 code. The results showed successful fitting of $k^{3} \chi$ spectra with a single shell fit of 4 oxygens at $1.64 \AA$ for both aqueous selenate and selenate on goethite at $\mathrm{pH} 6 . k^{3} \chi$ spectra for selenate on goethite at $\mathrm{pH} 3.5$ was reported to fit better with a two shell fit of 4 oxygens at $1.64 \AA$ and $1.5 \mathrm{Fe}$ at $3.31 \AA$. It indicated that inner-sphere complexation of selenate occurs on the goethite surface at $\mathrm{pH} 3.5$. They concluded that $\mathrm{pH}$ plays a significant effect on selenate adsorption on goethite, however, ionic strength and surface loading have a more subtle effect.

\subsubsection{Crystal Structure Investigation}

Olegario et al. (2009) used x-ray diffraction (XRD) to study the crystal structure of selenium on zero-valent iron nanoparticles. The spectra for untreated 100 mesh $\mathrm{Fe}^{0}$ powder, $\mathrm{Fe}^{0}$ nanoparticles, selenate with various concentrations deposited on $\mathrm{Fe}^{0}$ nanoparticles were presented. Peaks at $27.15,36.25$ and $46.90^{\circ} 2 \theta$ were identified 
indicating the formation of $\gamma-\mathrm{FeOOH}$ as a result of the oxidation of nano $\mathrm{Fe}^{0}$. The results also showed that the increasing concentration of selenate (from 0.5 to $5 \mathrm{mM}$ ) caused a conversion of $\gamma$-FeOOH to magnetite $\left(\mathrm{Fe}_{3} \mathrm{O}_{4}\right)$

Other instruments have the potential to increase our understanding of selenium adsorption on iron oxides, but have not been used. For example, scanning tunneling microscope (STM) and high resolution transmission electron microscope (HRTEM) were applied to study the sorbed crystal structure for other cations (e.g., $\mathrm{Cr}(\mathrm{III})$ ) and anions (e.g., sulfate) (Fendorf and Sparks, 1994; Eggleston et al., 1998). These atomic-scale microscopes could be useful methods used to analyze the crystal structure of surface sorbed selenium. 
Selenium productiong usage demand

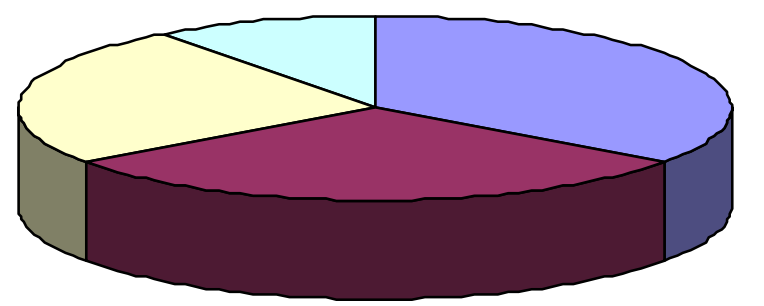

$\square$ Electronic and photocopier components, 35\%

$\square$ Glass manufacturing, 30\%

$\square$ Chemical and pigments, 25\%

口 Other, $10 \%$

Figure 1. Selenium production usage in each industry. 


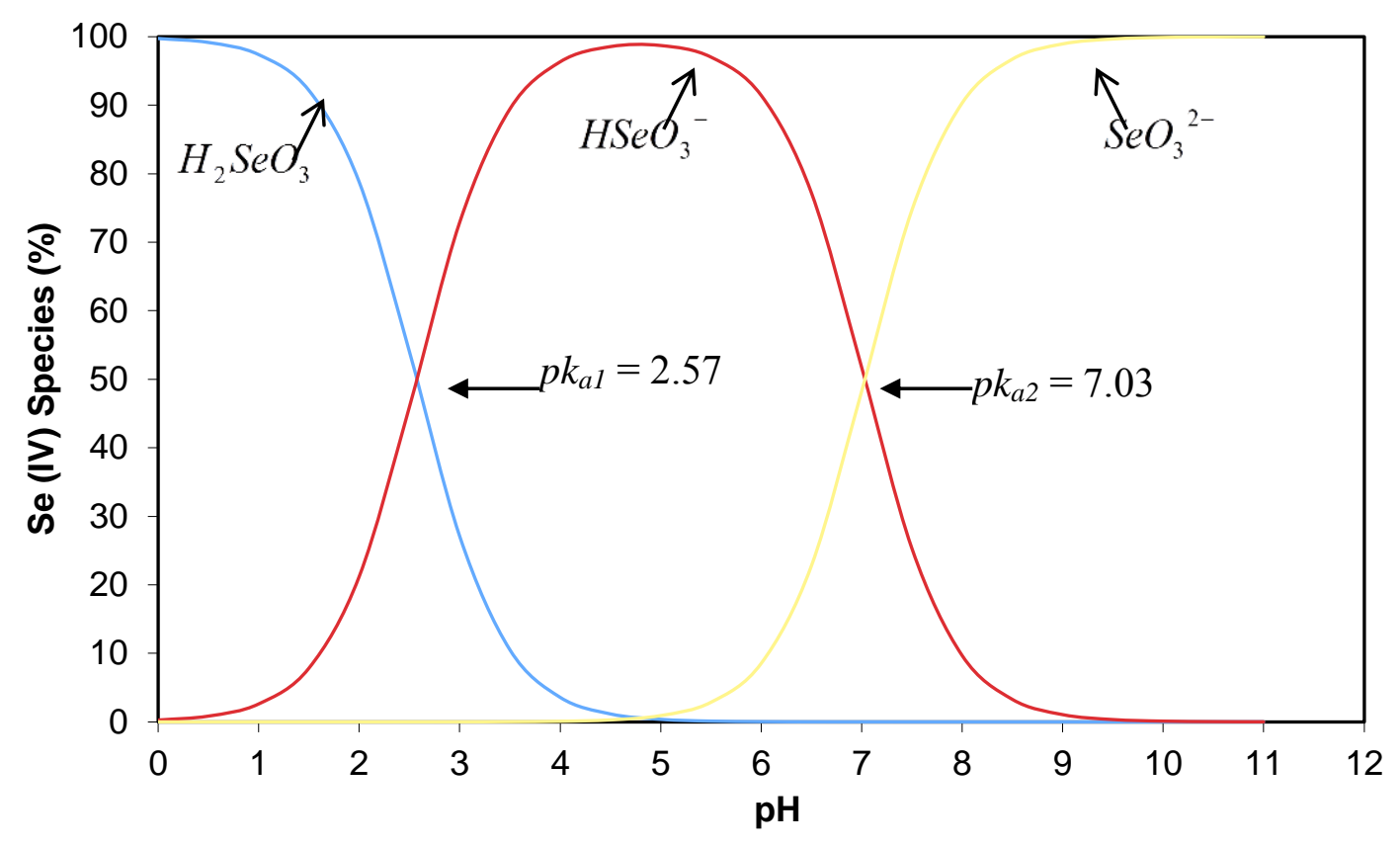

Figure 2. Species fraction diagram for Se (IV) as a function of $\mathrm{pH}$.

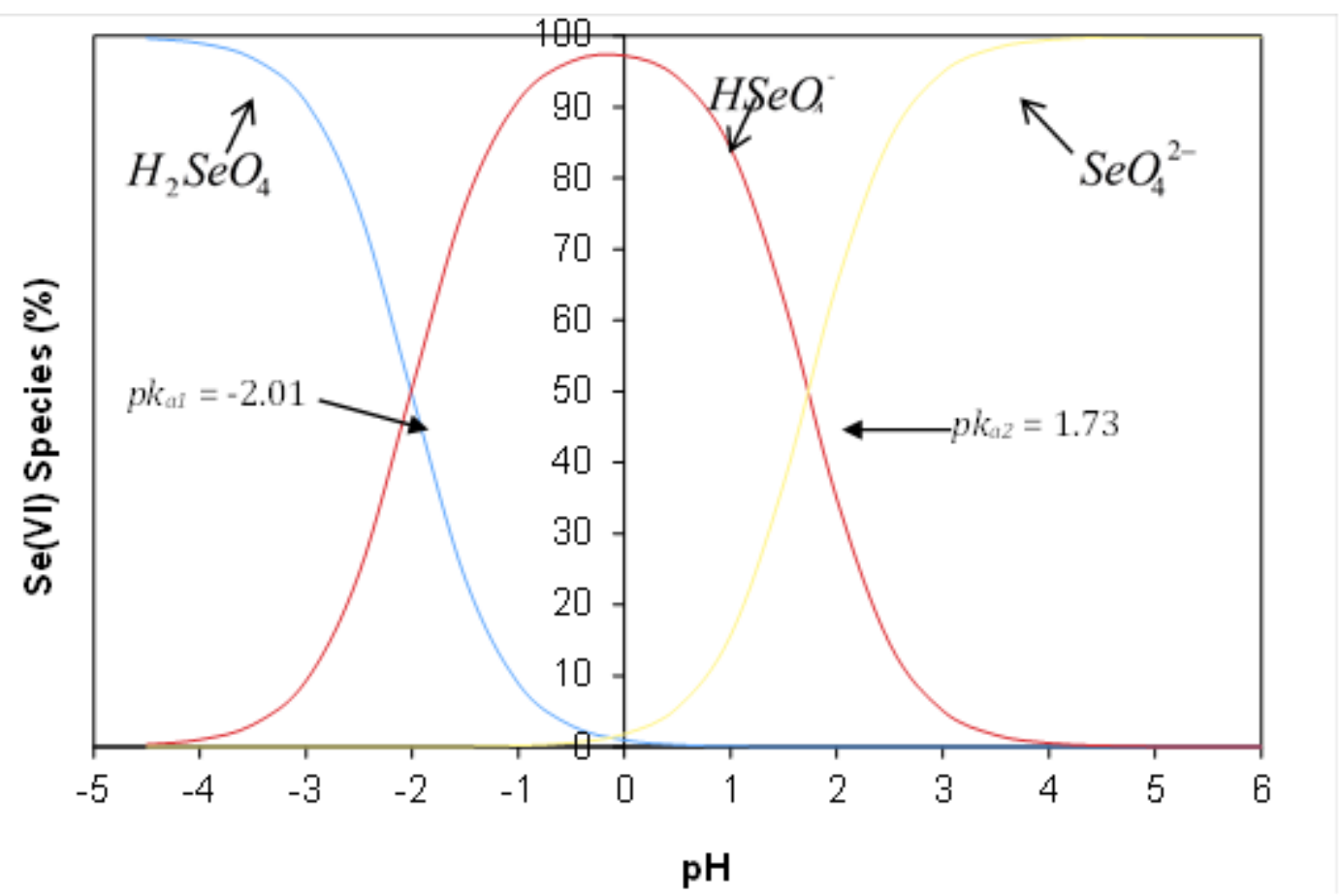

Figure 3. Species fraction diagram for $\mathrm{Se}(\mathrm{VI})$ as a function of $\mathrm{pH}$ 


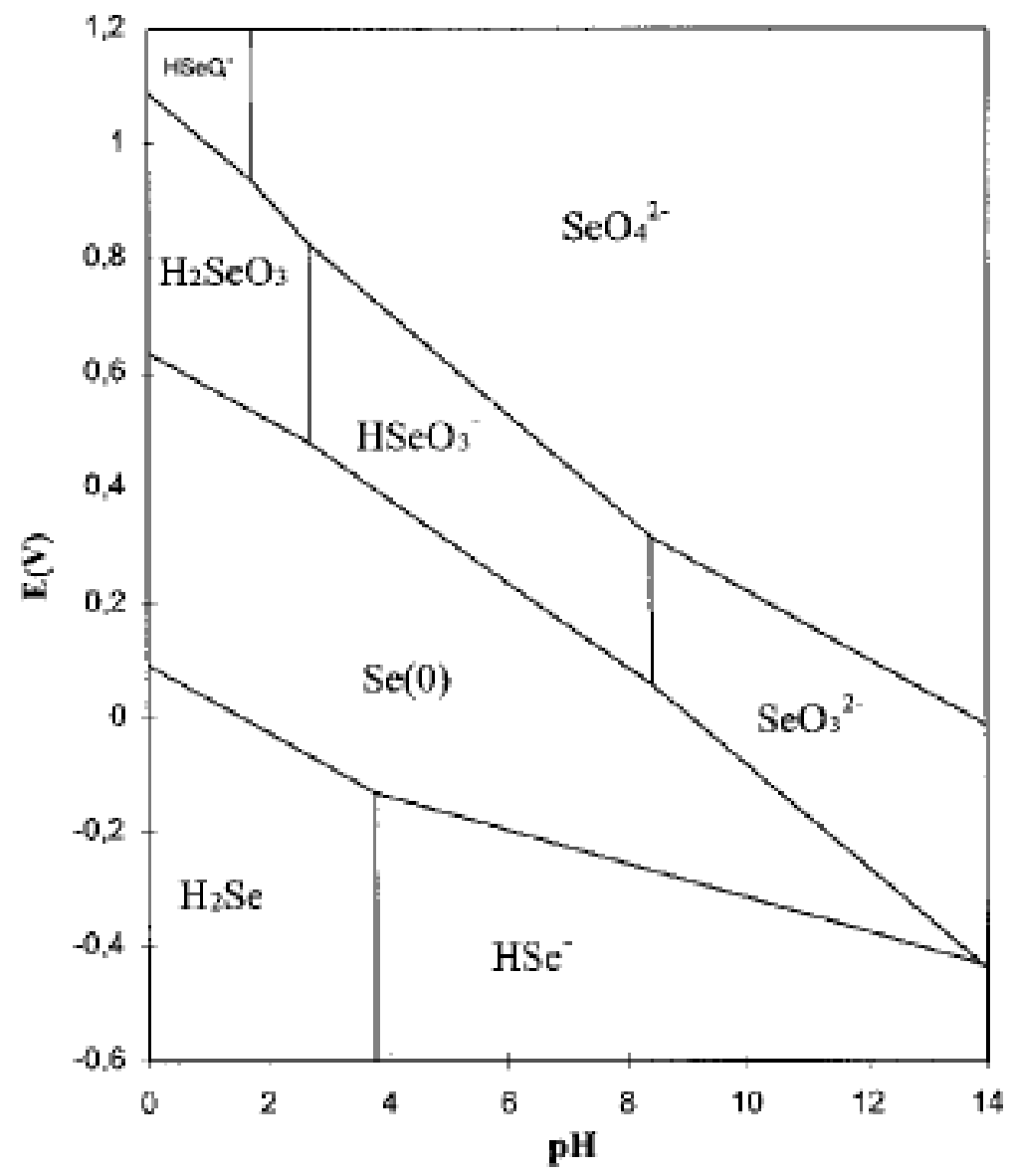

Figure 4. Selenium potential-pH diagram at $25^{\circ} \mathrm{C}$ for a dissolved selenium activity of 10 7 mol/L (Séby, et al., 1998).

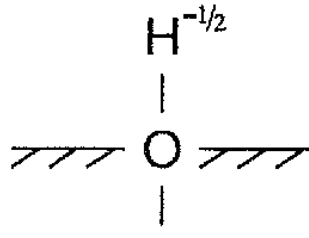

$\mathrm{Fe}$ singly

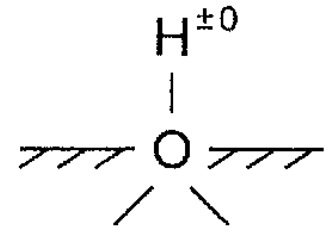

$\mathrm{Fe} \mathrm{Fe}$ doubly

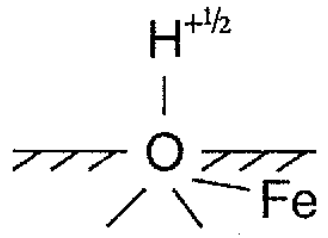

$\mathrm{Fe} \mathrm{Fe}$ triply coordinated hydroxyl

Figure 5. Structures of singly, doubly and triply coordinated surface hydroxyl groups on iron oxides (Cornell, 2003). 
Table 1. Standard thermodynamic data used to establish the potential-pH diagram (Séby, et al., 1998).

\section{Redox reactions}

Standard

potential (V)

\begin{tabular}{|c|c|}
\hline $\operatorname{Se}(0) / \operatorname{Se}(-\mathrm{II})$ & \\
\hline $\begin{array}{l}\mathrm{Se}(s)+2 H^{+}+2 e^{-} \Leftrightarrow \mathrm{H}_{2} \mathrm{Se}(a q) \\
\mathrm{Se}(s)+H^{+}+2 e^{-} \Leftrightarrow \mathrm{HSe}^{-} \\
\mathrm{Se}(s)+2 e^{-} \Leftrightarrow S e^{-}\end{array}$ & $\begin{array}{l}-0.115 \\
-0.227 \\
-0.641\end{array}$ \\
\hline $\mathrm{Se}(\mathrm{IV}) / \mathrm{Se}(0)$ & \\
\hline $\begin{array}{l}\mathrm{H}_{2} \mathrm{SeO}_{3}(a q)+4 \mathrm{H}^{+}+4 e^{-} \Leftrightarrow \mathrm{Se}(s)+3 \mathrm{H}_{2} \mathrm{O} \\
\mathrm{H}_{2} \mathrm{SeO}_{3}+5 \mathrm{H}^{+}+4 e^{-} \Leftrightarrow \mathrm{Se}(s)+3 \mathrm{H}_{2} \mathrm{O} \\
\mathrm{SeO}_{3}^{2}+6 \mathrm{H}^{+}+4 e^{-} \Leftrightarrow \mathrm{Se}(s)+3 \mathrm{H}_{2} \mathrm{O}\end{array}$ & $\begin{array}{l}0.740 \\
0.780 \\
0.903\end{array}$ \\
\hline $\operatorname{Se}(\mathbf{V I}) / \mathrm{Se}(\mathbf{I V})$ & \\
\hline $\mathrm{HSeO}_{4}^{-}+3 \mathrm{H}^{+}+2 e^{-} \Leftrightarrow \mathrm{H}_{2} \mathrm{SeO}_{3}(a q)+\mathrm{H}_{2} \mathrm{O}$ & 1.090 \\
\hline $\mathrm{HSeO}_{4}^{-}+2 \mathrm{H}^{+}+2 e^{-} \Leftrightarrow \mathrm{HSeO}_{3}^{-}+\mathrm{H}_{2} \mathrm{O}$ & 1.008 \\
\hline $\mathrm{HSeO}_{4}^{-}+\mathrm{H}^{+}+2 e^{-} \Leftrightarrow \mathrm{SeO}_{3}^{2-}+\mathrm{H}_{2} \mathrm{O}$ & 0.760 \\
\hline $\mathrm{SeO}_{4}^{2-}+4 \mathrm{H}^{+}+2 e^{-} \Leftrightarrow \mathrm{H}_{2} \mathrm{SeO}_{3}(a q)+\mathrm{H}_{2} \mathrm{O}$ & 1.139 \\
\hline $\mathrm{SeO}_{4}^{2-}+3 \mathrm{H}^{+}+2 e^{-} \Leftrightarrow \mathrm{HSeO}_{3}^{-}+\mathrm{H}_{2} \mathrm{O}$ & 1.060 \\
\hline $\mathrm{SeO}_{4}^{2-}+2 \mathrm{H}^{+}+2 e^{-} \Leftrightarrow \mathrm{SeO}_{3}^{2-}+\mathrm{H}_{2} \mathrm{O}$ & 0.811 \\
\hline Acid-Base reactions & $p K_{a}$ \\
\hline Se (-II) & \\
\hline $\begin{array}{l}\mathrm{H}_{2} \mathrm{Se}+\mathrm{H}_{2} \mathrm{O} \Leftrightarrow \mathrm{HSe}^{-}+\mathrm{H}_{3} \mathrm{O}^{+} \\
\mathrm{HSe}^{-}+\mathrm{H}_{2} \mathrm{O} \Leftrightarrow \mathrm{Se}^{2-}+\mathrm{H}_{3} \mathrm{O}^{+}\end{array}$ & $\begin{array}{c}3.8 \\
14\end{array}$ \\
\hline Se (IV) & \\
\hline $\mathrm{H}_{2} \mathrm{SeO}_{3}+\mathrm{H}_{2} \mathrm{O} \Leftrightarrow \mathrm{HSeO}_{3}^{-}+\mathrm{H}_{3} \mathrm{O}^{+}$ & 2.68 \\
\hline $\mathrm{HSeO}_{3}^{-}+\mathrm{H}_{2} \mathrm{O} \Leftrightarrow \mathrm{SeO}_{3}^{2-}+\mathrm{H}_{3} \mathrm{O}^{+}$ & 8.4 \\
\hline $\mathrm{Se}(\mathrm{VI})$ & \\
\hline $\mathrm{H}_{2} \mathrm{SeO}_{4}+\mathrm{H}_{2} \mathrm{O} \Leftrightarrow \mathrm{HSeO}_{4}^{-}+\mathrm{H}_{3} \mathrm{O}^{+}$ & -2.01 \\
\hline $\mathrm{HSeO}_{4}^{-}+\mathrm{H}_{2} \mathrm{O} \Leftrightarrow \mathrm{SeO}_{4}^{2-}+\mathrm{H}_{3} \mathrm{O}^{+}$ & 1.73 \\
\hline
\end{tabular}




\section{CHAPTER 3: MATERIALS AND METHODS}

\subsection{Materials}

All the chemical solutions used in this study were analytical grade and prepared using de-ionized water. Sodium selenite $\left(\mathrm{Na}_{2} \mathrm{SeO}_{3}\right)$ and sodium selenate $\left(\mathrm{Na}_{2} \mathrm{SeO}_{4}\right)$ were purchased from MP Biomedicals (Solon, $\mathrm{OH}$ ).

Sodium bicarbonate $\left(\mathrm{NaHCO}_{3}\right)$, sodium carbonate $\left(\mathrm{Na}_{2} \mathrm{CO}_{3}\right)$, sodium chloride $(\mathrm{NaCl})$, sodium citrate $\left(\mathrm{Na}_{3} \mathrm{C}_{6} \mathrm{H}_{5} \mathrm{O}_{7} \cdot 2 \mathrm{H}_{2} \mathrm{O}\right)$, sodium dithionite $\left(\mathrm{Na}_{2} \mathrm{~S}_{2} \mathrm{O}_{4}\right)$, sodium hydroxide $(\mathrm{NaOH})$, sodium phosphate $\left(\mathrm{Na}_{3} \mathrm{PO}_{4}\right)$, sodium silicate $\left(\mathrm{Na}_{2} \mathrm{SiO}_{4}\right)$, potassium acetate $(\mathrm{KAc})$, potassium chloride $(\mathrm{KCl})$, ferrous chloride $\left(\mathrm{FeCl}_{2} \cdot 4 \mathrm{H}_{2} \mathrm{O}\right)$ and cyclohexane (spectrophotemetric, 99+\%) were purchased from Fisher Scientific, Inc. (Rochester, NY).

Sodium hypochlorite $(\mathrm{NaClO}, 13 \%)$, sodium sulfate $\left(\mathrm{Na}_{2} \mathrm{SO}_{4}\right), 2, \quad 3-$ Diaminonaphthalene (97\%) (DAN) and hxdroxylamine hydrochloride reagents were obtained from ACROS Organics (Geel, Belgium).

Iron-coated GAC adsorbent used in this study was prepared using Darco $12 \times 20$ GAC provided by Norit Americas Inc. (Marshall, TX).

\subsection{Reagent Preparation}

\subsubsection{Selenium Stock Solutions}

A selenate stock solution $(1,000 \mathrm{mg}-\mathrm{Se} / \mathrm{L})$ was prepared by dissolving $\mathrm{Na}_{2} \mathrm{SeO}_{4}$ into $50 \mathrm{~mL}$ deionized water containing $0.5 \mathrm{~mL}$ concentrated $\mathrm{HCl}$. A selenite stock solution was prepared for the same concentration. Separate working solutions $(4 \mathrm{mg} / \mathrm{L})$ of selenite and selenate were prepared by further diluting the stock solutions and they were used in all adsorption experiments.

\subsubsection{Selenium Analysis Reagents}

The DAN solution was prepared by dissolving $200 \mathrm{mg}$ DAN in $200 \mathrm{~mL} \mathrm{HCl}(0.1$ $\mathrm{N}$ ), and then extracted three times using $25 \mathrm{~mL}$ cyclohexane, followed by filtration into 
an opaque container. It was then stored in cool place for no longer than 8 hours. An HAEDTA solutions prepared by adding $2.25 \mathrm{~g} \mathrm{Na} 2$ EDTA and $6.25 \mathrm{~g}$ hydroxylamine hydrochloride $\left(\mathrm{NH}_{2} \mathrm{OHHCl}\right)$ into $250 \mathrm{~mL}$ de-ionized water was used to eliminate negative interferences from $\mathrm{Fe}^{2+}$.

\subsubsection{Iron Extraction Reagents}

A sodium citrate solution $(0.3 \mathrm{M})$ was prepared by adding $22.05 \mathrm{~g}$ $\mathrm{Na}_{3} \mathrm{C}_{6} \mathrm{H}_{5} \mathrm{O}_{7} \cdot 2 \mathrm{H}_{2} \mathrm{O}$ to approximately $50 \mathrm{~mL}$ de-ionized water, completely dissolved and brought the volume to $250 \mathrm{~mL}$.

\subsubsection{Electrolytes and Other Salt Solutions}

Electrolyte solutions ( $\mathrm{LiCl}, \mathrm{NaCl}$ and $\mathrm{KCl}, 0.5 \mathrm{M}$ ) were prepared by dissolving the solid salts into $100 \mathrm{~mL}$ de-ionized water and brought the volume to $250 \mathrm{~mL}$ in volumetric flasks. Solutions for competitive anions experiments $\left(\mathrm{Na}_{2} \mathrm{SO}_{4}, \mathrm{Na}_{2} \mathrm{SiO}_{4}\right.$, $\mathrm{Na}_{2} \mathrm{CO}_{3}$ and $\mathrm{Na}_{3} \mathrm{PO}_{4}$ ) were also prepared for the anion concentration of $0.5 \mathrm{M}$ by dissolving corresponding salts into de-ionized water..

\subsection{Adsorbent Preparation and Characterization}

\subsubsection{Adsorbent Preparation}

The adsorbents were prepared by oxidizing ferrous iron into ferric iron using sodium hypochlorite on the outside surface and inner porous structures of GAC. The detailed synthesis procedure was described elsewhere ( $\mathrm{Gu}$ et al., 2005; Zhang et al., 2008). Figure 6 illustrates the ferrous mixing process incorporated with $\mathrm{NaClO}$ titration.

\subsubsection{Iron Percentage Measurement}

To investigate the efficiency of the coating procedure, total iron percentage and amorphous iron percentage on virgin GAC and Fe-GAC were determined using iron extraction methods followed by Inductively Coupled Plasma Spectroscopy Optical Emission Spectrometer (Optima 2100 DV, Perkin Elmer, CT) measurements. 


\subsubsection{Total Iron Percentage}

Total iron was extracted from GAC surface following an acid digestion procedure (Lu, 1995; Gu et al., 2005). Specifically, each type of adsorbents (0.1 g) was suspended in $30 \mathrm{~mL} \mathrm{HCl} \mathrm{(3:1)} \mathrm{and} \mathrm{shook} \mathrm{for} 2$ hours. The mixture solution was then heated in a water bath at $90{ }^{\circ} \mathrm{C}$ for 20 minutes. The liquid phase was separated by vacuum filtration through a $0.45 \mu \mathrm{m}$ membrane. Remaining solids were washed with de-ionized water several times and followed by filtration after each washout. All the aqueous filtrates were collected and mixed for iron determination using ICP-OES.

\subsubsection{Active/Amorphous Iron Oxide Percentage}

Amorphous iron on Fe-GAC was determined using a dark acid ammonium oxalate method (Schwertman, 1964; McKeague and Day, 1966; Loeppert and Inskeep, 1996). Fe-GAC adsorbents (approximately $1 \mathrm{~g}$ ) were ground to pass through a 100 mesh $\mathrm{in}^{-1}(0.15 \mathrm{~mm}$ nominal pore size $)$ sieve and transferred into a $50-\mathrm{mL}$ light-proof tube. Thirty $(30) \mathrm{mL}$ of ammonium oxalate solution $(\mathrm{pH}=3)$ was added and the tube was immediately capped. The suspension was agitated and placed on reciprocating shaker for 2 hours. The suspension was filtered through a $0.45 \mu \mathrm{m}$ membrane and solids were washed several times with de-ionized water following by filtration after each washout. All the aqueous filtrates were collected for iron determination as described above.

\subsubsection{Iron Composition Analysis}

Iron on Fe-GAC surface was studied to determine its chemical composition at various pH (e.g., 2 - 10) using X-ray Photoelectron Spectroscopy (XPS, PHI 5000 VersaProbe, Physical Electronics, Inc., MN). To obtain a high content of iron on GAC surface, Fe-GACs were prepared with $0.1 \mathrm{M}$ ferrous and at a solid loading rate of $5 \mathrm{~g} / \mathrm{L}$. A ratio of 1:20 was used for ferrous iron to hypochlorite. Fe-GAC adsorbents were suspended in electrolyte solutions $(\mathrm{NaCl}, 0.1 \mathrm{M})$ for 24 hours. The solution $\mathrm{pH}$ was adjusted to values (i.e., 2, 5 and 8) using $\mathrm{HCl}(0.1 \mathrm{~N})$ or $\mathrm{NaOH}(0.02 \mathrm{~N})$ and monitored every 6 hours. Then, aqueous and solids phases were separated by vacuum filtration through $45 \mu \mathrm{m}$ membranes. Solids were dried at room temperature and characterized by XPS along with raw GAC and non-suspended Fe-GAC. 


\subsubsection{Acid-Base Titration}

Point of zero charge $\left(\mathrm{pH}_{\mathrm{pzc}}\right)$ of the Fe-GAC under two ionic strengths $(0.01$ and $0.1 \mathrm{M} \mathrm{NaCl}$ ) was determined using an acid-base titration method. For each ionic strength, two suspension samples $(50 \mathrm{~mL})$ each containing de-ionized water with a predetermined amount of $\mathrm{NaCl}$, and $\mathrm{Fe}-\mathrm{GAC}(0.1 \mathrm{~g}$ to obtain adsorbent loading $2 \mathrm{~g} / \mathrm{L})$ were prepared in flasks. The suspension samples were mixed for 12 hours to equilibrate. Thereafter, one of the two suspension samples was filtered through a $0.45 \mu \mathrm{m}$ membrane by vacuum to remove the solids. The remaining suspension sample and the filtrate were then adjusted to $\mathrm{pH} 3$ with a $\mathrm{HCl}$ solution $(0.1 \mathrm{~N})$ as the initial titration point. Prior to the titration, nitrogen gas was bubbled into the samples to removal $\mathrm{CO}_{2}$. The solutions were then titrated to $\mathrm{pH} 10$ with a $\mathrm{NaOH}$ solution $(0.02 \mathrm{~N})$. Titration was performed by a $50 \mathrm{~mL}$ Digitrate $\mathrm{Pro}^{\mathrm{TM}}$, digital burette (Jencons, UK), during which $\mathrm{pH}$ was monitored by a $\mathrm{pH}$ meter (Accumet Basic AB15 Plus, Fisher Scientific, NY). During the titration, the aqueous solution along with burette and $\mathrm{pH}$ electrode was sealed with parafilm to prevent $\mathrm{CO}_{2}$ exchange between the atmosphere and the aqueous solution. Equilibrium for each data point were assumed if there was no change of 0.2 units for $\mathrm{pH}$ observed within 30 seconds and it ranged from a few seconds to 10 minutes to reach equilibrium. A net titration curve was obtained by subtracting the total added acid/base concentration for titrating the filtrate to $\mathrm{pH} 10$ from the added acid/base concentration for every titration data point of the suspension sample. The concentration of acid/base on the net titration curve can be calculated using the equation reported by Wen et al. (1998). The concentrations of added acid (-) or base $(+)$ were plotted as a function $\mathrm{pH}$, and $\mathrm{pH}_{\mathrm{pzc}}$ was determined by the intersection of the two net titration curves for two ionic strengths (Huang, 1981; Schulthess and Sparks, 1986; Reed and Matsumoto, 1991).

\subsection{Selenium Analysis}

\subsubsection{Selenite Analysis}

A colorimetric method was used to measure selenium concentration (USEPA standard methods 3500C, 1998). The method relied on a reaction of selenite ion with DAN that produced a brightly colored and strongly fluorescent piazselenol compound, 
which was extracted in cyclohexane and measured colorimetrically. The DAN solution was prepared by dissolving $200 \mathrm{mg} \mathrm{DAN}$ in $200 \mathrm{~mL} \mathrm{HCl}(0.1 \mathrm{~N})$, and then extracted three times using $25 \mathrm{~mL}$ cyclohexane, followed by filtration into an opaque container. An HA-EDTA solution prepared by adding $2.25 \mathrm{~g} \mathrm{Na} 2$ EDTA and $6.25 \mathrm{~g}$ hydroxylamine hydrochloride $\left(\mathrm{NH}_{2} \mathrm{OHHCl}\right)$ into $250 \mathrm{~mL}$ de-ionized water was used to eliminate negative interference from $\mathrm{Fe}^{2+}$. For the colometric measurements, $2 \mathrm{~mL}$ of the HAEDTA solution was added to a $50 \mathrm{~mL}$ test tube containing $10 \mathrm{~mL}$ selenium aqueous sample or deionized water (as blank). The mixture solution $\mathrm{pH}$ was adjusted to $1.5 \pm 0.3$ using a $0.1 \mathrm{~N} \mathrm{HCl}$ solution. All the samples solution along with blank control were then added with $5 \mathrm{~mL}$ of the DAN solution and put into a covered water bath at $45^{\circ} \mathrm{C}$ for one and half hours to allow color formation. The sample solution was allowed to cool down and followed by the addition of $2 \mathrm{~mL}$ cyclohexane. The sample test tube was capped with phenolic screw caps (PTFE rubber lined) securely and shaken vigorously for 5 minutes, followed by 5-minute without mixing to separate the organic layer from the aqueous solution. The aqueous phase was removed using a disposable pipet attached to a vacuum line. Organic layer was transferred into methacrylate disposable cuvettes for UV/Visible spectrophotometer (Cary 50, Varian) analysis at wavelength of $480 \mathrm{~nm}$ for selenium concentration.

\subsubsection{Selenate Analysis}

Selenate in the aqueous samples was first reduced to selenite using an acid digestion method (Blaylock and James, 1993) and the selenite concentration was then quantified using a colorimetric method with a detection limit of approximately $0.01 \mathrm{mg} / \mathrm{L}$ (Standard Methods 3500 C, USEPA, 1998). For samples containing both selenite and selenate, total selenium was measured as selenite after the reduction of selenate. It has been shown in previous studies that the recovery of selenate varied under different reaction conditions and several chemical digesters could be used for the selenate reduction (Bye, 1983). Among those, concentrated $\mathrm{HCl}$ was reported to be the most effective and reliable reductant. In this study, $8 \mathrm{~mL}$ of a concentrated $\mathrm{HCl}(12.1 \mathrm{~N})$ was added to $10 \mathrm{~mL}$ selenate sample in a $50 \mathrm{~mL}$ tube. The tube was then loosely capped and put into a $90{ }^{\circ} \mathrm{C}$ water bath for an hour, followed by sample cooling to room temperature 
with the cap tightly closed. Excess $\mathrm{HCl}$ was neutralized by a $\mathrm{NaOH}$ solution $(5 \mathrm{~N})$ before final adjustment of $\mathrm{pH}$ to $1.5 \pm 0.1$ for selenite measurement.

\subsection{Adsorption Kinetics}

All the adsorption batch experiments were prepared as follow unless particularly indicated: specifically, $12.5 \mathrm{~mL}$ of the selenate working solution $(4 \mathrm{mg} / \mathrm{L})$ was mixed with $0.5,2.5,5 \mathrm{~mL} \mathrm{NaCl}$ solution $(1 \mathrm{M})$ in separate flasks and brought to a final volume of $50 \mathrm{~mL}$ with de-ionized water. As a result, the solutions contained $1 \mathrm{mg} / \mathrm{L}$ of selenium with ionic strengths of $0.01,0.05$ and $0.1 \mathrm{M}$. An acetate buffer solution $(1 \mathrm{~mL})$ was added to each mixture to obtain $0.01 \mathrm{M}$ buffer concentration, and its interference with ionic strength was insignificant. Control experiments without solids for same initial selenium concentration were carried out under each ionic strength in the same type of flask. All the flasks were sealed with caps (phenolic screw caps with PTFE rubber liner) and placed in an incubator shaker for mixing. All the adsorption experiments along with control experiments were conducted at $\mathrm{pH} 5 \pm 0.2$ and $25{ }^{\circ} \mathrm{C}$. Figure 6 illustrates the selenate batch adsorption process in continuous shaking incubator. After adsorption experiments, vacuum filtration through $0.45 \mu \mathrm{m}$ membranes of all the samples was performed to separate solids and other possible precipitates from liquid phase, and a 10 $\mathrm{mL}$ filtrate was collected for each batch experiment for selenate reduction and concentration analysis.

Adsorption kinetics was examined for the initial selenium concentration of 1 $\mathrm{mg} / \mathrm{L}$ under three ionic strengths (i.e., 0.01, 0.05 and $0.1 \mathrm{M}$ ) for 48 hours. Adsorbent loading rate of $3.5 \mathrm{~g} / \mathrm{L}$ was used. The experiments were performed in triplicates for each ionic strength for data validation. A pseudo second-order kinetic model was applied to the kinetic data:

$$
\frac{t}{q}=\frac{1}{k q_{e}^{2}}+\frac{t}{q_{e}}
$$

where $q$ and $q_{e}$ (mg-Se/g-adsorbent) are the amount of selenate adsorbed at time $t$ and equilibrium, respectively; $t(\mathrm{~min})$ is the adsorption time; $k(\mathrm{~g} /(\mathrm{mg} \cdot \mathrm{min}))$ is the second 
order kinetic rate constant. The linear regression for $\frac{t}{q}$ over $t$ was performed, intercept and slope were used to calculate the values of $k$ and $q_{e}$.

\subsection{Adsorption Isotherm Experiments}

Adsorption isotherms of the Fe-GAC for selenate under three ionic strengths $(0.01$, 0.05 and $0.1 \mathrm{M}$ ) were determined. Adsorbent loading rates ranging from 0.5 to $7 \mathrm{~g} / \mathrm{L}$ with an increment of $0.5 \mathrm{~g} / \mathrm{L}$ were used. Adsorption was lasted for 48 hours. The adsorption isotherms were characterized by the Langmuir and the Freundlich isotherms. The Langmuir isotherm is given as below:

$$
q_{e}=\frac{q_{\max } C_{e}}{b+C_{e}}
$$

where $b(\mathrm{~L} / \mathrm{mg})$ is the Langmuir adsorption constant; $q_{\max }$ (mg-Se/g-adsorbent) is maximum adsorption capacity; $C_{e}(\mathrm{mg} / \mathrm{L})$ is the equilibrium selenium concentration in the aqueous phase; $q_{e}$ (mg-Se/g-adsorbent) is the solid-phase concentration at equilibrium.

The Freundlich isotherm is described by the following equation:

$$
q_{e}=K_{f} C_{e}^{\frac{1}{n}}
$$

where $K_{f}(m g / g)(L / m g)^{n}$ and $n$, (unitless) are model parameters related to adsorption capacity and intensity, respectively.

To describe the isotherm and calculate the parameters in each isotherm, nonlinear regression fitting were performed using SigmaPlot 11.0 (Systat Software Inc., IL). To evaluate the relative goodness of fit, Akaike's Information Criteria (AIC) analysis was performed. The AIC value was calculated according to the following equation (Faraway, 2005):

$$
A I C=n \times \ln \left(\frac{R S S}{n}\right)+2 k
$$

where $\mathrm{n}$ is the number of data points; RSS is the residual sums of squares; $k$ is the number of parameters in the model. The Akaike weights $\left(w_{i}\right)$ for each model was also calculated: 


$$
w_{i}=\frac{\exp \left[-0.5 \times\left(A I C_{i}-\min A I C\right)\right]}{\sum_{r=1}^{R} \exp \left[-0.5 \times\left(A I C_{i}-\min A I C\right)\right]}
$$

$\mathrm{AIC}_{\mathrm{i}}$ is $\mathrm{AIC}$ for model $i$; minAIC is the minimum AIC value of all models; $\mathrm{R}$ is the number of models compared.

\subsection{Relevant Factors Effect}

\subsubsection{Effect of $\mathrm{pH}$}

A range of $\mathrm{pH}(2-11)$ was used to evaluate $\mathrm{pH}$ effects on selenate adsorption. For each batch experiment, $\mathrm{pH}$ was monitored every 6 hours and maintained within \pm 0.2 of each $\mathrm{pH}$ value by adding $0.1 \mathrm{~N} \mathrm{HCl}$ or $0.02 \mathrm{~N} \mathrm{NaOH}$ to the mixture. Control experiments were conducted at each $\mathrm{pH}$ without the addition of solids. After 24-hour, a $10 \mathrm{~mL}$ liquid sample was collected from each batch experiment following the procedure described in section 3.5 and processed for analysis.

\subsubsection{Effect of Background Electrolytes}

Three different electrolytes $(\mathrm{LiCl}, \mathrm{NaCl}$ and $\mathrm{KCl})$ were used to study the effects of electrolytes' hydrated radius on selenate adsorption by Fe-GAC. Selenate adsorption was conducted under a range of ionic strength controlled by three electrolytes $(0.01,0.5$ and $0.1 \mathrm{M})$ with initial selenium concentration of $1 \mathrm{mg} / \mathrm{L}$. An acetate buffer solution $(1 \mathrm{~mL})$ was added to each mixture to obtain $0.01 \mathrm{M}$ buffer concentration. Solid loading rates ranging from 0.5 to $6 \mathrm{~g} / \mathrm{L}$ was employed in the adsorption experiments. Adsorption lasted for 48 hours at room temperature and $10 \mathrm{~mL}$ of aqueous sample was collected following the procedure described in section 3.5 from each batch experiment to determine selenate concentration. Kruskal - Wallis Test using Systat 12 (Systat Software Inc., IL) was performed to examine the possibility of graphical overlapping among three isotherms under the same ionic strength. 


\subsubsection{Effect of Competitive Oxy-anions}

Four anions ( $\mathrm{SiO}_{3}^{2-}, \mathrm{SO}_{4}^{2-}, \mathrm{PO}_{4}^{3-}$ and $\mathrm{CO}_{3}^{2-}$ ) were used to study their effects on selenate adsorption. Tests were conducted for initial selenium concentration of $1 \mathrm{mg} / \mathrm{L}$ with different competitive anion concentrations $(0,0.1,1$ and $5 \mathrm{mM})$. Experiments were carried out at room temperature at $\mathrm{pH} 5$ under ionic strength controlled by $0.05 \mathrm{M} \mathrm{NaCl}$ for 24 hours. A $10 \mathrm{~mL}$ aqueous sample was collected from each batch experiment following the procedure described in section 3.5.

\subsection{Selenite and Selenate Competitive Adsorption}

Both selenite and selenate working solutions were added to a series of flasks to obtain initial Se concentration of $1 \mathrm{mg} / \mathrm{L}$ for both anions. $\mathrm{NaCl}(1 \mathrm{M})$ and acetate $(0.01$ M) solutions were used to control ionic strength and stabilize $\mathrm{pH}$ at 5. Adsorbent loading rate was varied from 0.5 to $3.5 \mathrm{~g} / \mathrm{L}$ to obtain an isotherm for each chemical form. After 48-hour adsorption, two $10 \mathrm{~mL}$ sub-samples were collected from each flask with one sample used for selenite determination and the other for total selenium determination. Selenate concentration was calculated by subtracting the selenite concentration from the total Se concentration.

Freundlich-type multi-adsorbate adsorption isotherm model developed by Sheindorf et al. (1981) was used to characterize the competitive adsorption between selenite and selenate. The general Sheindorf-Rebuhn-Sheintuch (SRS) model equation for adsorbate $i$ in an $\mathrm{N}$-component system is given as:

$$
q_{e, i}=K_{F, i} c_{e, i}\left(\sum_{j=1}^{N} a_{i j} c_{e, j}\right)^{\frac{1}{n_{i}}-1}
$$

where $q_{e, i}$ (mg-Se/g-adsorbent) is the adsorption capacity for adsorbate $i ; c_{e, i}$ and $c_{e, j}$ $(\mathrm{mg} / \mathrm{L})$ are equilibrium concentrations in the solution for adsorbate $i$ and $j$, respectively. The pre-exponential coefficient $K_{F, i}$ and exponent $\frac{1}{n_{i}}$ are Freundlich parameters that determined from its single-adsorbate system. The competition coefficient $a_{i j}$ (unitless) describes the inhibition on the adsorption of adsorbate $i$ caused by adsorbate $j$. The SRS 
equation assumes that (i) each adsorbate individually follows the Freundlich isotherm; and (ii) there exists an exponential distribution of site adsorption energies for each component in a multi-component adsorbate adsorption system.

The competition coefficient $a_{i j}$ in the competitive model was estimated using the competitive adsorption data of selenite and selenate by minimizing the Marquardt's percent standard deviation (MPSD), which is described as below:

$$
M P S D=100 \sqrt{\frac{1}{n_{m}-n_{p}} \sum_{i=1}^{n} \sum_{j=1}^{N}\left(\frac{q_{e, i, \exp }-q_{e, i, c a l}}{q_{e, i, \exp }}\right)^{2}} \%
$$

where $n_{m}$ is the number of measurements and $n_{p}$ is the number of parameters in the model. In this study, $n_{m}$ and $n_{p}$ equal to 7 and 3 , respectively. $N$ is the number of experimental data points and $n$ is the number of adsorbates in the system. The subscripts "exp" and "cal" represent the solid phase concentrations determined from the competitive adsorption experiments and model predictions, respectively. Sheindorf et al. (1982) suggested that values for $a_{i j}$ typically are larger than zero and normally smaller than 10 . An iterative algorithm was implemented in MS EXCEL to estimate the values of $a_{i j}$ that minimizes the MPSD. In the algorithm, an initial value ranging from 0 to 1000 was assigned to $a_{12}$ (inhibition on selenite adsorption caused by selenate) in order to obtain the global minimum MPSD, and $a_{21}$ which was equal to $1 / a_{12}$ (by default for binary systems was calculated). The MPSD value was then calculated. The value of $a_{12}$ was then adjusted iteratively until the minimum MPSD was obtained.

\subsection{Raman Spectrum Collection}

Raman spectra were collected using an inVia Renishaw Raman imaging microscope (Renishaw Inc., Schaumburg, IL). The instrument is comprised of several components including a laser source with a wavelength of $532 \mathrm{~nm}$, a Leica microscope, a single spectrograph and a Pertier cooled CCD detector. The laser power was $100 \mathrm{~mW}$, and excitation laser power could be adjusted from $0.001 \%$ to $100 \%$ by passing the laser through different filters. The laser beam was focused on the sample with a $\times 20$ lens to give a spot size of approximately $1 \mu \mathrm{m}$. Before the data collection for selenium loaded 
Fe-GAC samples, the instrument was calibrated using pure $\mathrm{Si}$ at $521.5 \mathrm{~cm}^{-1}$. All the data were collected using effective laser power no higher than $10 \mathrm{~mW}$ to avoid sample damage or chemical degradation, unless for assessing the effect of laser power on spectra noise elimination.

Selenium loaded Fe-GAC samples were prepared by suspending small amount of Fe-GAC adsorbents into $10 \mathrm{~mL}$ selenate $(0.1 \mathrm{M})$ solutions. $\mathrm{pH}$ of each suspension was adjusted from 3 to 8 with increment of 1 to investigate its effect on the bridging structure and coordination mechanism. To perform an in situ measurement, all the selenium loaded suspension samples were spread out on a microscope slide and analyzed immediately. The exposure time was $20 \mathrm{~s} / \mathrm{scan}$ and the final spectra were obtained as a result of 10 accumulated scans.

\subsection{XPS Spectrum Collection}

Core level X-ray photon electron (XPS) spectra were collected using PHI 5000 VersaProbe XPS (Physical Electronics, inc., Chanhassen, MN). Prior to analysis, all the samples were put into vacuum chamber to remove the impurities. Monochromatic Al Xrays $(1486.6 \mathrm{eV})$ were used for both low resolution survey and high resolution scans. The analysis passing energy of $117.4 \mathrm{eV}$ and step size of 0.5 were used for survey scans, passing energy of $23.5 \mathrm{eV}$ and step size of $0.05 \mathrm{eV}$ were used for high resolution scans. All the spectra were charge corrected using C1s line at $284.8 \mathrm{eV}$. Background of high resolution spectra for $\mathrm{Fe}$ and $\mathrm{O}$ were deducted by Shirley type background to remove spectra distortion. Gauss-Lorentz Multiplet peak fitting was conducted using PHI Multipak Software (ULVAC-PHI, Inc., MN). 


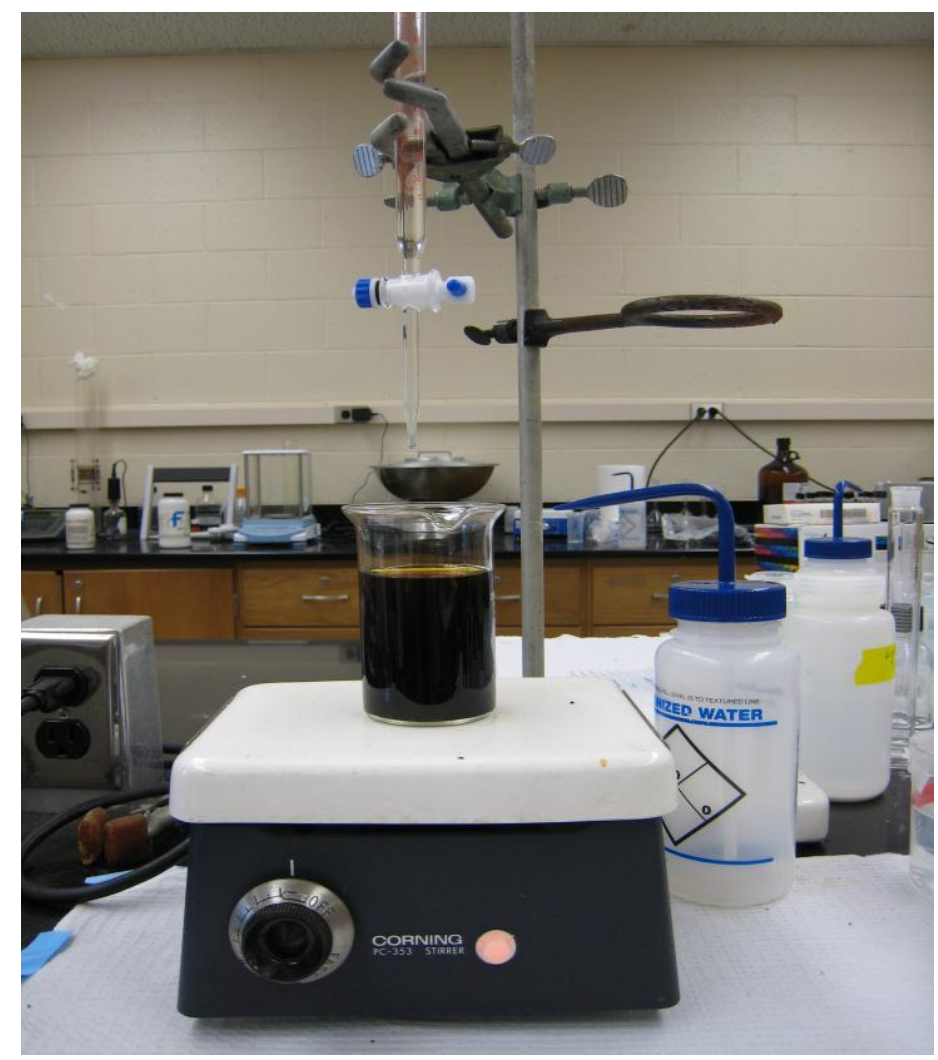

Figure 6. Illustration of FeGAC preparation procedure. 


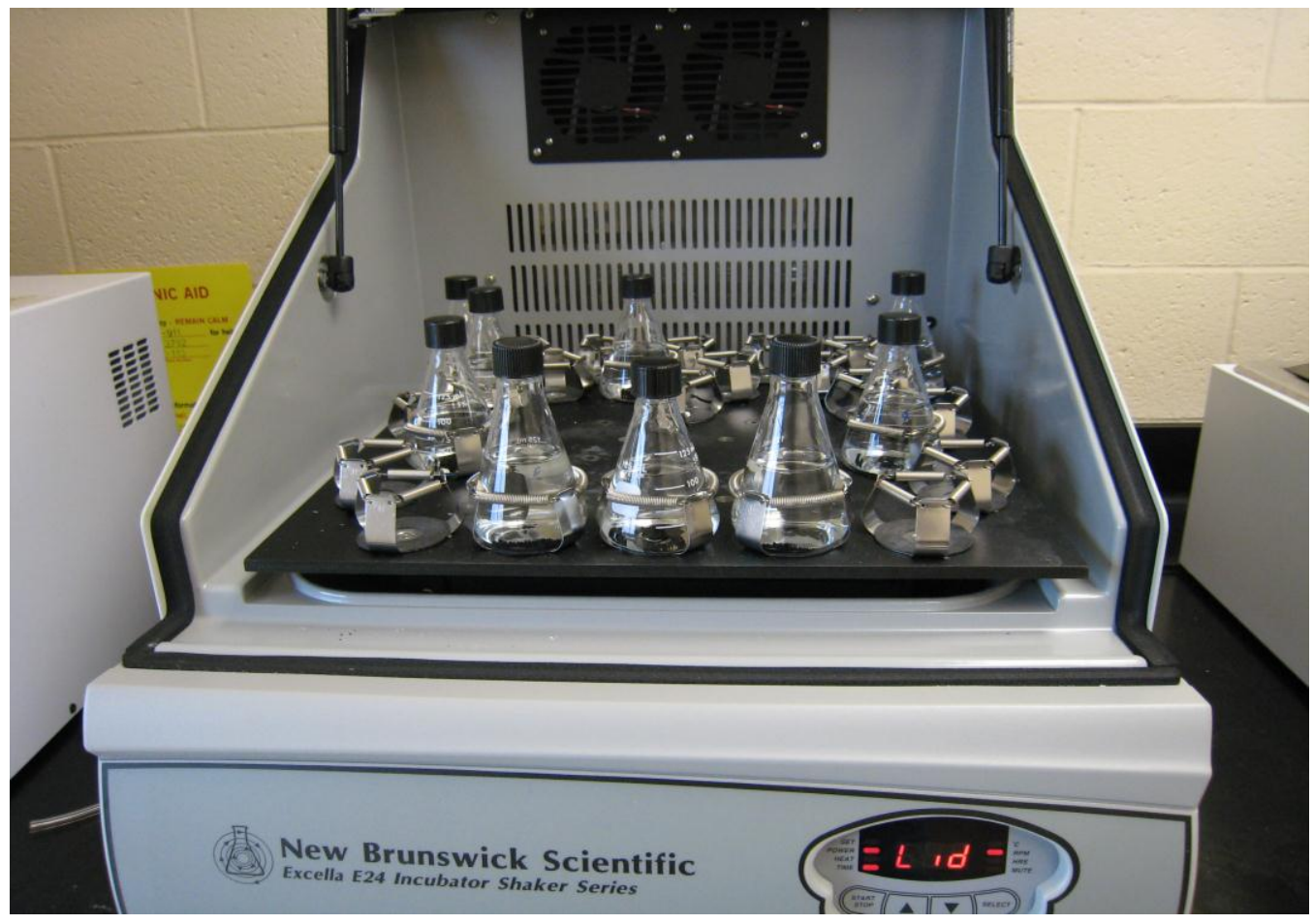

Figure 7. Illustration of batch adsorption experiments incubated in a reciprocating shaker. 


\section{CHAPTER 4: RESULTS AND DISCUSSION}

\subsection{Investigation of Iron Chemical States and Composition on Fe-GAC}

\subsubsection{Iron Coating Percentage}

Percentages of coated total iron and amorphous iron in Fe-GAC (Darco $12 \times 20$ ) are listed in Table 2. The data showed that amorphous iron was approximately half of the total iron. Also, the coated iron percentage increases from $0.18 \%$ to $2.8 \%$ with the increase of ferrous concentration employed in coating process. Gu et al. (2005) reported a total amount of $3.32 \%$ iron coated onto Darco $12 \times 20$ GAC when treated with $0.1 \mathrm{M} \mathrm{Fe}$ (II). They also suggested that the Darco GAC produced by steam activation of lignite may result in structures and reactive moieties with high abilities for Fe impregnation.

Table 3 shows the percentage of iron (in total coated iron) dissolved in aqueous solutions after suspended in $0.1 \mathrm{M} \mathrm{NaCl}$ solution at different $\mathrm{pHs}$. The values of iron concentration in aqueous phase indicated that when $\mathrm{pH}$ was greater than 3 , there was no dissolved iron detected; as $\mathrm{pH}$ was increased to 2 , approximately $12 \%$ coated iron was found dissolved in aqueous phase. Therefore, within the mild $\mathrm{pH}$ range (e.g., 4 to 8), coated iron was stable on GAC surface.

\subsubsection{Chemical States of Oxygen}

XPS survey scans for the Virgin GAC (Darco 12X20), 0.1 M iron coated Fe-GAC, and suspended $\mathrm{Fe}-\mathrm{GAC}$ in $0.1 \mathrm{M} \mathrm{NaCl}$ solution at $\mathrm{pH} 5$ are shown in Figures 8 and $\underline{9}$. Peaks for $\mathrm{C}$ and $\mathrm{O}$ were readily identified for Virgin GAC. Small amount of Si are also recognized. After GAC was coated with $0.1 \mathrm{M}$ ferrous, strong peaks for $\mathrm{Fe}$ and $\mathrm{Cl}$ are present in survey scan, indicating that effective iron coating was achieved on the GAC surface.

The high resolution core level XPS spectra for $\mathrm{Fe} 2 \mathrm{p}, \mathrm{Fe} 2 \mathrm{p}_{3 / 2}$ and $\mathrm{O} 1 \mathrm{~s}$ for Virgin $\mathrm{GAC}, \mathrm{Fe}-\mathrm{GAC}$ and $\mathrm{Fe}-\mathrm{GAC}$ suspended in $\mathrm{NaCl}$ solution at $\mathrm{pH} 5$ are shown in Figure 10 15. As no iron identified in virgin GAC, high resolution XPS spectrum investigation was not performed. The Gauss-Lorentz multiplet peak fitting was conducted for $\mathrm{Fe} 2 \mathrm{p}_{3 / 2}$ spectra. The summation of the peak fitting is also shown as bold line in order to compare 
the peak fitting results with experimental data. The parameter values of peak fitting are listed in Table 4. For O1s on virgin GAC, the multiplets found at 530.8, 532.1 and 533.4 eV can be assigned to metal oxides (Ismail et al., 1996), carbon oxygen double bonds (Hontoria-Lucas et al., 1995), and carbon-oxygen single bonds (e.g, phenols and ethers) (de La Puente et al., 1997). After coated with ferrous chloride, the O1s spectrum of the Fe-GAC was found to fit well with peaks for metal oxides $(529.9 \mathrm{eV})$, hydroxyl $(\mathrm{OH})$ $(531.3 \mathrm{eV})$ (Moulded et al., 1995) and silicon dioxides $(532.4 \mathrm{eV})$. The peak area ratio of hydroxyl to oxides was estimated around 1. The missing peak bonds of carbon-oxygen can be attributed to the shallow detection of laser caused by thin layer coating of ferric on GAC surface. McIntyre and Zetaruk (1977) reported the similar multiplet peak fittings results for $\alpha$-FeOOH XPS spectra. They found the hydroxyl peak at binding energy of $531.4 \pm 0.2 \mathrm{eV}$ and oxides peak at $530.3 \pm 0.2 \mathrm{eV}$. Additionally, they found the peak area ratio to be 0.9 for $\alpha-\mathrm{FeOOH}$. After the Fe-GAC was suspended in $0.1 \mathrm{M} \mathrm{NaCl}$ solutions for 24 hours, the spectrum for O1s is found to fit with peaks at similar position with those for non suspended Fe-GAC. It indicates no transformation of chemical composition occurred after Fe-GAC was suspended in electrolytes solution. Moreover, an increasing in peak area for hydroxyl was observed.

\subsubsection{Iron Oxide Compositions}

Figure 13 shows the XPS Fe2p core level spectrum for Fe-GAC. The center of gravity for $\mathrm{Fe} 2 \mathrm{p}_{3 / 2}$ and $\mathrm{Fe} 2 \mathrm{p}_{1 / 2}$ were estimated at $711.3 \mathrm{eV}$ and $725.0 \mathrm{eV}$. The binding energy difference between two peaks was approximately $13.7 \mathrm{eV}$. A shakeup satellite was also observed between $\mathrm{Fe}_{2 \mathrm{p} 3 / 2}$ and $\mathrm{Fe}_{2 \mathrm{p} 1 / 2}$ peaks. According to the literatures, the $2 \mathrm{p}$ peaks for $\mathrm{Fe}$ element are around 707 and $720 \mathrm{eV}$ for $2 \mathrm{p}_{3 / 2}$ and $2 \mathrm{p}_{1 / 2}$, respectively ((Moulded et al., 1995); and $2 \mathrm{p}_{3 / 2}$ peak for $\mathrm{Fe}(\mathrm{II})$ ferrous oxide $(\mathrm{FeO})$ is reported within binding energy range of 709.1 - $709.6 \mathrm{eV}$. Comparing the peak positions for different chemical states of iron, peak shifting to higher binding energy region and the relative large binding energy difference between peaks were both observed in this study. These facts indicate that the Fe (III) was successfully precipitated onto the GAC surface.

$\mathrm{Fe} 2 \mathrm{p}_{3 / 2}$ spectra is also widely used to identify iron compounds compositions and structures. Fe $2 p_{3 / 2}$ spectrum for Fe-GAC and suspended Fe-GAC can be fitted well with 
four multiplet peaks, ranging from $710.2 \mathrm{eV}$ to $713.4 \mathrm{eV}$. Based on the peak shapes and peak fitting parameters (Table 3), it can be concluded that there is no difference between $\mathrm{Fe} 2 \mathrm{p}_{3 / 2}$ spectra for suspended and non suspended Fe-GAC. The most intense fitted peaks were both found at low binding energy region (i.e., $710.2 \mathrm{eV}$ ) with slightly higher area percentage than those for second intense fitted peaks. The difference in positions among peaks is $1.0 \mathrm{eV}$ except that between peak 3 and peak 4. Grosvenor et al. (2004) reported the similar peak fitting results for $\alpha-\mathrm{FeOOH}$. They found the most intense peak at 710.3 $\mathrm{eV}$ with full width at half maximum (FWHM) of 1.4 and area percentage of $31.4 \%$. They also observed the position difference between peak 1 and $2(711.2 \mathrm{eV})$ is $1.0 \mathrm{eV}$. Comparing with their results, it implies a possible chemical composition for iron on $\mathrm{Fe}$ $\mathrm{GAC}$ is $\alpha-\mathrm{FeOOH}$ and suspension in background electrolytes may not result in any changes for this composition.

\subsection{Adsorption Kinetics}

Adsorption kinetic experiments were carried out in triplicates to examine the replicability of the experiments. The averages of the adsorption capacities and the removal percentage were plotted over time in Figure 16,17 and 18. The error of the adsorption capacity for each data is indicated by the upper and lower bar. The errors were generally within $10 \%$ indicating the experimental procedures are replicable and reliable. The figures illustrated that selenate adsorption equilibrium was reached within 48 hours for all three ionic strengths $(0.01,0.05$ and $0.1 \mathrm{M})$ with more than $85 \%$ of the equilibrium capacities being obtained in 6 hours. Removal efficiency increased from $62 \%$ to $78 \%$ with the decrease of ionic strength from $0.1 \mathrm{M}$ to $0.01 \mathrm{M}$. Pseudo second-order kinetic model characterized the selenate adsorption kinetics well $\left(\mathrm{R}^{2}>0.99\right)$. Adsorption rate constants and equilibrium adsorption capacities obtained from the kinetic model are listed in Table 5. The decrease of adsorption capacity and increase of the rate constant were both observed along with the increase of ionic strength. This significant effect of ionic strength was not observed in selenite adsorption. The obtained rate constants under all three ionic strengths were larger than that for selenite adsorption $(0.018 \mathrm{~g} /(\mathrm{mg} \cdot \mathrm{min}))$ under $0.1 \mathrm{M}$ ionic strength using the same adsorbent $(1.5 \mathrm{~g} / \mathrm{L}$ loading rate) obtained in 
previous studies (Zhang et al., 2008). Nonetheless, the adsorption capacities were much smaller than that of selenite (i.e., $0.66 \mathrm{mg}-\mathrm{Se} / \mathrm{g}$-adsorbent) (Zhang et al., 2008). This could be attributed to the lower adsorption capacities for selenate, which maintained a relatively high concentration gradient for mass transfer across the liquid film around the adsorbent particles. This resulted in rapid removal of the adsorbate due to large mass diffusion flux across the liquid film, thereby exhibiting faster adsorption kinetics. These explain the trend of adsorption capacity and rate constant observed in this study.

\subsection{Adsorption Isotherms}

Adsorption isotherm data and model fits for the Freundlich model under three ionic strengths are shown in Figure 19. The parameters for the Freundlich model are listed in Table $\underline{6}$. Overall, there were no observed isotherm plateaus, suggesting that the adsorption capacities observed were well below the maximum adsorption capacity of the Fe-GAC for selenate given the initial selenium concentration (i.e., $1 \mathrm{mg} / \mathrm{L}$ ) and adsorbent loading rates. The Fe-GAC adsorbent exhibited lower adsorption capacities for selenate than those for selenite given the same initial selenium concentration and other conditions (e.g., $\mathrm{pH}$, ionic strength) (Zhang et al., 2008). The difference in the affinity for selenate and selenite is consistent with other studies using different adsorbents (Goh and Lim, 2004; Rovira et al., 2008). In this study, the results show that adsorption capacity increased as ionic strength decreased. This effect of ionic strength was not observed in selenite adsorption (Zhang et al., 2008). Su and Suarez (2000) reported that adsorption capacity of amorphous- $\mathrm{Fe}(\mathrm{OH})_{3}$ and goethite was 20 and $444 \mathrm{mg}-\mathrm{Se} / \mathrm{g}$-adsorbent, respectively with a solid loading rate of $4 \mathrm{~g} / \mathrm{L}$ under $0.01 \mathrm{M}$ ionic strength. Since substantially higher initial selenium concentrations (79 to $790 \mathrm{mg} / \mathrm{L}$ ) and different adsorbent sizes were used in their study, the comparison of the values with those reported in this study is not appropriate.

A comparison between the Freundlich model and the Langmuir model fits results (Table 7) was conducted for 0.01 and $0.05 \mathrm{M}$ ionic strength. For higher ionic strength (e.g., $0.1 \mathrm{M})$, the maximum adsorption capacity $\left(q_{\max }\right)$ and the Langmuir coefficient (b) obtained from the Langmuir model fit are dramatically large, which are not physically 
reasonable, therefore the Langmuir model fit results for $0.1 \mathrm{M}$ ionic strength are not present. Values of the nonlinear regression coefficient $\left(\mathrm{R}^{2}\right)$ and AIC weights calculated from the Freundlich model are both slightly larger than the values for the Langmuir model under the studied ionic strengths $(0.01$ and $0.05 \mathrm{M})$. It indicates that the experimental data are fitted better with the Freundlich model than the Langmuir model. Overall, the results show that selenate adsorption was lowered by $30 \%$ as ionic strength increased from $0.01 \mathrm{M}$ to $0.1 \mathrm{M}$. The value of $K_{f}$ decreased with the increase of ionic strength, reflecting the fact that selenate adsorption capacity decreased in the presence of higher ionic strength. In contrast to selenate, selenite was not affected by ionic strength and found to follow the Langmuir isotherm better for similar adsorbent loading rates (Zhang et al., 2008). Goh and Lim (2004) used an initial selenium concentration of 15.8 $\mathrm{mg} / \mathrm{L}$ in adsorption experiments with tropical soil and found that selenate adsorption followed the Freundlich isotherm model $\left(R^{2}=0.929\right)$ under $0.01 \mathrm{M}$ ionic strength. Rovira et al. (2008) applied initial selenium concentrations ranging from 0.2 to $4.0 \mathrm{mg} / \mathrm{L}$ to goethite and hematite adsorption and found that selenate adsorption followed the

Langmuir model for the two adsorbents $\left(R^{2}=0.96\right.$ for goethite and $R^{2}=0.91$ for hematite $)$ under ionic strength of $0.1 \mathrm{M}$.

\subsection{Investigation of Relevant Factors Effect on Selenate Adsorption}

\subsection{1 $\mathrm{pH}$ effect}

Figure 20 shows that removal efficiency of selenate as a function of $\mathrm{pH}$. Percent selenate removal was above $80 \%$ for $\mathrm{pHs}$ below 4 and $\sim 75 \%$ at $\mathrm{pH} 5$, and showed a decreasing trend for higher $\mathrm{pHs}$. For treatment of acid mine drainage with a typical $\mathrm{pH}$ range of 2 - 6 (Gazea et al., 1996), adsorptive removal of selenate could be operated in the optimal $\mathrm{pH}$ range of the Fe-GAC. The $\mathrm{pH}$-dependent result exhibited an adsorptive removal pattern similar to that of selenite but to a lower degree under the same adsorption conditions (Zhang et al., 2008). The pH-dependent removal pattern was consistent with other adsorbents reported in the literature. Su and Suarez (2000) reported a dramatic decrease in selenate adsorption onto goethite when $\mathrm{pH}$ was raised above 4 . Rovira et al. 
(2008) observed that adsorptive removal of selenate by goethite and hematite decreased at alkaline pHs.

The $\mathrm{pH}$-dependent adsorption of selenate observed in this study can be attributed to electrostatic interactions between the dominant selenate ion (i.e., fully deprontonated $\mathrm{SeO}_{4}{ }^{2-}$ given its $p K_{a 2}$ 1.73) and the $\mathrm{Fe}-\mathrm{GAC}$ surface charges. Figure 21 shows the titration results for determining point of zero charge of the Fe-GAC. The titration curves gave an estimate of the $\mathrm{pH}_{\mathrm{pzc}}$ at 7.8. The result is consistent with the conclusion drawn by Vaughan and Reed (2005) for iron impregnated GAC (using virgin GAC1240), which was reported to be $\mathrm{pH}$ 7.5. This result provides a reasonable explanation for the $\mathrm{pH}$ dependent adsorptive removal of selenate. At low pHs (e.g., 2 - 5), adsorbent surface was dominated by positive charge, which was favorable for the electrostatic attraction between positive functional groups and $\mathrm{SeO}_{4}{ }^{2-}$. The decreasing trend of the selenate removal reflected the change in surface charges of the adsorbent for $\mathrm{pHs}$ above 5.

\subsubsection{Oxyanions Competitive Effect}

Figure 22 shows that all four types of anions (e.g., $\mathrm{SiO}_{3}{ }^{2-}, \mathrm{PO}_{4}{ }^{3-}, \mathrm{SO}_{4}{ }^{2-}$ and $\mathrm{CO}_{3}{ }^{2-}$ ) competed individually with selenate adsorption to various degrees depending on types and concentrations of the anions. In general, the oxy-anions had more significant impacts on selenate than selenite for the same adsorbent (Zhang et al., 2008). Among the four anions, $\mathrm{PO}_{4}^{3-}$ was the most competitive anion which reduced selenate remove efficiency from $70 \%$ to zero as its concentration increased from 0 to $5 \mathrm{mM}$. With the same Fe-GAC, a decrease in selenite adsorption in the presence of $\mathrm{PO}_{4}^{3-}$ was also found but to a lesser degree than selenate (Zhang et al., 2008). Goh and Lim (2004) reported a significant impact of $\mathrm{PO}_{4}^{3-}$ in a low concentration range on both selenate and selenite adsorption onto tropical soil. Sulfate ion was also found to compete with selenate significantly. Selenate removal decreased to $11 \%$ in the presence of $5 \mathrm{mM} \mathrm{SO}_{4}^{2-}$, which is believed to be due to the similar anion structure and adsorption behavior between sulfate and selenate. These two anions both tend to form weak bonds with surface sites and be more easily released (Davis and Leckie, 1980; Goh and Lim, 2004). At $5 \mathrm{mM}$ of $\mathrm{SiO}_{3}^{2-}$ and $\mathrm{CO}_{3}^{2-}$, only $14 \%$ and $9 \%$ selenate removals were achieved. 


\subsubsection{Background Electrolyte Effect}

It was found that the background electrolyte could affect ion adsorption when anions or cations are adsorbed by iron oxides (Crisenti and Svenjensky, 1999), especially result in the decline of adsorption under high ionic strength (e.g., $0.1 \mathrm{M}$ ). As in the same alkaline group, $\mathrm{LiCl}, \mathrm{NaCl}$ and $\mathrm{KCl}$ were selected to control the ionic strength at 0.01 , 0.05 and $0.1 \mathrm{M}$ in this study. To investigate the effect of these three electrolytes on selenate adsorption by $\mathrm{Fe}-\mathrm{GAC}$, adsorption isotherms were conducted under the same condition except different electrolytes were used. The adsorption isotherms and corresponding Freundlich isotherm modeling are shown in Figure 23, 24 and 25. The calculated parameters for Freundlich fitting and statistical analysis are listed in Table 8. The results of statistical analysis show a much higher $p$ value (i.e., 0.872) calculated for $0.01 \mathrm{M}$ ionic strength than those for 0.05 and $0.1 \mathrm{M}$. It indicates high possibility of variation among isotherms existing under high ionic strength (i.e., 0.05 and $0.1 \mathrm{M}$ ). Additionally, under high ionic strength (Figure 24 and 25), relatively high selenate adsorption is observed along with the increase of molecular weight of electrolyte cations. This result can be attributed to the changes of cation hydrated radii. It is well understood that large ions with small charges tend to bind water less tightly, hence, resulting smaller hydration number as well as hydrated radius. In this study, the hydrated radii for electrolyte cations decline in the order: $\mathrm{Li}>\mathrm{Na}>\mathrm{K}$. As the increase of hydrated radii, it becomes hard for ions to transfer into inner sphere layer and bind with surface sites. Under elevated ionic strength, when $\mathrm{KCl}$ is present, a large number of $\mathrm{K}$ cation are adsorbed by surface, therefore, the adsorbent surface possesses more positive zeta potential and higher affinity to anions (Ma and Pawlik, 2005). Therefore, anion adsorption is increased. Under low ionic strength (Figure 23), there is no significant difference due to background electrolytes, which is consistent with the finding of statistical analysis (i.e., p value). It can be explained by the lack of sufficient cations in aqueous solution to cause distinguishable difference. The fact that $\mathrm{KCl}$ shows the least interference to selenate adsorption also implies an inner sphere complex formation of selenate adsorption.

Furthermore, when same electrolyte is used, the selenate adsorption is found decrease by various percentages as ionic strength increases (i.e., $25 \%$ for $\mathrm{KCl}, 35 \%$ for 
$\mathrm{NaCl}$ and $49 \%$ for $\mathrm{LiCl}$ ). It implicates an improvement of selenate adsorption in the presence of large amount of $\mathrm{KCl}$ in the treatment system.

\subsection{Competitive Adsorption between Selenite and Selenate}

Results of the competitive adsorption of selenate and selenite are shown in Figure 26, 27 and 28. As both selenite and selenate adsorption follow the Freundlich model in single adsorbate syste, the SRS competitive model was applied to predict the adsorption behavior of the two adsorbates in the binary system. The model parameter values are listed in Table 9. Overall, selenite showed an adsorption advantage over selenate for the Fe-GAC under all three ionic strengths.

Selenite and selenate adsorption was only lowered slightly compared to its respective single-adsorbate system. Total adsorbed amounts of selenium in the binary system were also slightly lower than the summations of the two single-adsorbate capacities. A comparison of adsorption capacities between the binary (initial Se concentration of $2 \mathrm{mg} / \mathrm{L}$ ) and single (initial selenium concentration of $1 \mathrm{mg} / \mathrm{L}$ ) adsorbate systems is presented in Table 3. The results indicate that co-occurrence of selenate and selenite would only slightly decrease the overall removal efficiency. For treatment of mine drainage impacted water, the Fe-GAC can achieve a similar level of removal efficiency of selenium for water containing both selenate and selenite as for water with only one Se form. The competition coefficient of selenite (i.e., $a_{21}$ ) increased as ionic strength increased, accompanied with decreased values of the competition coefficient of selenate (i.e., $a_{12}$ ) (Table 9). This suggests that selenate competed against selenite more effectively under high ionic strengths. The competitive model can potentially be used as a predicting tool for Se removal from water containing both the chemical forms.

\subsection{Selenate Adsorption Mechanism}

\subsubsection{Selenate Anion Normal Vibration}

To make a comparison of adsorbed and free selenate anions, it is necessary to understand the normal vibration of selenate anion first. Selenate structure is tetrahedral 
with its molecular symmetry belonging to $T_{d}$ point group (Nakamoto, 2009). Point group is defined as a possible combination of symmetry operations whose axes intersect at the same point. For $T_{d}$ point group, there are three mutually perpendicular two-fold $\left(C_{2}\right)$ axes, four three-fold $\left(C_{3}\right)$ axes and a reflection plane $\left(\sigma_{d}\right)$ through each pair of $C_{3}$ axes. All these symmetric axes intersect at the tetrahedral center, which, in this case, is selenium atom.

There are four normal vibration modes for fully de-protonated selenate anions and they are all Raman active as shown in Figure 29 and as reported by Schulze et al. (1973). They are nondegenerate symmetric $\mathrm{SeO}$ stretching at $836 \mathrm{~cm}^{-1}$, which is denoted as $v_{1}$; doubly degenerated $\mathrm{OSeO}$ bending at $349 \mathrm{~cm}^{-1}, v_{2}$; triply degenerated $\mathrm{SeO}$ stretching at $873 \mathrm{~cm}^{-1}, v_{3}$; and triply degenerated $\mathrm{OSeO}$ bending at $413 \mathrm{~cm}^{-1}, v_{4}$. It is found that the peak intensity for stretching vibrations are generally stronger than those for bending vibrations (Wijnja and Schulthess, 2000; Nakamoto, 2009). As fully deprotonated selenate is the predominant species at a broad $\mathrm{pH}$ range (i.e., $\mathrm{pH}>2$ ), therefore, the Raman spectra in Figure 29 conducted at $\mathrm{pH} \mathrm{3,5}$ and 8 are generally for selenate deprotonated form only. Comparing the three spectra, neither peak shifting nor splitting is observed. It indicates that as $\mathrm{pH}$ higher than 2 , the spectra for selenate solutions show no variations. The results are consistent with previous finding reported by Wijnja and Schulthess (2000).

\subsubsection{Raman Spectra for Adsorbed Selenate}

Figure 30, 31 and 32 show the Raman spectra for adsorbed selenate on Fe-GAC at different $\mathrm{pH}$. All spectra were conducted under the same conditions (i.e., $10 \mathrm{mw}$ laser power, $20 \mathrm{~s}$ exposure time, $\times 20$ lens and 10 accumulation times) except spectra in Figure 31 (a), which was conducted with a higher laser power (i.e., $50 \mathrm{mw}$ ) to minimize noise level. In Figure 31, both spectra were taken for the same spot but with different laser power. Overall, both peak shifting $\left(v_{1}\right)$ and splitting $\left(v_{3}\right.$ and $\left.v_{4}\right)$ are clearly observed for selenate adsorption at $\mathrm{pH}$ lower than 6 . Obscure peak splitting is also shown for $v_{2}$ band. Specially, at $\mathrm{pH} 6, v_{2}$ splitting is intense and obvious. At $\mathrm{pH} 7$, peak splitting is not distinguishable for $v_{3}$ under excitation of low laser power. When further increasing $\mathrm{pH}$ to 8 , only peak shifting is observed. 
Theoretically, when molecules coordinate with surface sites, their symmetry will vary from their free status and further lead the change of vibration modes. When one selenate anion with its original symmetry of $T_{d}$ coordinates with one surface site to form mono-dentate bind, its molecular symmetry is lowered to $C_{3 v}$, which results the $v_{1}$ vibration peak shifting to either higher or lower wave number depending on the type of coordinating ions. Meanwhile, the triply degenerated vibration peaks will split into two bands. When one selenate anion coordinates with two surface sites and form bi-dentate bind, its molecular symmetry is further lowered to $C_{2 v}$. In addition to $v_{1}$ vibration peak shifting, the doubly degenerated and triply degenerated binds are found to split into two and three vibration bands, respectively (1970; Benelli et al., 1977; Wijnja and Schulthess, 2000; Nakamoto, 2009).

In this study, as $v_{l}$ vibration peak shifting is observed for all studied $\mathrm{pH}$, it indicates an inner sphere coordination occurring for adsorbed selenate adsorption on FeGAC. The conclusion is consistent with the deduction drawn from electrolytes effect results. The intense double splitting of $v_{3}$ and $v_{4}$ bands at $\mathrm{pH}$ lower than 7 reveals the formation of mono-dentate complex for adsorbed selenate. Moreover, the weak splitting of $v_{2}$ doubly degenerate band implies the presence of bi-dentate complex as well. The missing of triple splitting bands may be attributed to low content of bi-dentate complex on adsorbent surface for the instrument to detect. At pH 7 (Figure 32), low bands intensities are observed even with high laser power excitation. It indicates selenate adsorption is decreased dramatically when $\mathrm{pH}$ is close or higher than adsorbent $\mathrm{pH}_{\mathrm{zpc}}$ (i.e., 7.5). At pH 8 (Figure 32.a), a shoulder band at $837 \mathrm{~cm}^{-1}$ for $v_{l}$ non-degenerated vibration is identified along with a strong band at $846 \mathrm{~cm}^{-1}$. Also, the splitting of other vibration bands (i.e., $v_{2}, v_{3}$, and $v_{4}$ ) are either obscure or absent. Comparing the spectra of adsorbed selenate at $\mathrm{pH} 8$ with that for free selenate solution, similarity in peak positions and peak shapes can be found, which indicates the formation of outer sphere complex. In addition, the variation features (e.g., peak shifting of $v_{1}$ band) between two spectra reveals the presence of inner sphere complex. Therefore, it can be concluded that at $\mathrm{pH}$ greater than 7 , inner sphere and outer sphere complexs both occur. Wijnja and Schulthess (2000) also reported the formation of outer sphere complex for selenate adsorbed by goethite at $\mathrm{pH} 7.2$ along with inner sphere complex. As partial selenate is 
retained as the form of outer sphere complex by the surface, the coordination is easily broken and therefore result in the much lower adsorption comparing with that occurring at acidic condition.

\subsection{Proposed Fe-GAC Modifications}

The $\mathrm{pH}_{\mathrm{zpc}}$ for the Fe-GAC was reported to be at $\mathrm{pH}$ of 7.5 (Zhang et al., 2010). Our results showed that selenate adsorption mechanism does not vary when $\mathrm{pH}$ was lower than $\mathrm{pH}_{\mathrm{zpc}}$. As $\mathrm{pH}$ was close to $\mathrm{pH}_{\mathrm{zpc}}$ (e.g. around 7), selenate was adsorbed only via mono-dentate complex. Portion of selenate anions form outer sphere complex with surface sites, which may lead to desorption as $\mathrm{pH}$ higher than 8 . These results explained the low selenate adsorption under alkaline conditions. As $\mathrm{pH}_{\mathrm{zpc}}$ plays a key

role in selenate adsorption, Fe-GAC can be modified to increase the $\mathrm{pH}_{\mathrm{zpc}}$ in order to extend the effective selenate adsorption to high $\mathrm{pH}$. To increase the $\mathrm{pH}_{\mathrm{zpc}}$, other metal oxides may be coated with iron oxides together, such as aluminum oxides $\left(\mathrm{pH}_{\mathrm{zpc}}=9.1\right)$ and magnesium oxides $\left(\mathrm{pH}_{\mathrm{zpc}}=12.4\right)$ (Stumm and Morgan, 1981; Fierro, 2006). Some of the binary metal oxides adsorbents have been successfully applied to arsenic and other similar oxyanions' removal. Substaintial increase of the removal was reported for arsenic. Up to $100 \%$ of adsorptive removal of As (III) was reported by Zhang et al. (2007) when they used the Fe-Mn binary oxide adsorbent in As (III) and As (V) adsorption. Ren et al. (2011) reported the similar adsorptive removal (approximately 90\%) for As (III) and As (V) using Fe-Zr binary oxide adsorbent. Generally, As (III) was observed to experience noticeable lower adsorption than that for As (V) for most of adsorbents. This phenomenon of lower adsorption was also found in selenate comparing with selenite. Considering the similarity between arsenic and selenium, it is very promising to increase the selenium adsorption by using the binary oxides adsorbents.

Alternatively, as selenite was reported to be easily removed by Fe-GAC adsorption (Zhang et al., 2008), it is possible to first reduce selenate to selenite and then remove it by adsorption. This process involves the coating of reducing agents, such as 
$\mathrm{Fe}(\mathrm{II})$, along with $\mathrm{Fe}(\mathrm{III})$ oxides. The redox potential for selenate reduction and ferrous oxidation half reactions are as follow (Séby, et al., 1998):

$$
\begin{array}{ll}
\mathrm{SeO}_{4}^{2-}+4 \mathrm{H}^{+}+2 e^{-} \Leftrightarrow \mathrm{H}_{2} \mathrm{SeO}_{3}(\mathrm{aq})+\mathrm{H}_{2} \mathrm{O} & E^{0}=1.14 \\
\mathrm{SeO}_{4}^{2-}+3 \mathrm{H}^{+}+2 e^{-} \Leftrightarrow \mathrm{HSeO}_{3}^{-}+\mathrm{H}_{2} \mathrm{O} & E^{0}=1.06 \\
\mathrm{SeO}_{4}^{2-}+2 \mathrm{H}^{+}+2 e^{-} \Leftrightarrow \mathrm{SeO}_{3}^{2-}+\mathrm{H}_{2} \mathrm{O} & E^{0}=0.81 \\
\mathrm{Fe}^{3+}+e^{-} \Leftrightarrow \mathrm{Fe}^{2+} & E^{0}=0.77
\end{array}
$$

According to the values of redox potentials, at acidic condition, selenate reduction by ferrous can occur spontaneously. Green Rust (iron(II)-iron(III) hydroxyl-salts) was synthesized and found effective to remove selenate by combining processes of reduction, precipitation and adsorption (Refait et al., 2000; Hayashi et al., 2009). Therefore, virgin GAC coated with green rust precipitants will create a promising material with large specific surface areas consisting of both reducing agents ( $\mathrm{Fe}(\mathrm{II}))$ and adsorbing sites (Fe(III)). It can easily be packed into columns and applied in large scale. 
Table 2. Total and amorphous iron on GAC surface coated with four initial ferrous iron conentrations.

\begin{tabular}{l|cccc}
\hline \multirow{2}{*}{ Iron Percentage (\%) } & \multicolumn{4}{|c}{ Ferrous Concentration (M) } \\
\cline { 2 - 5 } & 0 & 0.01 & 0.05 & 0.1 \\
\hline Total Iron & 0.06 & 0.18 & 2.10 & 2.80 \\
Amorphous Iron & 0.00 & 0.10 & 1.00 & 1.20 \\
\hline
\end{tabular}

Table 3. Percentage of iron dissolved in aqueous solutions at different $\mathrm{pH}$.

\begin{tabular}{l|cccc}
\hline \multirow{2}{*}{ Iron Percentage (\%) } & \multicolumn{4}{c}{$\mathrm{pH}$} \\
\cline { 2 - 5 } & 2 & 3 & 5 & 10 \\
\hline Dissolved / Total Coated & 11.7 & 0 & 0 & 0 \\
\hline
\end{tabular}


Table 4. Parameters values of Gauss - Lorentz multiplet peak fittings for Fe2 $\mathrm{p}_{3 / 2}$ and O1s XPS spectra.

\begin{tabular}{|c|c|c|c|c|c|c|c|c|c|c|c|c|}
\hline Sample & Element & $\begin{array}{c}\text { Peak1 } \\
(\mathrm{eV}) \\
{[\mathrm{FWMH}]}\end{array}$ & Area $\%$ & $\begin{array}{c}\text { Peak2 } \\
(\mathrm{eV}) \\
{[\mathrm{FWMH}]}\end{array}$ & Area \% & $\begin{array}{l}\triangle E_{\text {Peak }} \\
\text { 2-Peak 1 }\end{array}$ & $\begin{array}{c}\text { Peak3 } \\
(\mathrm{eV}) \\
{[\mathrm{FWMH}]}\end{array}$ & Area $\%$ & $\begin{array}{c}\triangle E_{\text {Peak } 3} \\
\text { - Peak 2 }\end{array}$ & $\begin{array}{c}\text { Peak4 } \\
(\mathrm{eV}) \\
{[\mathrm{FWMH}]}\end{array}$ & Area \% & 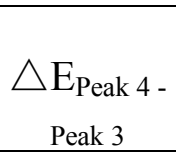 \\
\hline $\begin{array}{c}\text { Virgina } \\
\text { GAC }\end{array}$ & O1s & $\begin{array}{l}530.8 \\
{[1.7]} \\
710.2\end{array}$ & 28.80 & $\begin{array}{l}532.1 \\
{[1.7]} \\
711.2\end{array}$ & 46.74 & 1.3 & $\begin{array}{l}533.4 \\
{[1.7]} \\
712.2\end{array}$ & 24.47 & 1.3 & 713.3 & NA & \\
\hline Fe-GAC & $\mathrm{Fe} 2 \mathrm{p}_{3 / 2}$ & $\begin{array}{l}{[1.4]} \\
529.9\end{array}$ & 34.02 & $\begin{array}{l}{[1.4]} \\
531.3\end{array}$ & 32.83 & 1.0 & $\begin{array}{l}{[1.4]} \\
532.4\end{array}$ & 21.09 & 1.0 & [1.4] & 12.06 & 1.1 \\
\hline & $\mathrm{O} 1 \mathrm{~s}$ & $\begin{array}{l}{[1.4]} \\
710.2\end{array}$ & 41.17 & $\begin{array}{l}{[1.4]} \\
711.2\end{array}$ & 47.78 & 1.4 & $\begin{array}{l}{[1.4]} \\
712.2\end{array}$ & 11.05 & 1.1 & 713.4 & NA & \\
\hline $\begin{array}{c}\mathrm{FeGAC} \text { in } \\
\mathrm{NaCl} \text { at }\end{array}$ & $\mathrm{Fe} 2 \mathrm{p}_{3 / 2}$ & $\begin{array}{l}{[1.4]} \\
529.9\end{array}$ & 32.45 & $\begin{array}{l}{[1.4]} \\
531.4\end{array}$ & 31.82 & 1.0 & $\begin{array}{l}{[1.4]} \\
532.6\end{array}$ & 23.64 & 1.0 & [1.4] & 12.07 & 1.2 \\
\hline & O1s & {$[1.7]$} & 27.16 & {$[1.7]$} & 56.78 & 1.5 & [1.7] & 16.06 & 1.2 & & NA & \\
\hline $\begin{array}{l}\mathrm{FeGAC} \text { in } \\
\mathrm{NaCl} \text { at }\end{array}$ & $\mathrm{Fe} 2 \mathrm{p}_{3 / 2}$ & $\begin{array}{l}710.1 \\
{[1.6]} \\
529.6\end{array}$ & 40.50 & $\begin{array}{l}711.2 \\
{[1.6]} \\
531.1\end{array}$ & 31.55 & 1.1 & $\begin{array}{l}712.3 \\
{[1.6]} \\
532.3\end{array}$ & 20.01 & 1.1 & $\begin{array}{l}713.5 \\
{[1.6]}\end{array}$ & 7.92 & 1.2 \\
\hline & O1s & [1.7] & 39.47 & [1.7] & 45.67 & 1.5 & {$[1.7]$} & 14.85 & 1.1 & & NA & \\
\hline $\begin{array}{l}\mathrm{FeGAC} \text { in } \\
\mathrm{NaCl} \text { at }\end{array}$ & $\mathrm{Fe} 2 \mathrm{p}_{3 / 2}$ & $\begin{array}{l}710.3 \\
{[1.7]} \\
529.9\end{array}$ & 25.75 & $\begin{array}{l}711.2 \\
{[1.7]} \\
531.2\end{array}$ & 35.46 & 0.9 & $\begin{array}{l}712.3 \\
{[1.7]} \\
532.4\end{array}$ & 25.63 & 1.1 & $\begin{array}{l}713.5 \\
{[1.7]}\end{array}$ & 13.00 & 1.2 \\
\hline pl & O1s & {$[1.7]$} & 25.56 & {$[1.7]$} & 44.97 & 1.3 & {$[1.7]$} & 29.46 & 1.2 & & NA & \\
\hline
\end{tabular}


Table 5. Second-order adsorption rate constants $(\mathrm{k})$ and adsorption capacities $\left(\mathrm{q}_{\mathrm{e}}\right)$ of FeGAC (loading rate $=3.5 \mathrm{~g} / \mathrm{L}$ ) for selenate (initial Se concentration $=1 \mathrm{mg} / \mathrm{L}$ ) at $\mathrm{pH} 5$ and $25^{\circ} \mathrm{C}$.

\begin{tabular}{ccccc}
\hline $\begin{array}{c}\text { Initial Se conc. } \\
(\mathrm{mg} / \mathrm{L})\end{array}$ & $\begin{array}{c}\text { Ionic strength } \\
(\mathrm{M})\end{array}$ & $\begin{array}{c}k \\
\mathrm{~g} /(\mathrm{mg} \cdot \mathrm{min})\end{array}$ & $\begin{array}{c}q_{e} \\
\mathrm{mg}-\mathrm{Se} / \mathrm{g}-\mathrm{FeGAC}\end{array}$ & $\mathrm{R}^{2}$ \\
\hline 1.0 & 0.01 & 0.13 & 0.22 & 0.999 \\
1.0 & 0.05 & 0.15 & 0.21 & 0.999 \\
1.0 & 0.1 & 0.28 & 0.17 & 0.998 \\
\hline
\end{tabular}

Table 6. Parameter values of the Freundlich model for selenate and selenite adsorption.

\begin{tabular}{cccccccc}
\hline \multirow{2}{*}{$\begin{array}{c}\text { Initial } \\
\text { Selenate }\end{array}$} & Ionic & \multicolumn{3}{c}{ Selenate } & \multicolumn{3}{c}{ Selenite } \\
\cline { 3 - 8 } $\begin{array}{c}\text { Conc. } \\
(\mathrm{mg-Se} / \mathrm{L})\end{array}$ & $\begin{array}{c}\text { Strength } \\
(\mathrm{M})\end{array}$ & $K_{f}$ & $\frac{1}{n}$ & $K_{f}$ & 1 & $\mathrm{R}^{2}$ \\
\hline 1.0 & 0.01 & 0.55 & 0.70 & 0.98 & 1.70 & 0.45 & 0.99 \\
1.0 & 0.05 & 0.44 & 0.82 & 0.97 & 1.57 & 0.53 & 0.99 \\
1.0 & 0.1 & 0.36 & 1.10 & 0.98 & 1.61 & 0.48 & 0.99 \\
\hline
\end{tabular}

Table 7. Parameter values of the Freundlich model and the Langmuir model for selenate adsorption under two ionic strengths and AIC comparison results for the two models.

\begin{tabular}{|c|c|c|c|c|c|c|c|c|c|c|}
\hline \multirow{2}{*}{$\begin{array}{c}\text { Initial } \\
\text { Selenate } \\
\text { Conc. } \\
\text { (mg-Se/L) }\end{array}$} & \multirow[b]{2}{*}{$\begin{array}{c}\text { Ionic } \\
\text { Strength } \\
(\mathrm{M})\end{array}$} & \multicolumn{5}{|c|}{ The Freundlich Model } & \multicolumn{4}{|c|}{ The Langmuir Model } \\
\hline & & $\begin{array}{c}K_{f} \\
(m g / g)(L / m g)^{n}\end{array}$ & $\frac{1}{n}$ & $\mathrm{R}^{2}$ & $\mathrm{AIC}$ & $\mathrm{W}$ & $\begin{array}{l}q_{\max } \\
(\mathrm{mg}- \\
\mathrm{Se} / \mathrm{g})\end{array}$ & $\begin{array}{c}\mathrm{b} \\
(\mathrm{L} / \mathrm{mg})\end{array}$ & $\mathrm{R}^{2}$ & AIC \\
\hline 1.0 & 0.01 & 0.55 & 0.70 & 0.98 & -55.1 & 0.87 & 0.96 & 0.88 & 0.97 & -51.4 \\
\hline 1.0 & 0.05 & 0.44 & 0.82 & 0.97 & -47.6 & 0.57 & 1.42 & 2.30 & 0.96 & -47.0 \\
\hline
\end{tabular}


Table 8. Parameter values of the Freundlich model for selenate adsorption in presence of different background electrolytes and Kruskal - Wallis testing values (p).

\begin{tabular}{cccccc}
\hline $\begin{array}{c}\text { Ionic Strength } \\
(\mathrm{M})\end{array}$ & Electrolyte & $\begin{array}{c}K_{f} \\
(m g / g)(L / m g)^{n}\end{array}$ & $\frac{1}{n}$ & $\mathrm{R}^{2}$ & $\begin{array}{c}\mathrm{K}-\mathrm{W} \\
\mathrm{p}\end{array}$ \\
\hline & $\mathrm{LiCl}$ & 0.55 & 0.83 & 0.99 & \\
0.01 & $\mathrm{NaCl}$ & 0.55 & 0.70 & 0.98 & 0.872 \\
& $\mathrm{KCl}$ & 0.59 & 0.84 & 0.99 & \\
\hline \multirow{3}{*}{0.05} & $\mathrm{LiCl}$ & 0.44 & 1.12 & 0.93 & \\
& $\mathrm{NaCl}$ & 0.44 & 0.82 & 0.97 & 0.358 \\
& $\mathrm{KCl}$ & 0.53 & 0.91 & 0.99 & \\
\hline & $\mathrm{LiCl}$ & 0.28 & 1.06 & 0.97 & \\
0.1 & $\mathrm{NaCl}$ & 0.36 & 1.10 & 0.98 & 0.419 \\
& $\mathrm{KCl}$ & 0.44 & 1.11 & 0.99 & \\
\hline
\end{tabular}

Table 9. Adsorption capacities (mg-Se/g-adsorbent) of the Fe-GAC (loading rate $=1 \mathrm{~g} / \mathrm{L}$ ) for selenite and selenate in a binary adsorbate system (initial Se concentration $=1 \mathrm{mg} / \mathrm{L}$ for each) and single-adsorbate system (initial Se concentration $=1 \mathrm{mg} / \mathrm{L}$ ) at $\mathrm{pH} 5$ and $25^{\circ} \mathrm{C}$. SRS model parameter values: $a_{12}$ - competition coefficient of selenate against selenite, and vice versa for $a_{21}$.

\begin{tabular}{ccccccc}
\hline $\begin{array}{c}\text { Ionic } \\
\text { Strength } \\
(\mathrm{M})\end{array}$ & $\begin{array}{c}\text { Capacity, Binary } \\
\text { (Selenate+Selenite) }\end{array}$ & $\boldsymbol{a}_{\mathbf{1 2}}$ & $\boldsymbol{a}_{\mathbf{2 1}}$ & $\begin{array}{c}\text { MPSD } \\
(\%)\end{array}$ & $\begin{array}{c}\text { Capacity } \\
\text { Single } \\
\text { (Selenite) }\end{array}$ & $\begin{array}{c}\text { Capacity } \\
\text { Single } \\
\text { (Selenate) }\end{array}$ \\
\hline 0.01 & 1.22 & 0.25 & 40.0 & 23.7 & 0.93 & 0.39 \\
0.05 & 1.19 & 0.37 & 27.0 & 21.1 & 0.90 & 0.32 \\
0.10 & 1.12 & 0.42 & 23.8 & 25.6 & 0.91 & 0.23 \\
\hline
\end{tabular}




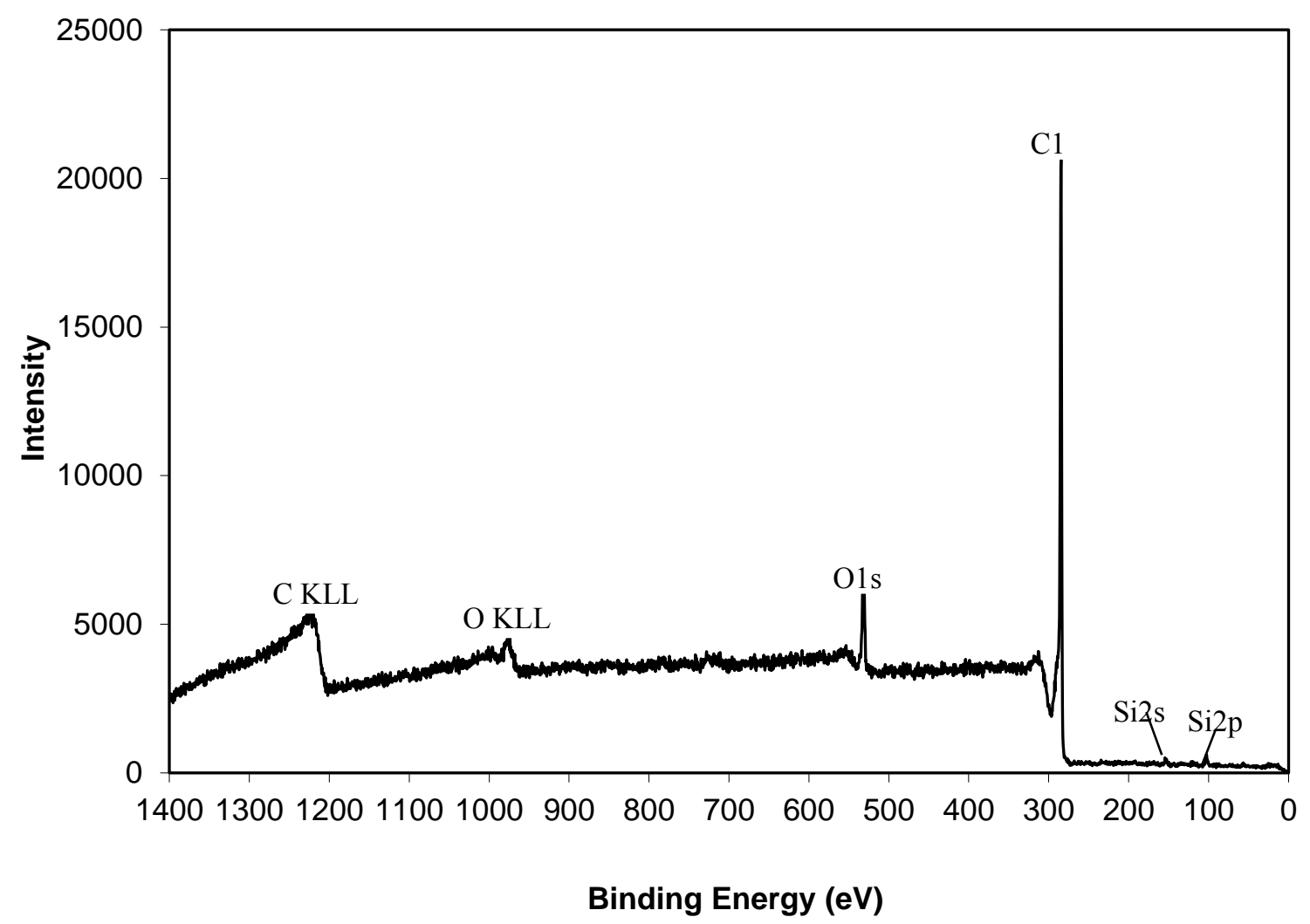

Figure 8. XPS survey scan for Virgin GAC (Darco 12X20). 


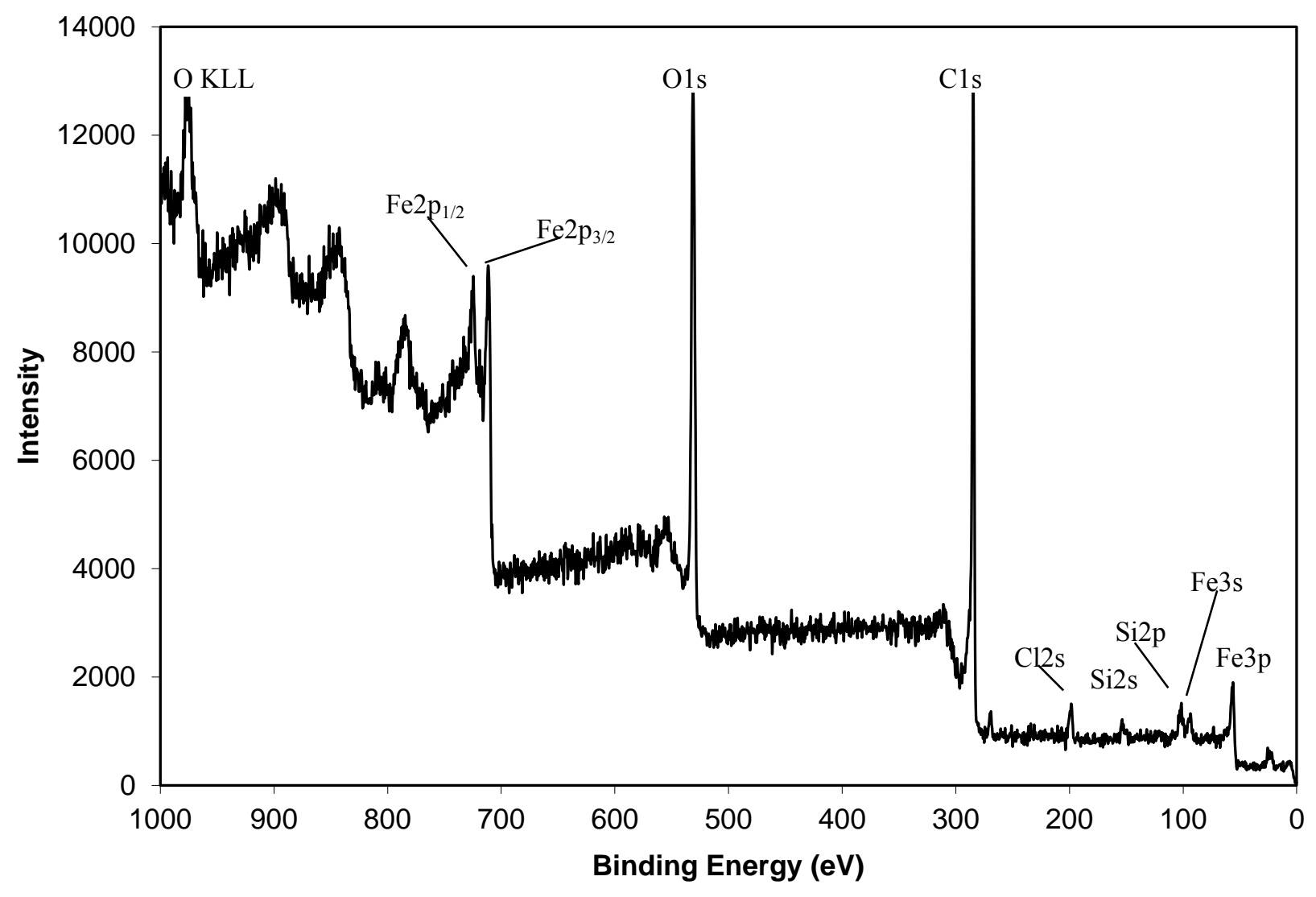

Figure 9. XPS survey scan for 0.1 M iron coated Fe-GAC (Darco 12X20). 


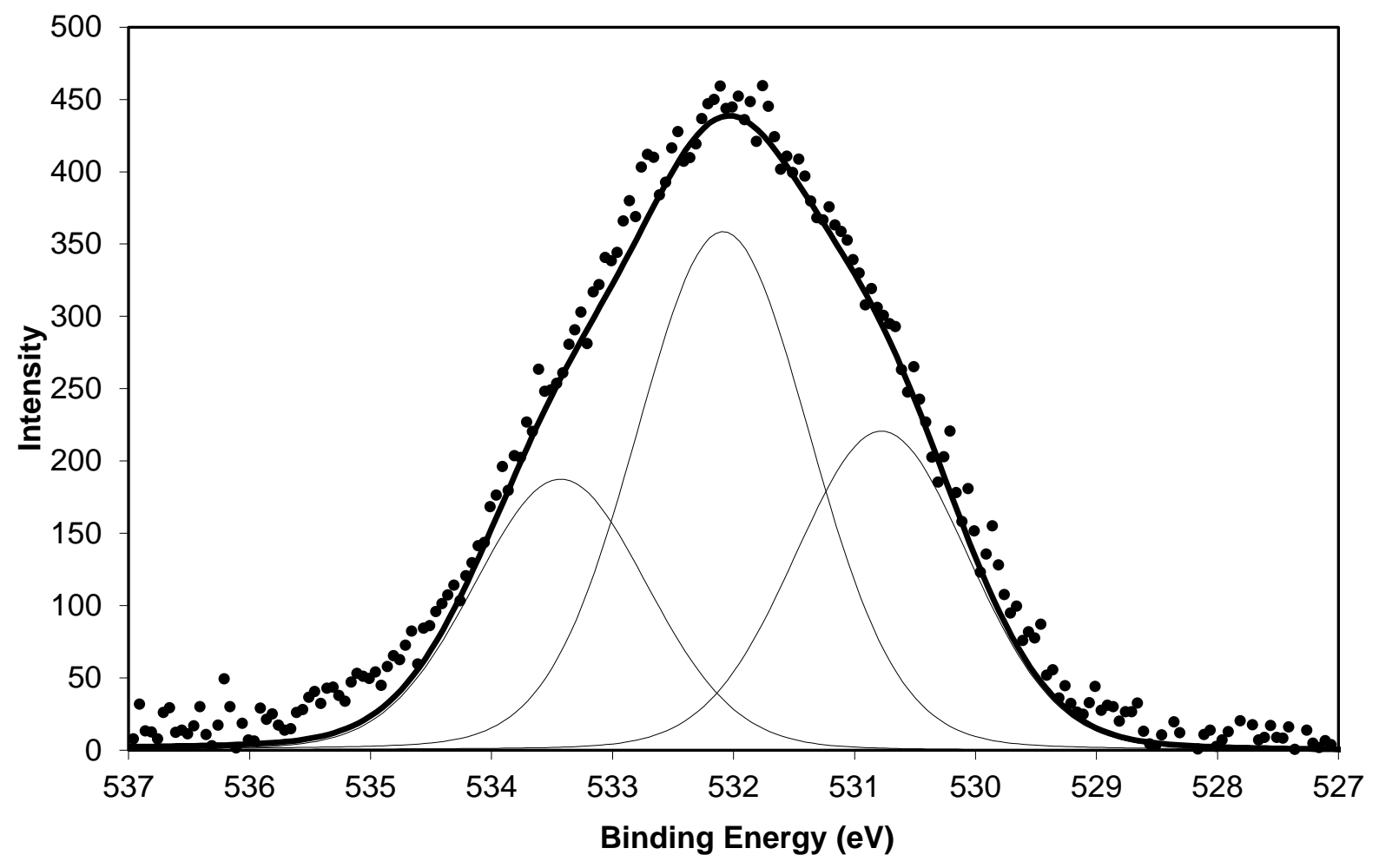

Figure 10. XPS spectrum with multiplet peak fittings (thin solid lines) for O1s on virgin GAC. Summation of the peak fittings is shown as bold solid line. Experimental data are indicated by solid dots. 


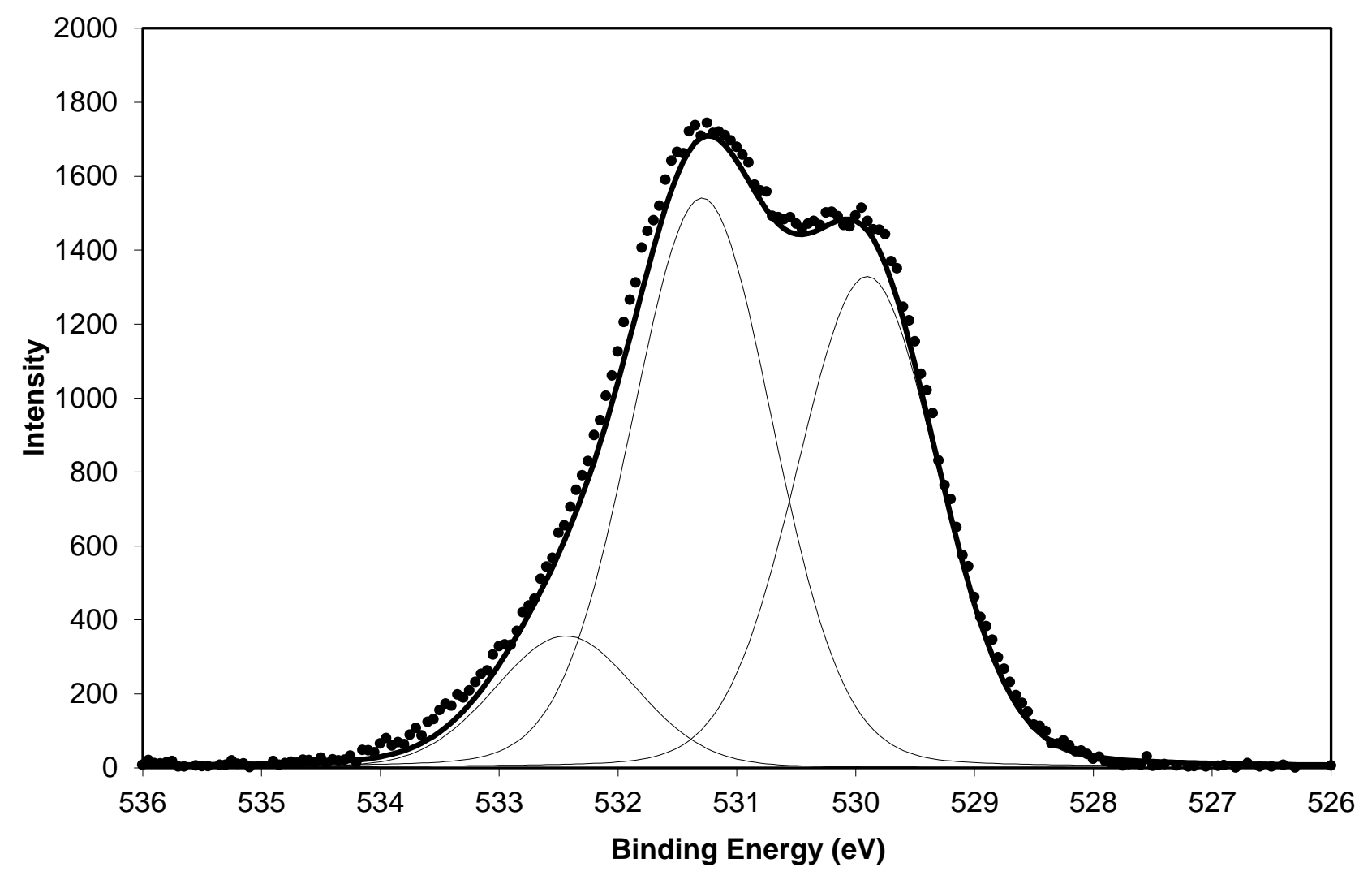

Figure 11. XPS spectrum with multiplet peak fittings (thin solid lines) for O1s on $0.1 \mathrm{M}$ iron coated Fe-GAC. Summation of the peak fittings is shown as bold solid line. Experimental data are indicated by solid dots. 


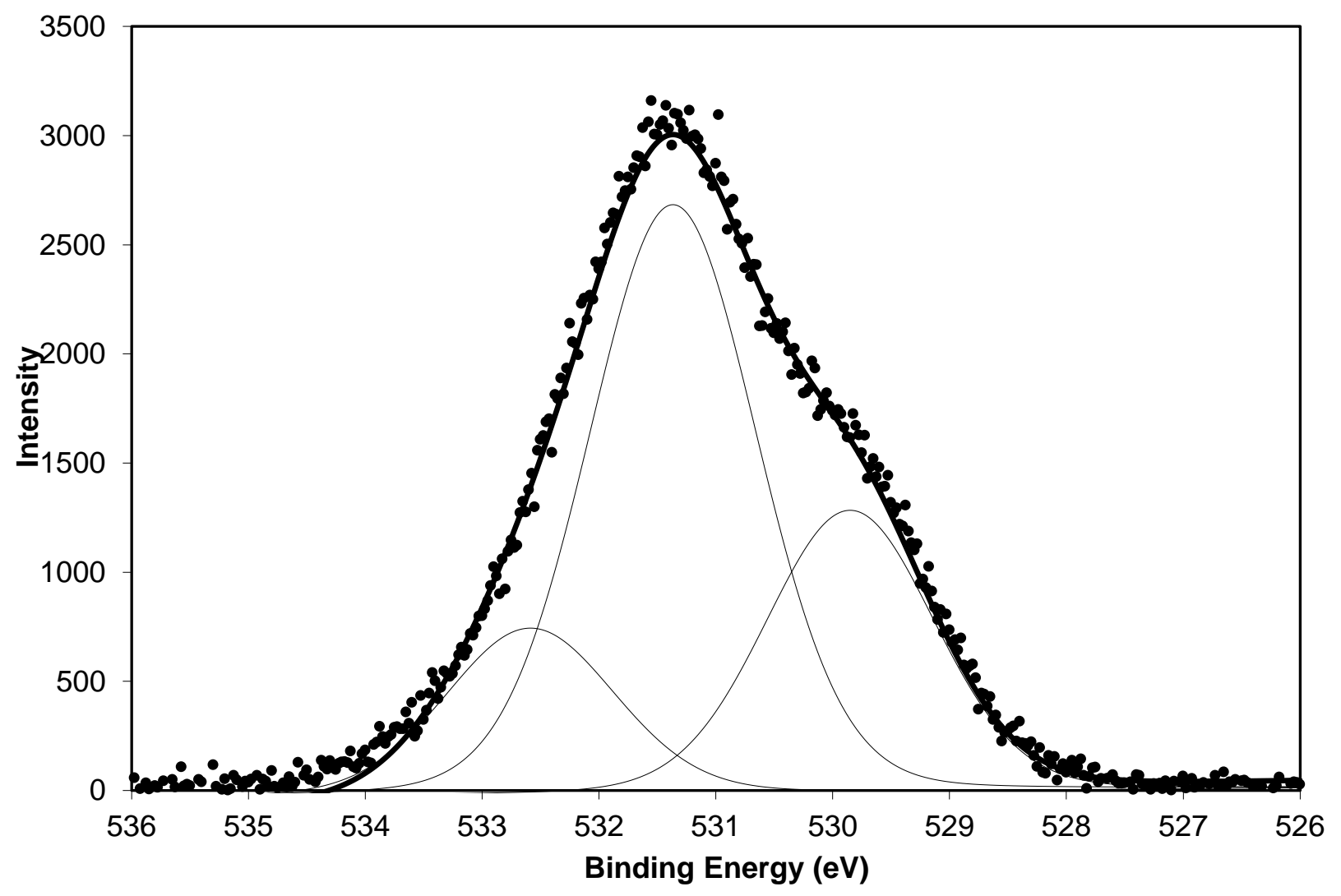

Figure 12. XPS spectrum with multiplet peak fittings (thin solid lines) for O1s on $0.1 \mathrm{M}$ iron coated Fe-GAC suspended in $0.1 \mathrm{M} \mathrm{NaCl}$. Summation of the peak fittings is shown as bold solid line. Experimental data are indicated by solid dots. 


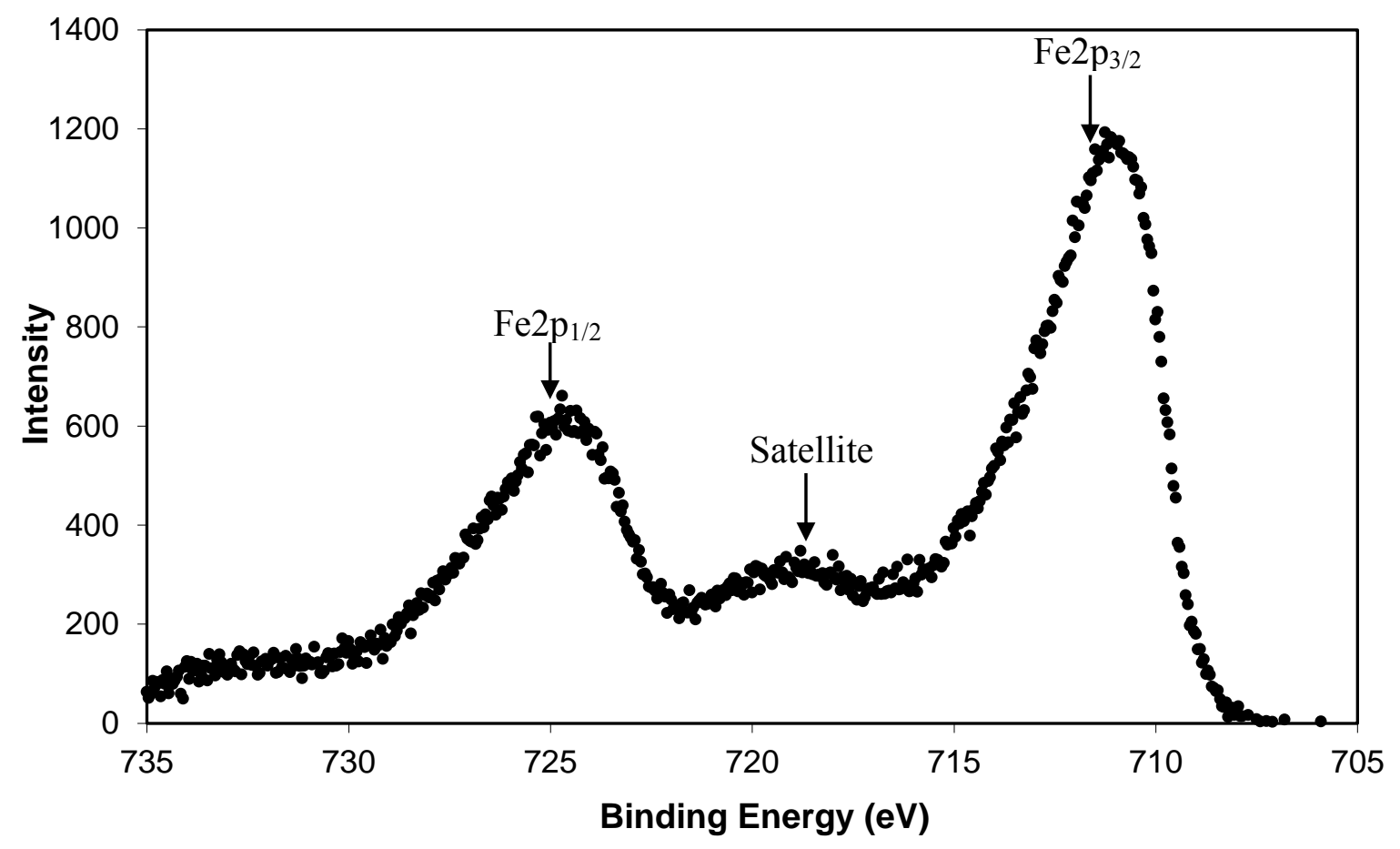

Figure 13. XPS spectrum for Fe2p on $0.1 \mathrm{M}$ iron coated Fe-GAC. 


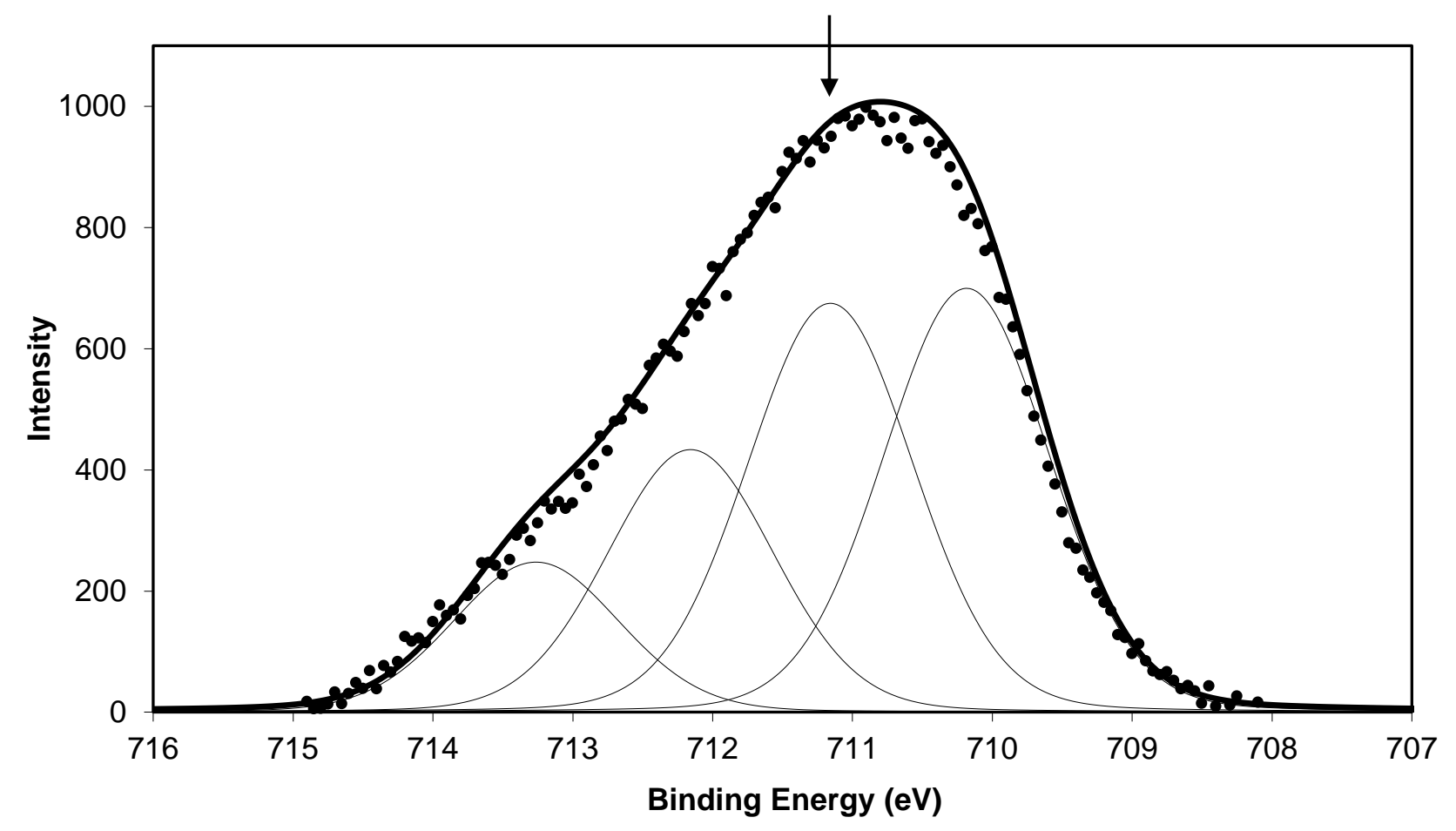

Figure 14. XPS spectrum for $\mathrm{Fe} 2 \mathrm{p}_{3 / 2}$ on $0.1 \mathrm{M}$ iron coated $\mathrm{Fe}-\mathrm{GAC}$ with multiplet peak fittings (thin solid lines). Summation of the peak fittings is shown as bold solid line. Experimental data is indicated by solid dots. Center of gravity at $711.3 \mathrm{eV}$ for spectrum is indicated by arrow. 


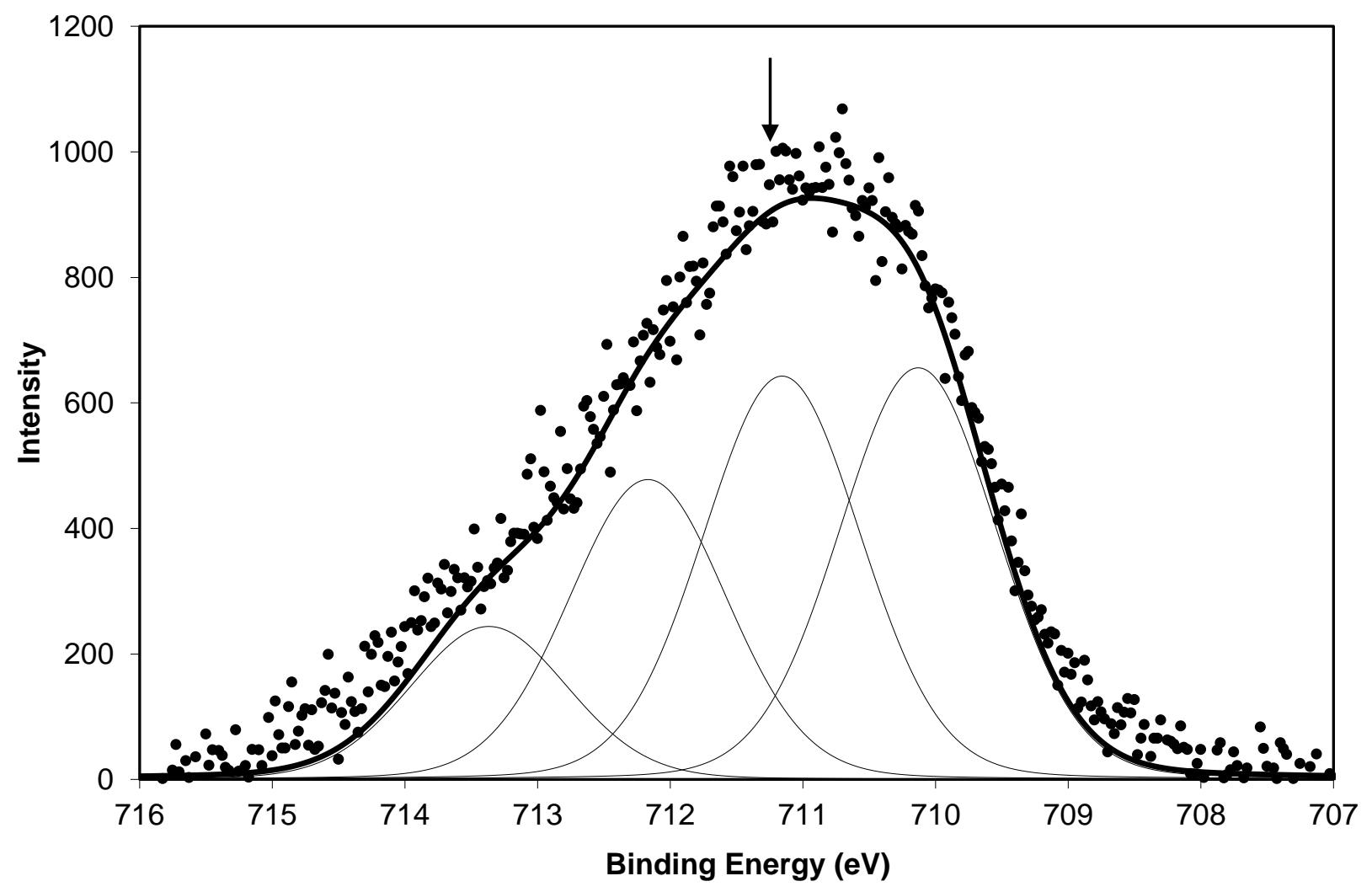

Figure 15. XPS spectrum with multiplet peak fittings (thin solid lines) for $\mathrm{Fe} 2 \mathrm{p}_{3 / 2}$ on 0.1 $\mathrm{M}$ iron coated Fe-GAC suspended in $0.1 \mathrm{M} \mathrm{NaCl}$. Summation of the peak fittings is shown as bold solid line. Experimental data is indicated by solid dots. Center of gravity at $711.3 \mathrm{eV}$ for spectrum is indicated by arrow. 


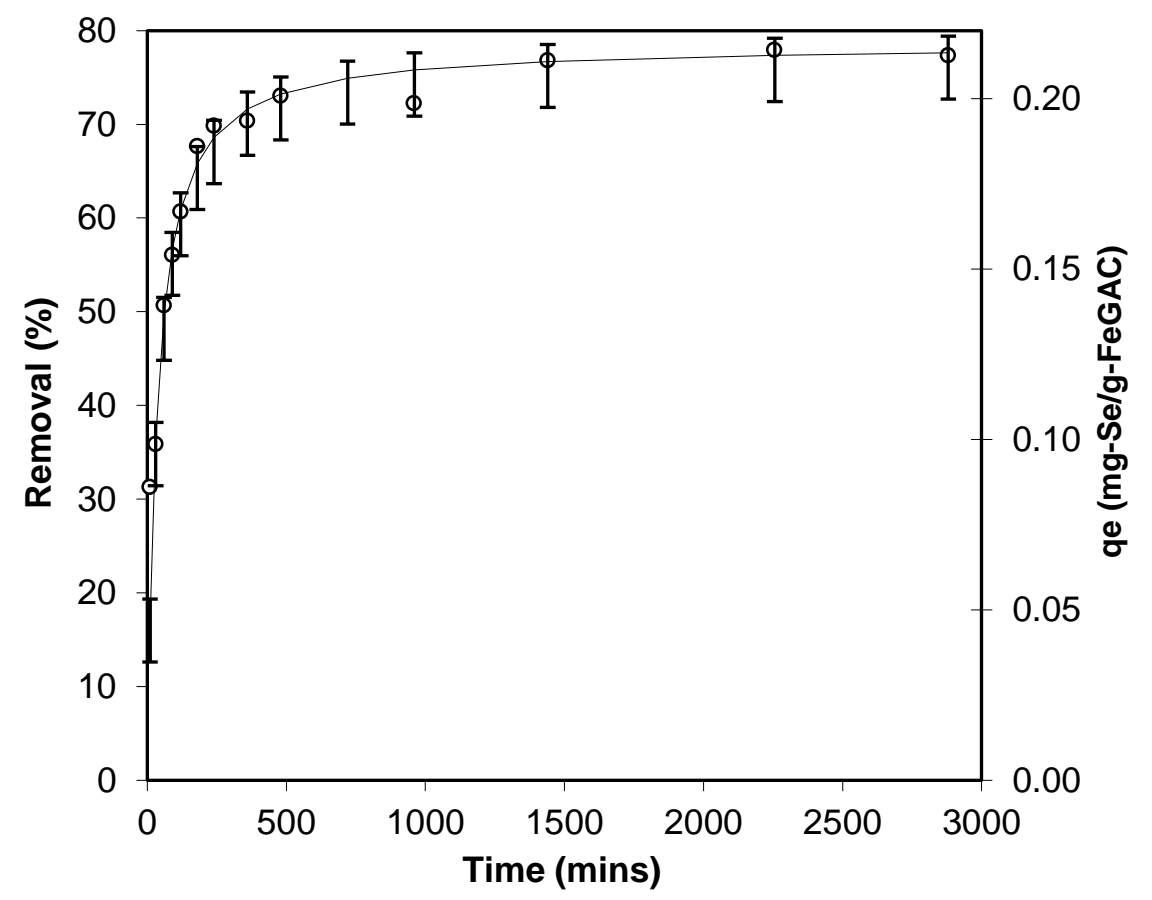

Figure 16. Selenate adsorption kinetics for initial Se concentration of $1 \mathrm{mg} / \mathrm{L}$ at $\mathrm{pH} 5$ and $0.01 \mathrm{M}$ ionic strength in the presence of $3.5 \mathrm{~g} / \mathrm{L} \mathrm{Fe}-\mathrm{GAC}$. The pseudo-second order kinetic model is indicated by the curve. 


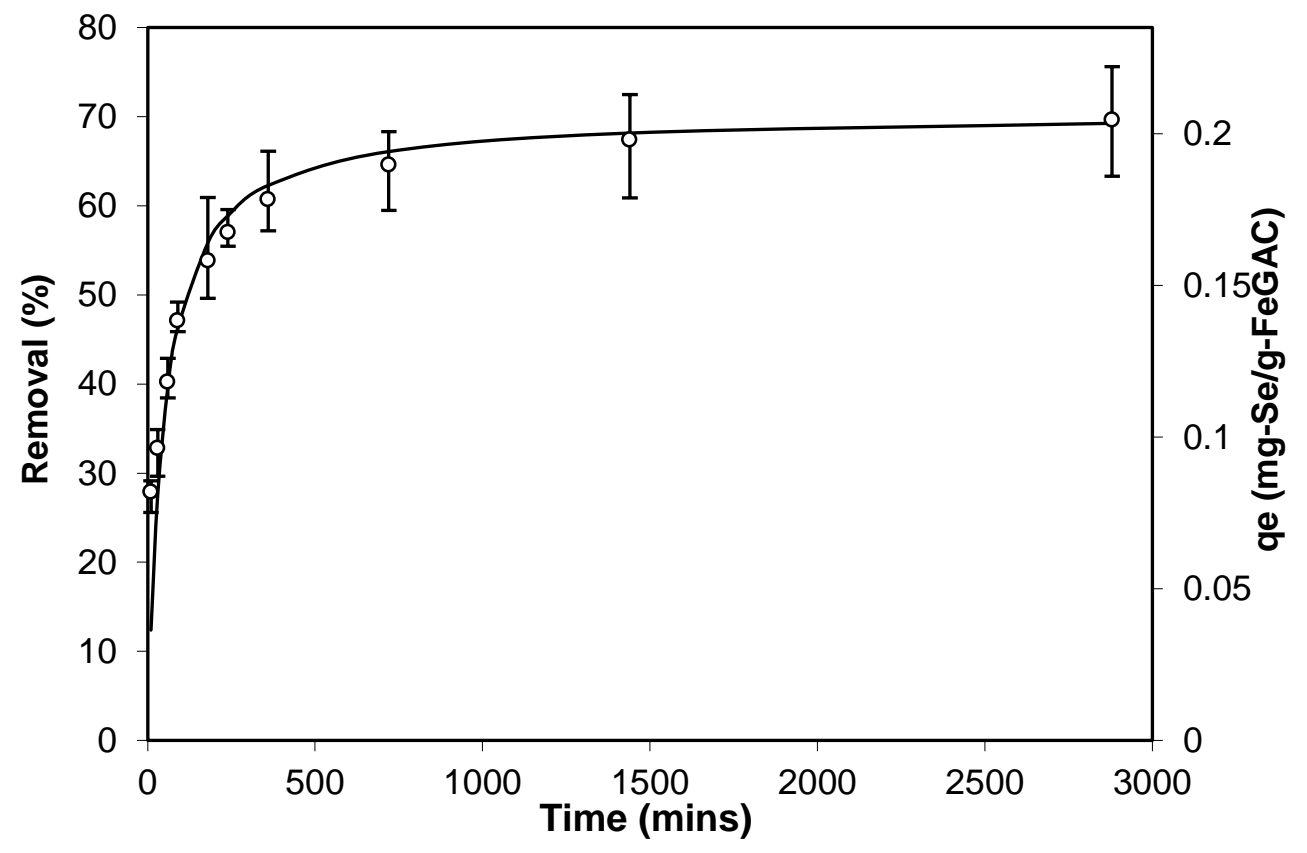

Figure 17. Selenate adsorption kinetics for initial Se concentration of $1 \mathrm{mg} / \mathrm{L}$ at $\mathrm{pH} 5$ and $0.05 \mathrm{M}$ ionic strength in the presence of $3.5 \mathrm{~g} / \mathrm{L} \mathrm{Fe}-\mathrm{GAC}$. The pseudo-second order kinetic model is indicated by the curve. 


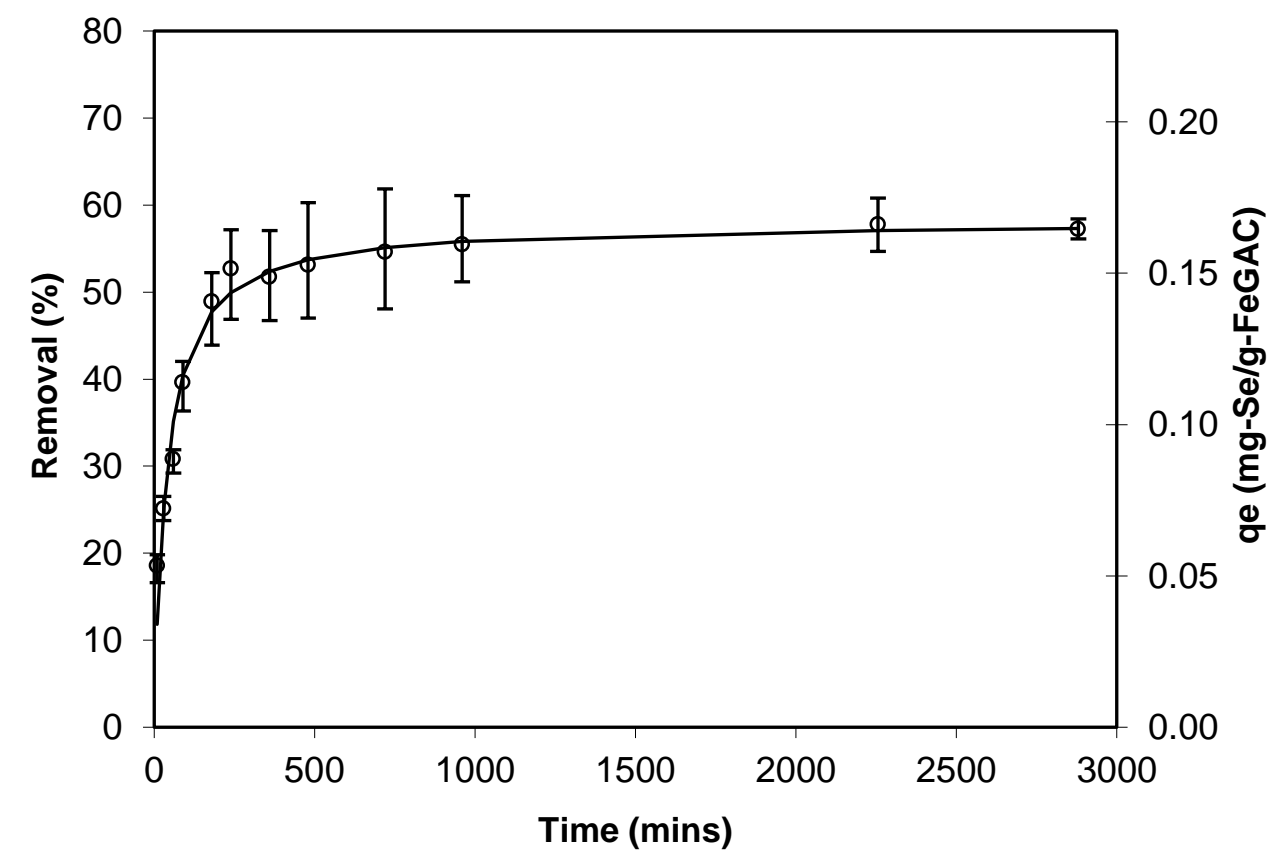

Figure 18. Selenate adsorption kinetics for initial Se concentration of $1 \mathrm{mg} / \mathrm{L}$ at $\mathrm{pH} 5$ and $0.1 \mathrm{M}$ ionic strength in the presence of $3.5 \mathrm{~g} / \mathrm{L} \mathrm{Fe}-\mathrm{GAC}$. The pseudo-second order kinetic model is indicated by the curve. 


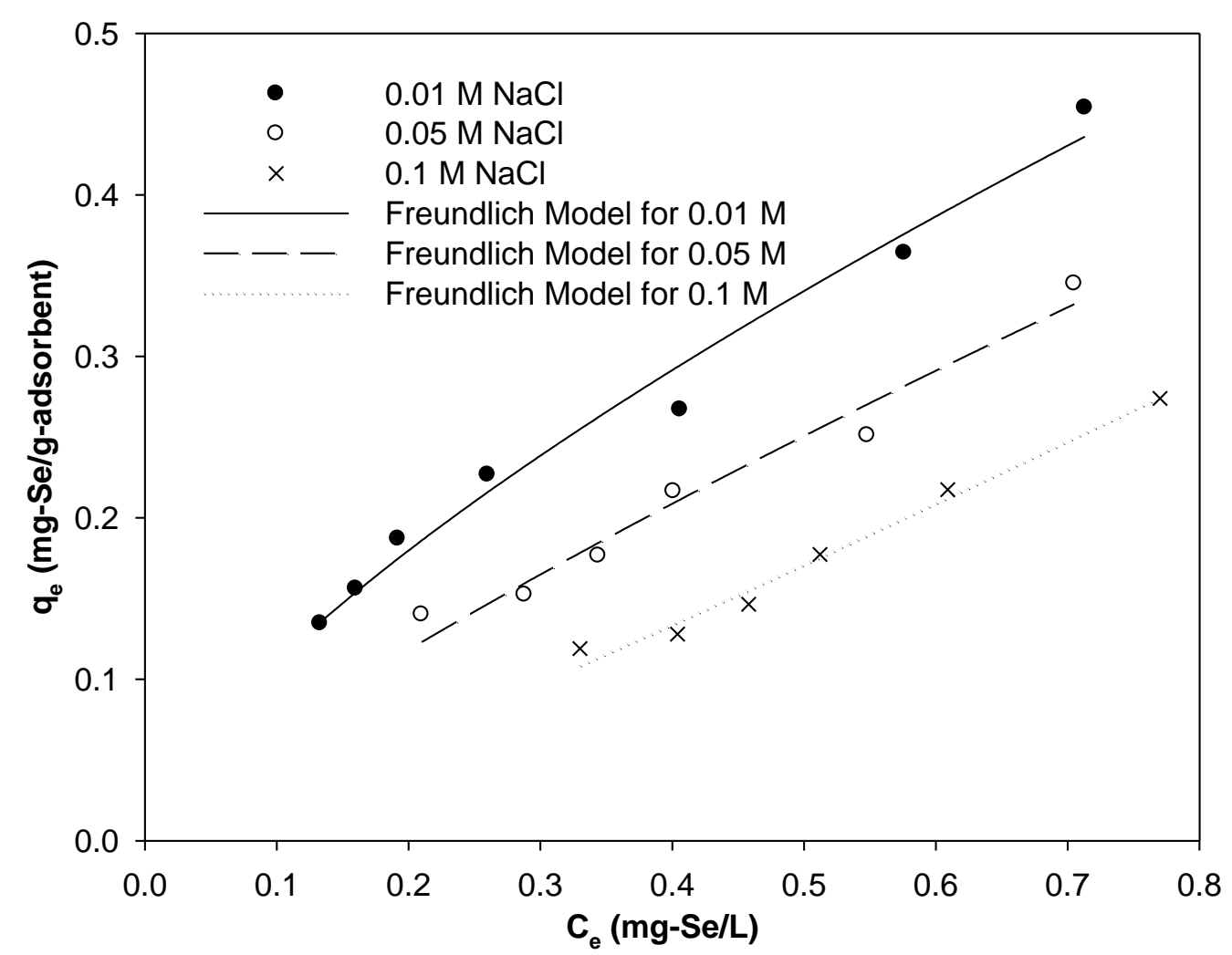

Figure 19. Adsorption isotherms of the Fe-GAC for selenate (initial Se concentration $=1$ $\mathrm{mg} / \mathrm{L}$ ) at $\mathrm{pH} 5$ and $25^{\circ} \mathrm{C}$. The Freundlich models are indicated by the curves. 


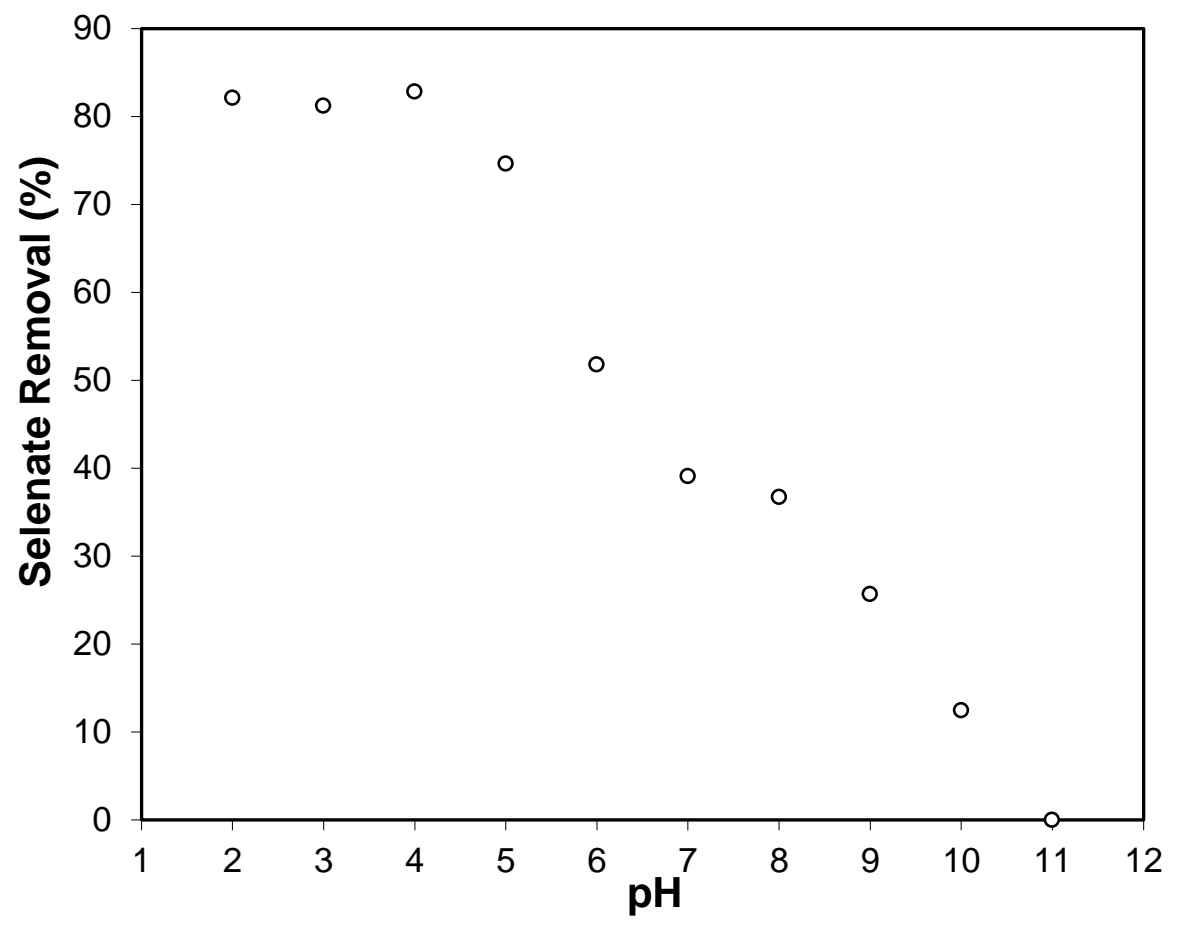

Figure 20. Adsorptive removal of selenate (initial Se concentration $=1 \mathrm{mg} / \mathrm{L}$ ) as a function of $\mathrm{pH}$ under ionic strength $0.05 \mathrm{M}$ and $25^{\circ} \mathrm{C}$. 


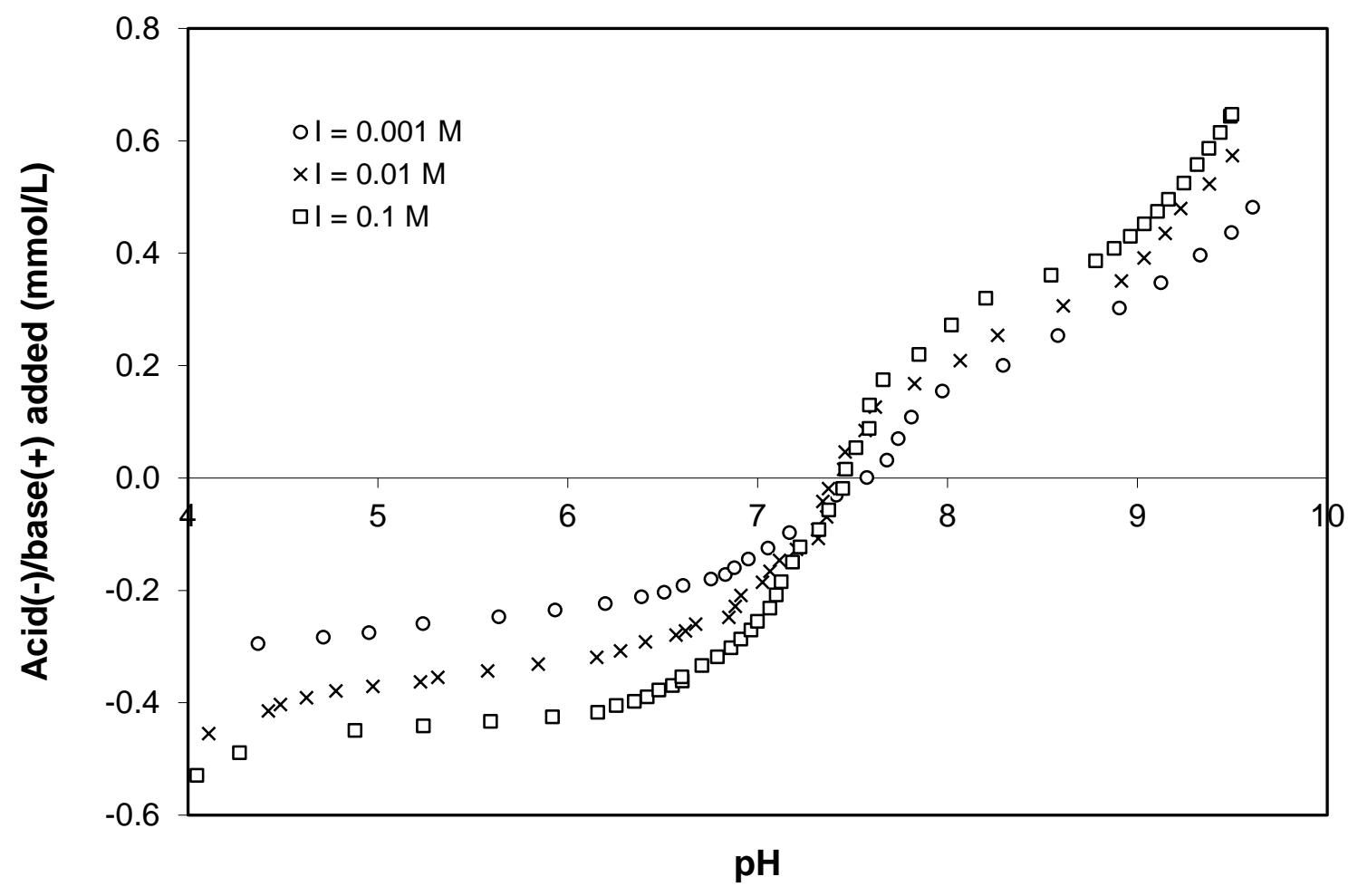

Figure 21. Acid base titration curves for the Fe-GAC (loading rate $=2 \mathrm{~g} / \mathrm{L}$ ) under ionic strengths $0.01,0.05$ and $0.1 \mathrm{M}$. 


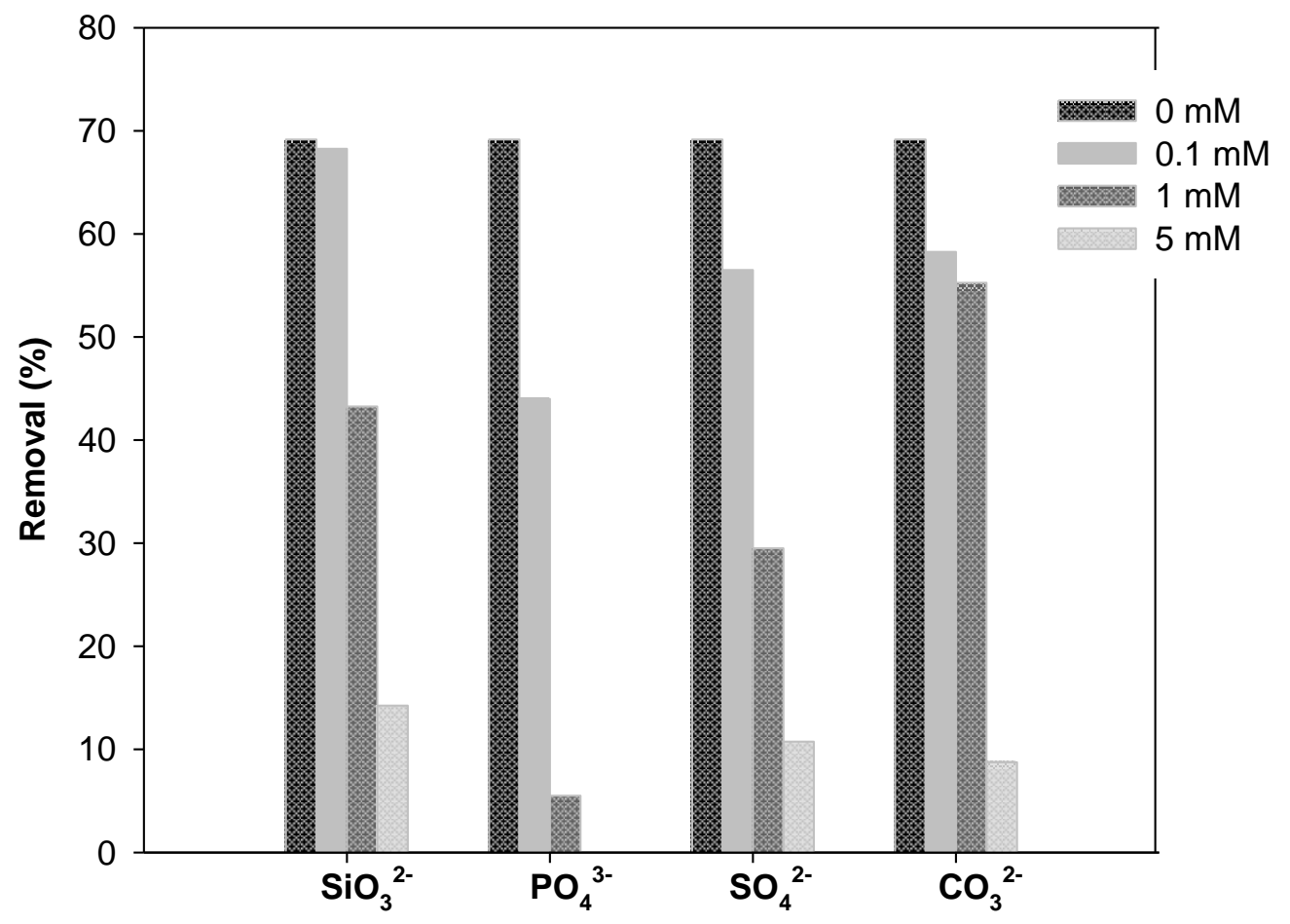

Figure 22. Oxy-anion competitive adsorption against selenate (initial Se concentration $=$ $1 \mathrm{mg} / \mathrm{L}$ ) under ionic strengths $0.05 \mathrm{M}, \mathrm{pH} 5$, and $25^{\circ} \mathrm{C}$ after 24 hours. 


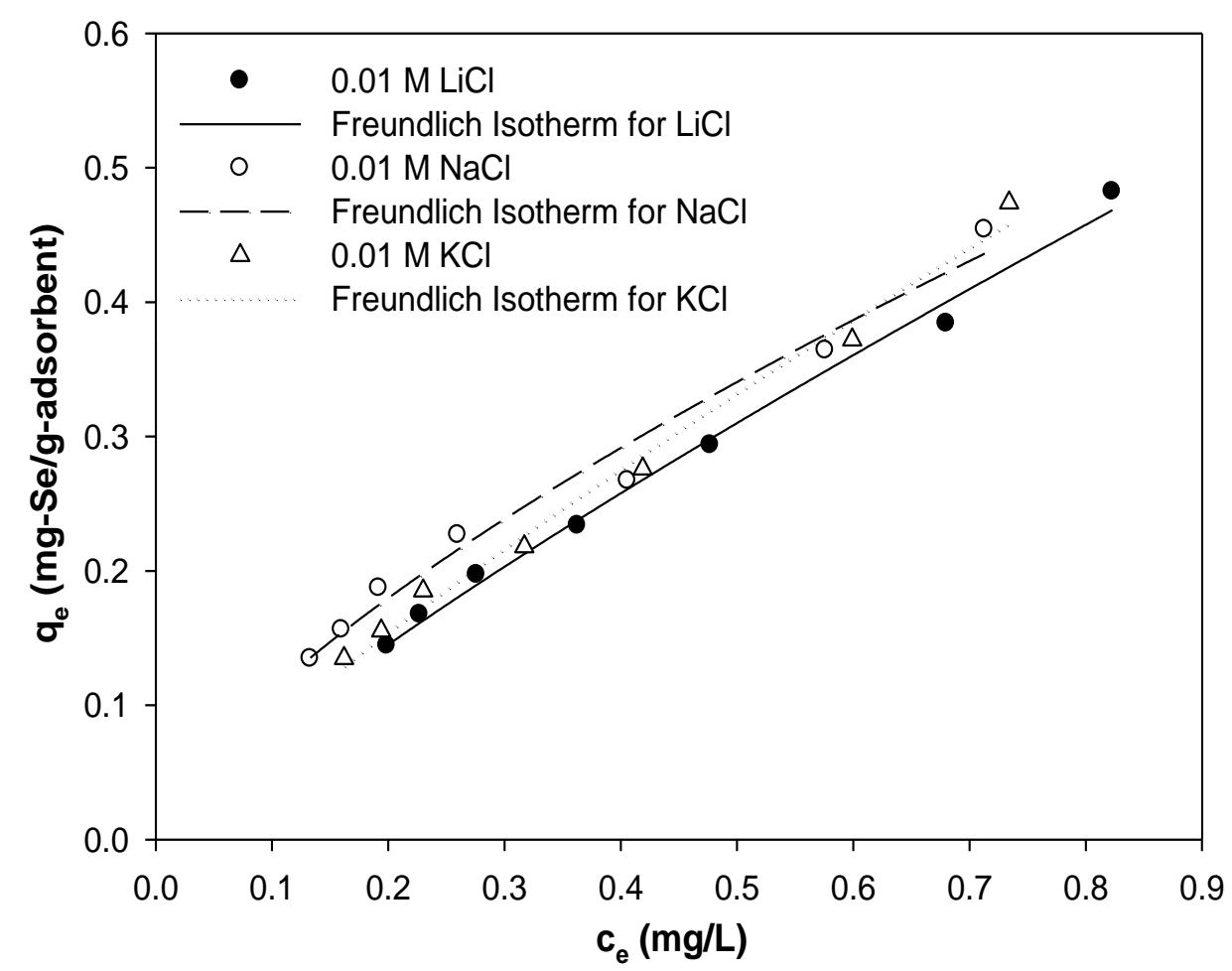

Figure 23. Adsorption isotherms of the Fe-GAC for selenate (initial Se concentration $=1$ $\mathrm{mg} / \mathrm{L}$ ) with the presence of different background electrolytes $(\mathrm{LiCl}, \mathrm{NaCl}$, and $\mathrm{KCl})$ at $\mathrm{pH}$ 5, $0.01 \mathrm{M}$ ionic strength and $25^{\circ} \mathrm{C}$. The Freundlich models are indicated by the curves. 


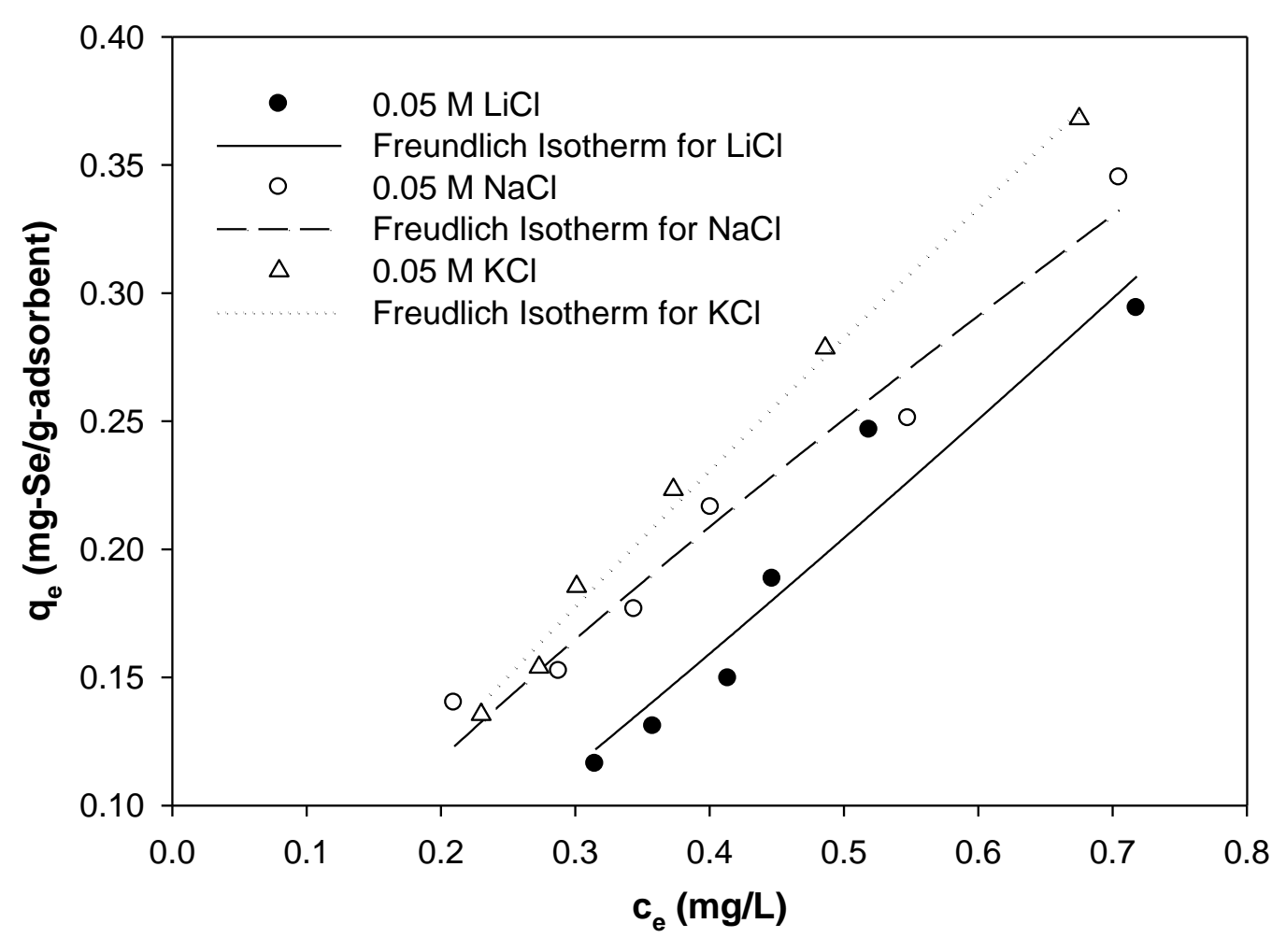

Figure 24. Adsorption isotherms of the Fe-GAC for selenate (initial Se concentration $=1$ $\mathrm{mg} / \mathrm{L}$ ) with the presence of different background electrolytes $(\mathrm{LiCl}, \mathrm{NaCl}$, and $\mathrm{KCl})$ at $\mathrm{pH}$ 5, $0.05 \mathrm{M}$ ionic strength and $25^{\circ} \mathrm{C}$. The Freundlich models are indicated by the curves. 


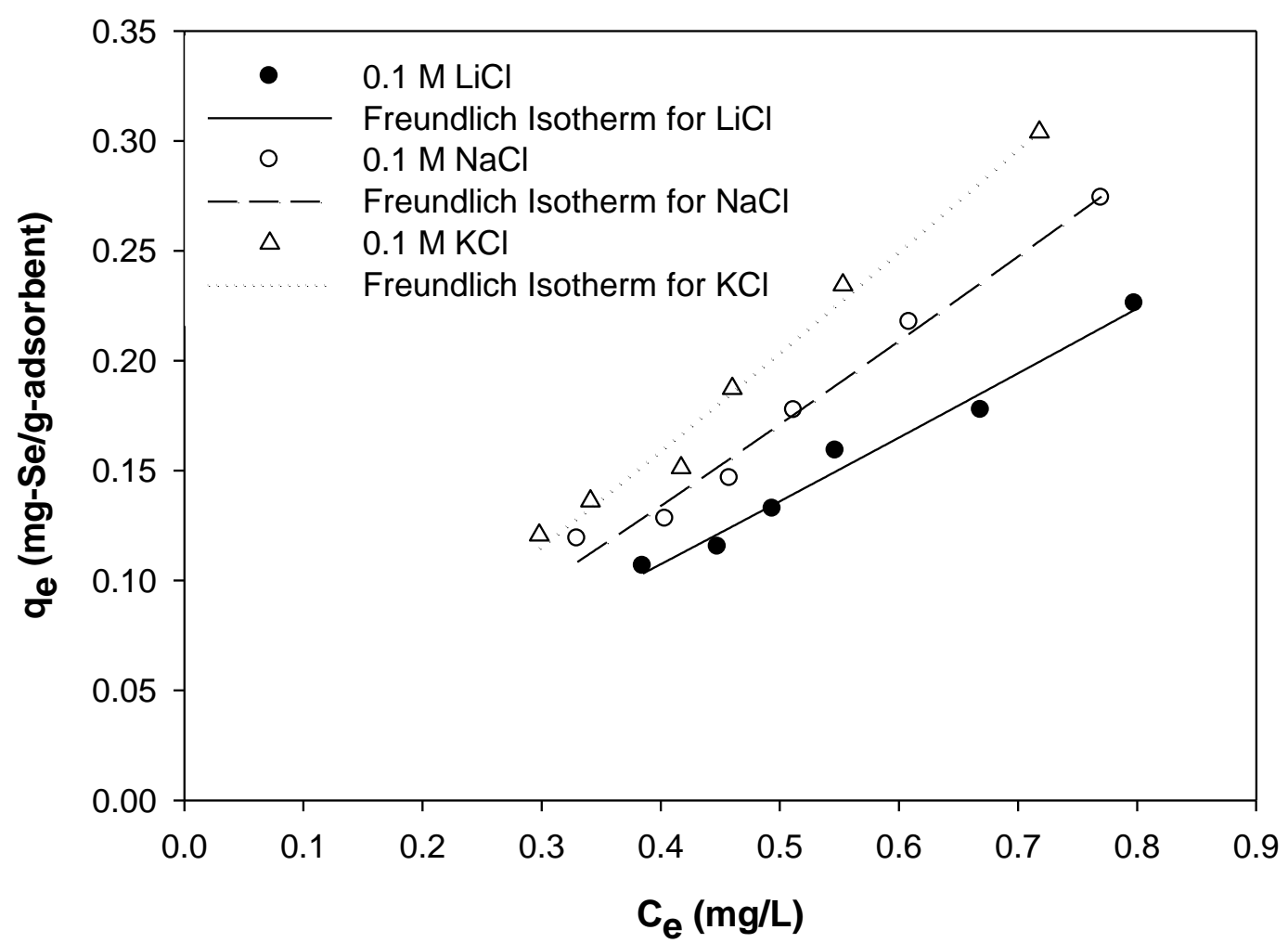

Figure 25. Adsorption isotherms of the Fe-GAC for selenate (initial Se concentration $=1$ $\mathrm{mg} / \mathrm{L}$ ) with the presence of different background electrolytes ( $\mathrm{LiCl}, \mathrm{NaCl}$, and $\mathrm{KCl})$ at $\mathrm{pH}$ 5, $0.1 \mathrm{M}$ ionic strength and $25^{\circ} \mathrm{C}$. The Freundlich models are indicated by the curves. 


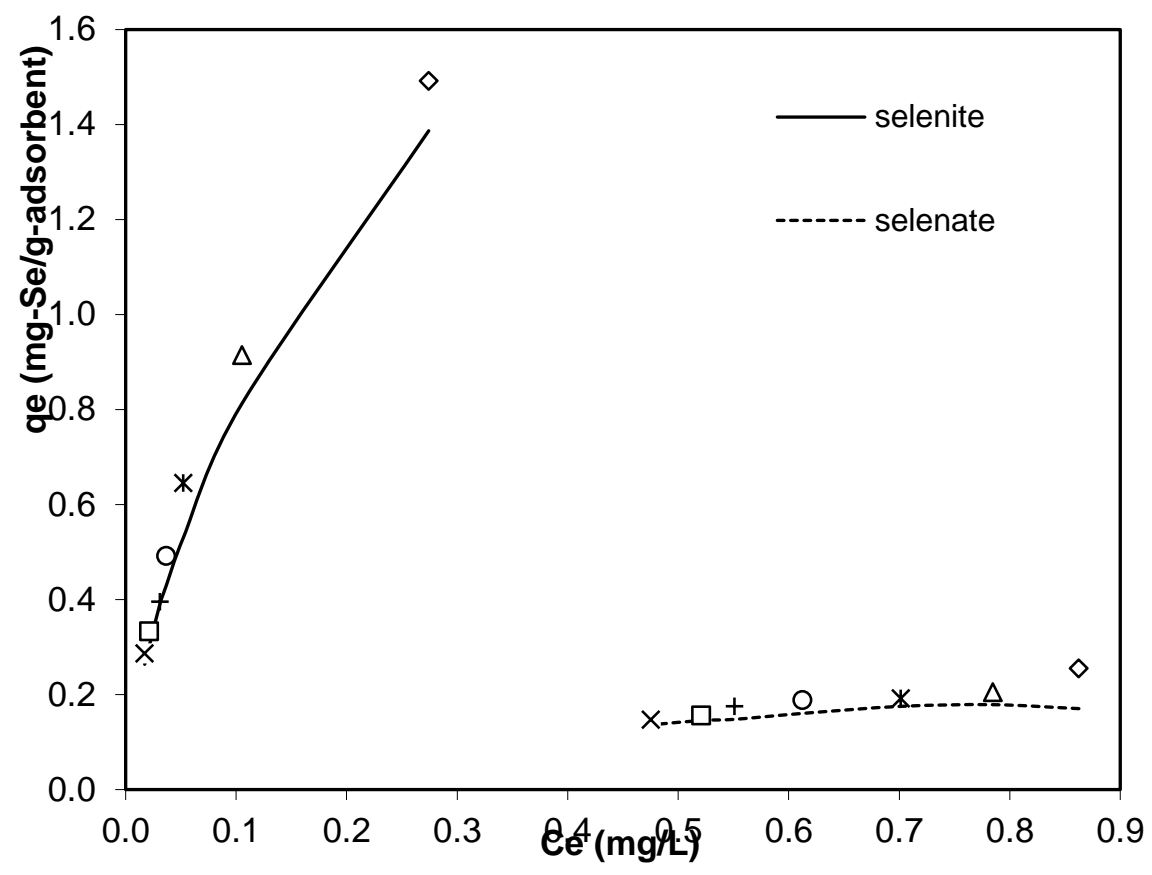

Figure 26. Competitive adsorption isotherms of the Fe-GAC for selenite and selenate (initial Se concentration $1 \mathrm{mg} / \mathrm{L}$ for each) under ionic strength of $0.1 \mathrm{M}, \mathrm{pH} 5$ and $25^{\circ} \mathrm{C}$. Pairs of the same symbols represent selenate/selenite concentrations in the same batch reactor. $\times: 0.5 \mathrm{~g} / \mathrm{L} ; \square: 1.0 \mathrm{~g} / \mathrm{L} ;+: 1.5 \mathrm{~g} / \mathrm{L} ; \circ: 2.0 \mathrm{~g} / \mathrm{L} ; *: 2.5 \mathrm{~g} / \mathrm{L} ; \Delta: 3.0 \mathrm{~g} / \mathrm{L}$ and $\diamond: 3.5 \mathrm{~g} / \mathrm{L}$. 


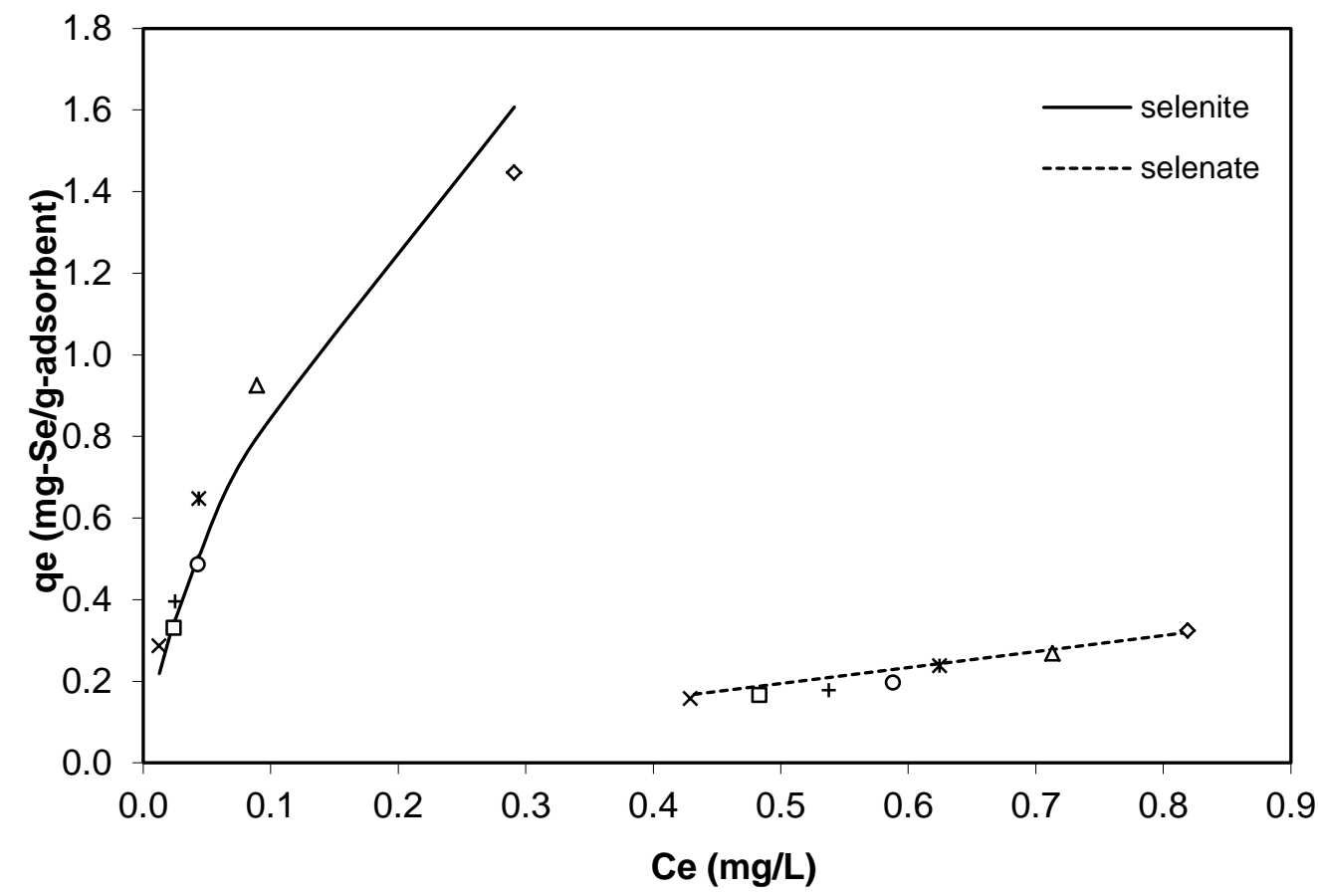

Figure 27. Competitive adsorption isotherms of the Fe-GAC for selenite and selenate (initial Se concentration $1 \mathrm{mg} / \mathrm{L}$ for each) under ionic strength of $0.05 \mathrm{M}, \mathrm{pH} 5$ and $25^{\circ} \mathrm{C}$. Pairs of the same symbols represent selenate/selenite concentrations in the same batch reactor. ×: $0.5 \mathrm{~g} / \mathrm{L} ; \square: 1.0 \mathrm{~g} / \mathrm{L} ;+: 1.5 \mathrm{~g} / \mathrm{L} ; \circ: 2.0 \mathrm{~g} / \mathrm{L} ; *: 2.5 \mathrm{~g} / \mathrm{L} ; \Delta: 3.0 \mathrm{~g} / \mathrm{L}$ and $\diamond: 3.5 \mathrm{~g} / \mathrm{L}$. 


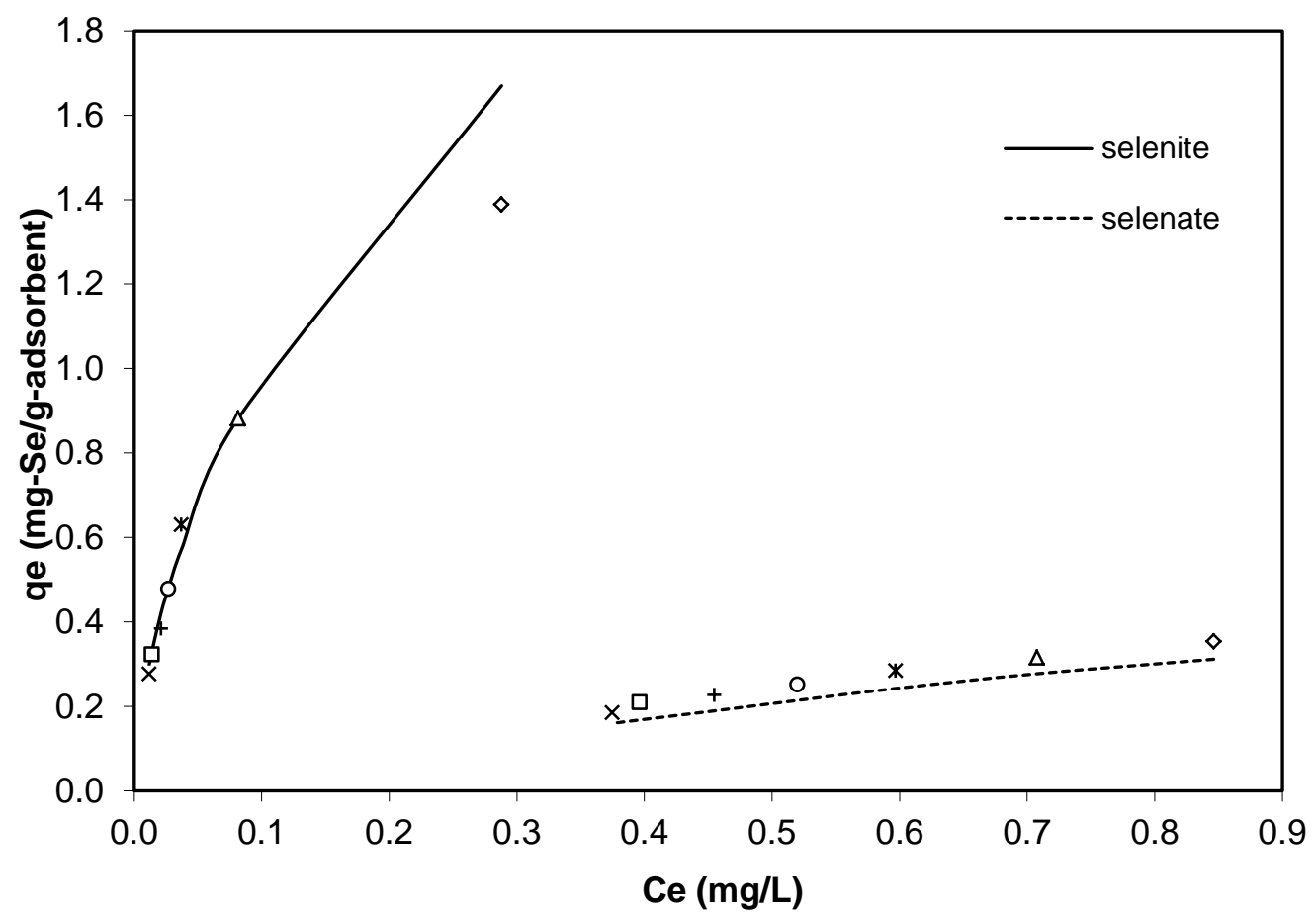

Figure 28. Competitive adsorption isotherms of the Fe-GAC for selenite and selenate (initial Se concentration $1 \mathrm{mg} / \mathrm{L}$ for each) under ionic strength of $0.05 \mathrm{M}$, pH 5 and $25{ }^{\circ} \mathrm{C}$. Pairs of the same symbols represent selenate/selenite concentrations in the same batch reactor. $\times: 0.5 \mathrm{~g} / \mathrm{L} ; \square: 1.0 \mathrm{~g} / \mathrm{L} ;+: 1.5 \mathrm{~g} / \mathrm{L} ; \circ: 2.0 \mathrm{~g} / \mathrm{L} ; *: 2.5 \mathrm{~g} / \mathrm{L} ; \Delta: 3.0 \mathrm{~g} / \mathrm{L}$ and $\diamond: 3.5 \mathrm{~g} / \mathrm{L}$. 


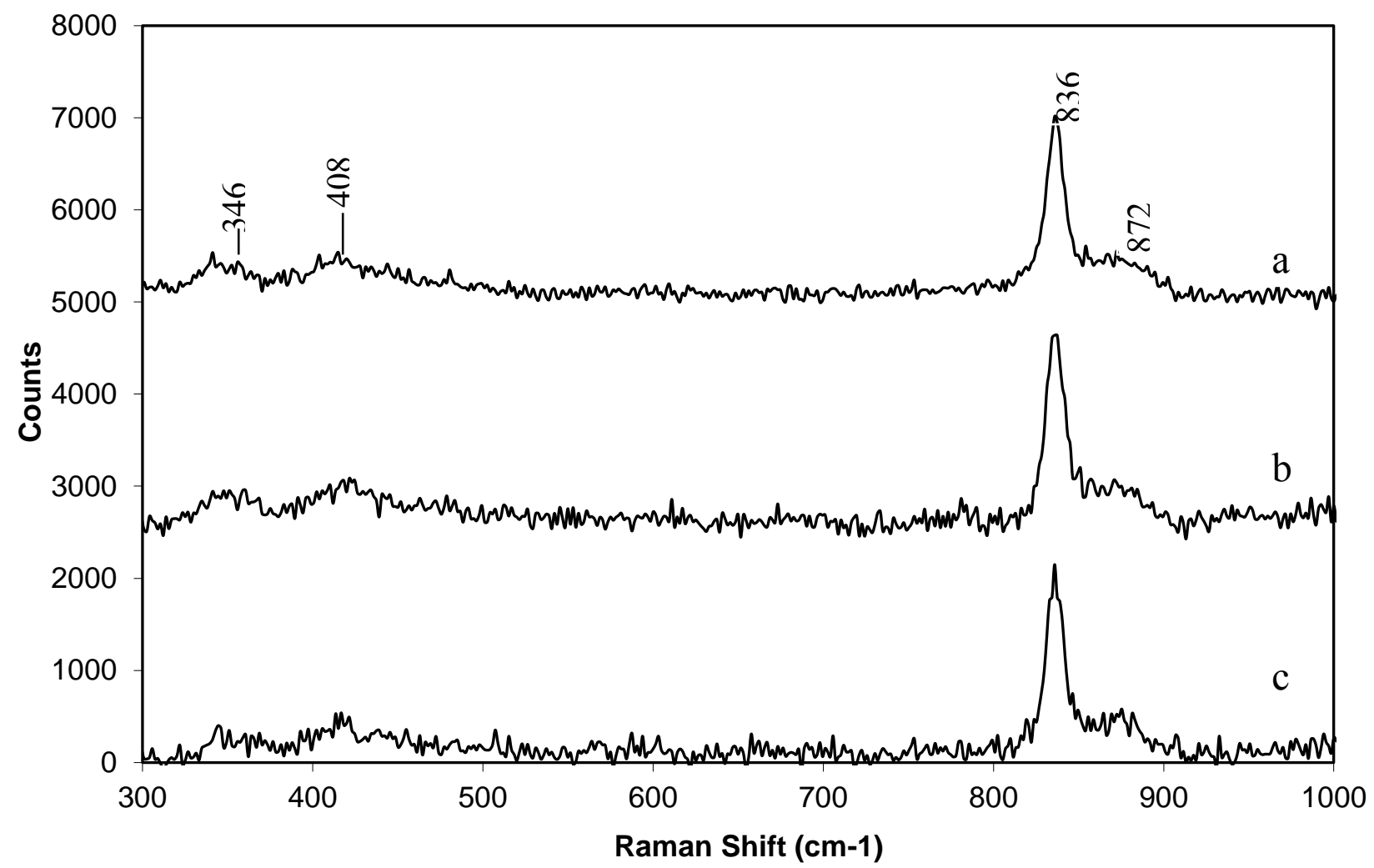

Figure 29. Raman spectra of $\mathrm{Na}_{2} \mathrm{SeO}_{4}$ solutions $(0.1 \mathrm{M})$ at $\mathrm{pH}(\mathrm{a}) 3$; (b) 5 ; and (c) 8 . 


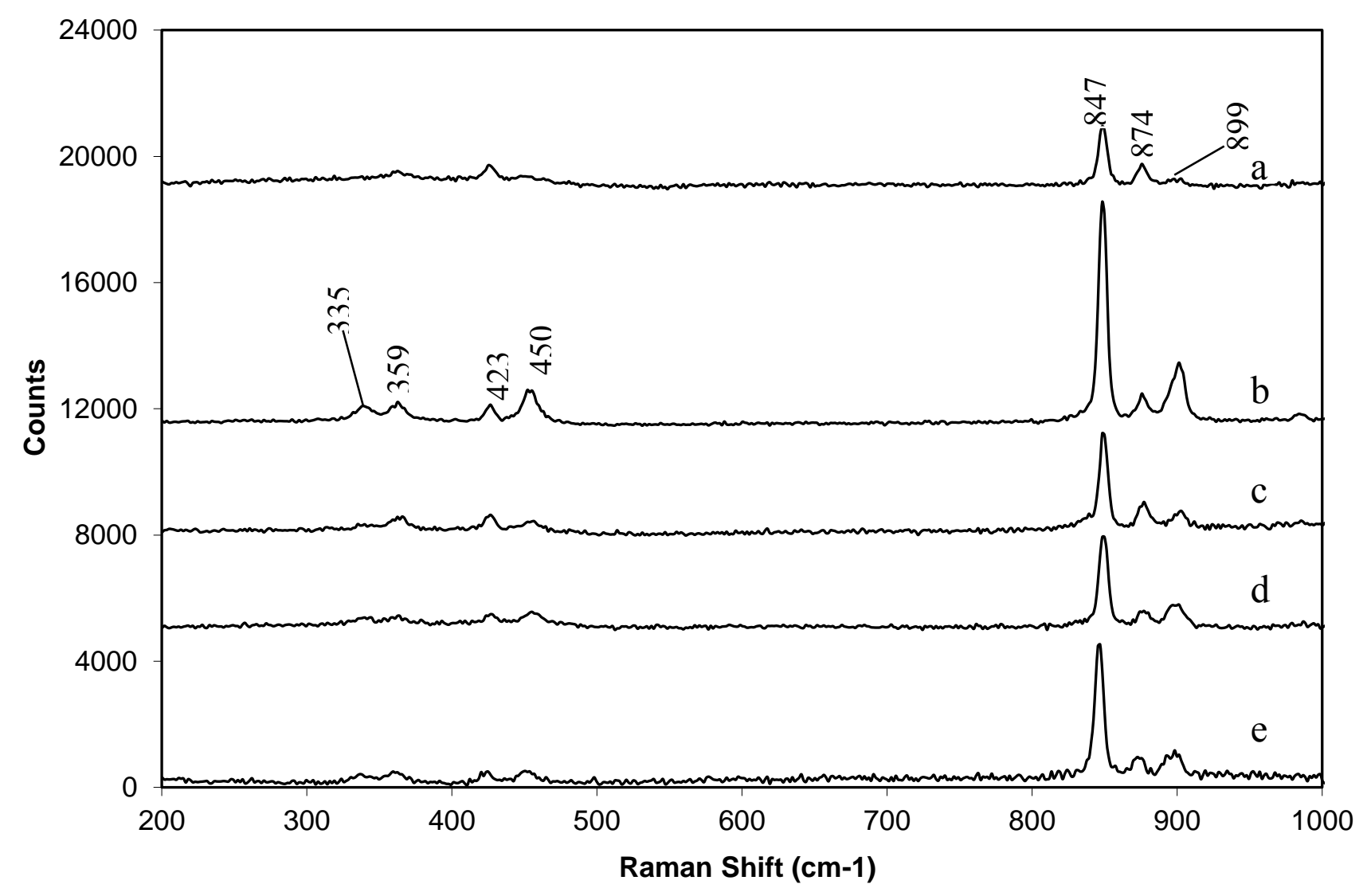

Figure 30. Raman spectra for adsorbed selenate with $0.1 \mathrm{M}$ initial selenate concentration at $\mathrm{pH}$ (a) 7; (b) 6; (c) 5; (d) 4; and (e) 3 . 


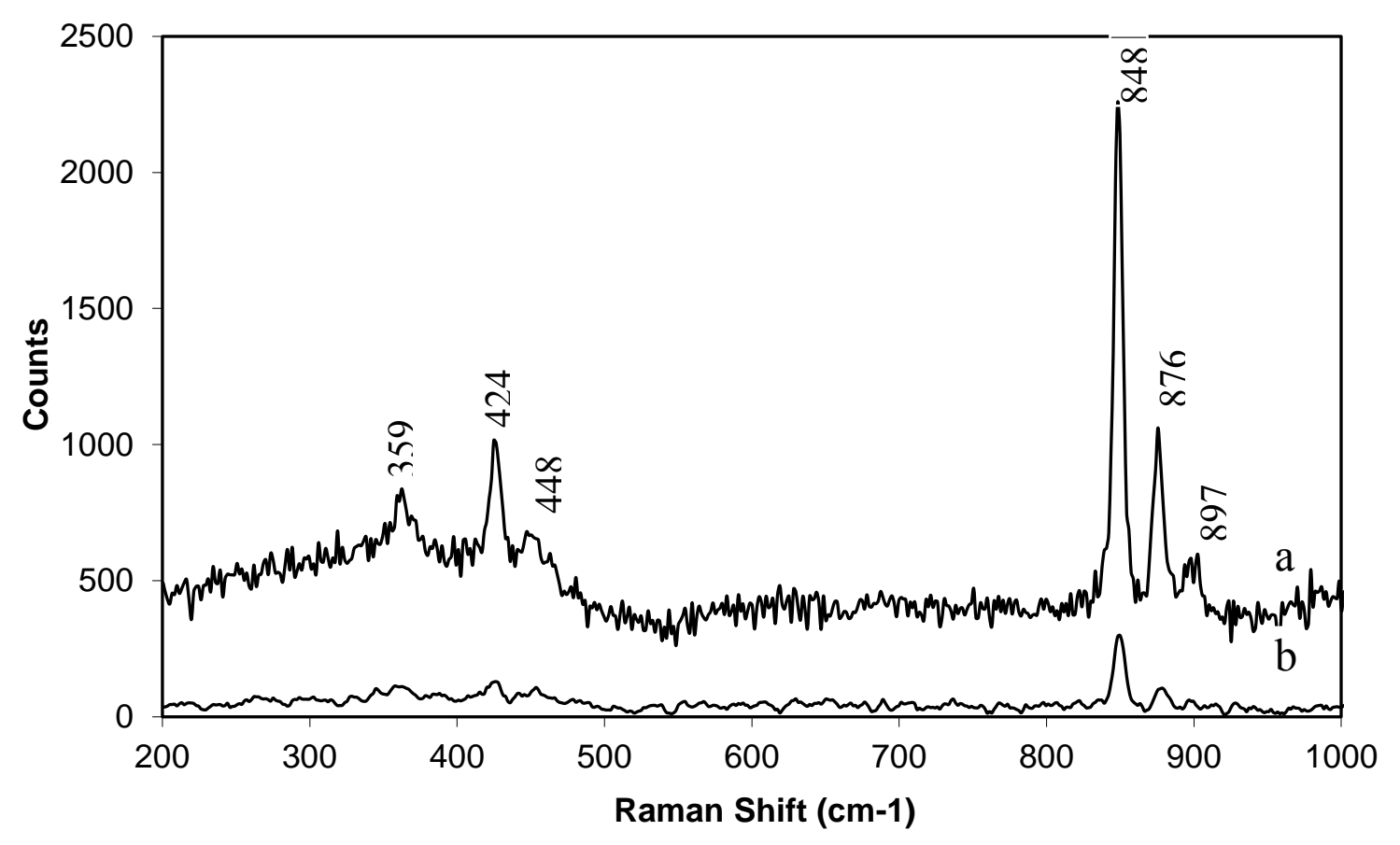

Figure 31. Raman spectra for adsorbed selenate with $0.1 \mathrm{M}$ initial selenate concentration at $\mathrm{pH}=7$ under excitation of laser power (a) $50 \mathrm{~mW}$; and (b) $10 \mathrm{~mW}$. 


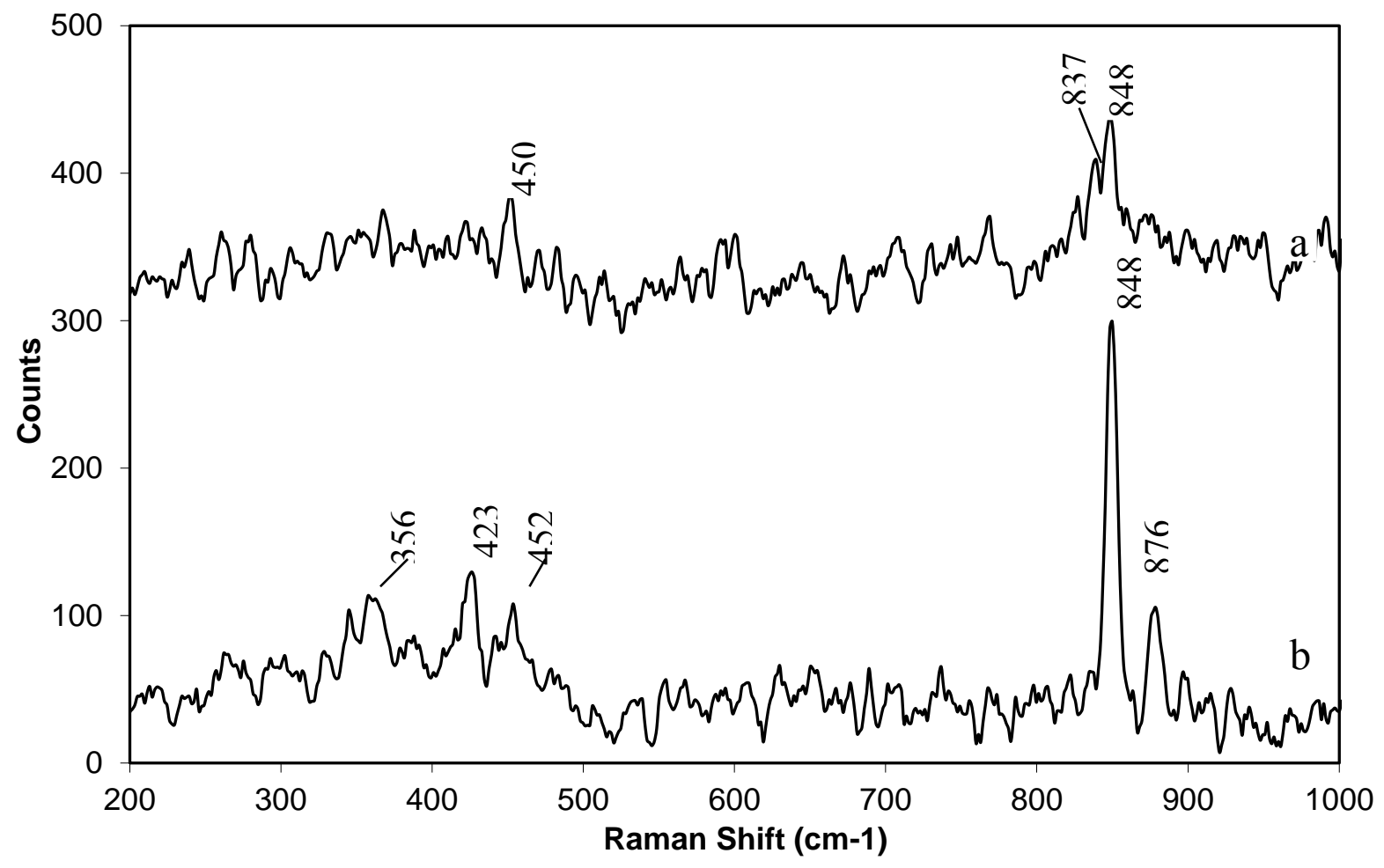

Figure 32. Raman spectra for adsorbed selenate with $0.1 \mathrm{M}$ initial selenate concentration at $\mathrm{pH}$ (a) 8 and (b) 7. 


\section{CHARPTER 5: CONCLUSION}

The adsorptive removal of ppm-level selenate by Fe-GAC was studied along with detailed investigation for the adsorbed selenate coordination structures in this study. Main conclusions are summarized in the followings:

- $\quad$ Removal efficiency of the Fe-GAC for selenate achieved more than $75 \%$ for $\mathrm{pH}$ range 2 - 5. It is promising to use the Fe-GAC for selenate removal from acid mine drainages typically found in acidic conditions.

- $\quad$ Selenate adsorption equilibrium was reached within 48 hours with more than $85 \%$ of the equilibrium capacity being obtained in 6 hours. Adsorption capacities showed a decreasing trend as ionic strength increased from 0.01 to $0.1 \mathrm{M}$.

- Adsorption isotherms were characterized by the Freundlich isotherm model. The lack of plateaus in the adsorption isotherms suggested that the maximum adsorption capacity of Fe-GAC was substantially higher than the adsorption capacities observed in the study.

- $\quad$ Effect of background electrolytes was examined on selenate adsorption.

The results showed that the increasing of hydrated radius caused variations in selenate adsorption at $\mathrm{pH} 5$, which implied that an inner sphere complexation occurred.

- $\quad$ Four oxy-anions $\left(\mathrm{SiO}_{3}{ }^{2-}, \mathrm{SO}_{4}{ }^{2-}, \mathrm{PO}_{4}{ }^{3-}\right.$ and $\left.\mathrm{CO}_{3}{ }^{2-}\right)$ were found to compete with selenate adsorption to various degrees, with phosphate showing the most impact on selenate adsorption.

- $\quad$ Competitive adsorption of binary adsorbates (selenite and selenate) was modeled by SRS multi-adsorbate competitive adsorption isotherms. Selenate was found to compete against selenite more strongly under low 
ionic strengths. Only slight decreases in the selenite and selenate adsorption capacities in binary system were observed as they were compared to their respective single-adsorbate systems. This suggests the feasibility of removing selenite and selenate simultaneously.

- Various chemical and physical properties of Fe-GAC were examined in details. The acid base titration results showed that $\mathrm{pH}_{\mathrm{zpc}}$ for Fe-GAC is 7.5. High resolution XPS spectra conducted for $\mathrm{Fe} 2 \mathrm{p} 3 / 2$ and $\mathrm{O} 1 \mathrm{~s}$ indicated the ferrous was successfully oxidized to form ferric on GAC surface. The possible chemical composition for the coated iron was $\alpha$ $\mathrm{FeOOH}$. Additionally, spectra obtained at different pHs suggested that Fe-GAC was stable and no transformation was observed as $\mathrm{pH}$ changed.

- Raman spectra showed that selenate was adsorbed via mixing coordination structure of mono-dentate and bi-dentate inner sphere complexation at acidic conditions (i.e., $\mathrm{pH}<6$ ). When $\mathrm{pH}$ was close to $\mathrm{pH}_{\mathrm{zpc}}$, bi-dentate complexation was not clearly observed. When $\mathrm{pH}$ was further increased to 8 , portion of selenate was adsorbed via outer sphere complexation. These results explained the low selenate adsorption when $\mathrm{pH}$ was higher than $\mathrm{pH}_{\mathrm{zpc}}$.

- Two feasible modification methods to the adsorbent preparation were proposed in order to improve selenate adsorption. One was to coat other oxides (e.g., magnesium oxides) along with iron oxides to increase $\mathrm{pH}_{\mathrm{zpc}}$ and broaden effective $\mathrm{pH}$ range for selenate adsorption. Alternatively, reduced iron (e.g., ferrous) could be precipitated with ferric oxides in order to reduce selenate to selenite first, followed by high adsorption of selenite. 


\section{REFERENCES}

Abdullah, M. I., Shiyu, Z. and Mosgren, K. (1995) Arsenic and selenium species in the oxic and anoxic waters of the Oslofjord, Norway, Marine Pollution Bulletin, 31, 116126.

Ahlrichs, J. S.; Hossner, L. R. (1987) Selenate and selenite mobility in overburden by. saturated flow, Journal of Environment Quality, 16, 95-98.

Azizian, S. (2004) Kinetic models of sorption: a theoretical analysis, Journal of Colloid and Interface Science, 276, 47 - 52.

Barr n, V. and Torrent, J. (1996) Surface hydroxyl configuration of different crystal faces of hematite and goethite, Journal of Colloid and Interface Science, 177, 407411.

Balistrieri, L.S., and Chao, T.T. (1987) Selenium adsorption by goethite, Soil Science Society of America Journal, 51, 1145-1151.

Benelli, C.; Di Vaira, M.; Noccioli, G. and Sacconi, L. (1977) Synhesis, properties, and characterization of sulfato and selenato complexes of cobalt (II) and nickel (II) with 1, 1, 1 - tris (diphenylphosphinomethyl)ethane (p3). Crystal and molecular structures of $\mathrm{Co}(\mathrm{p} 3) \mathrm{SO}_{4}$ and $\mathrm{Ni}(\mathrm{p} 3) \mathrm{SeO}_{4}$, Inorganic Chemistry, 1977, 16, 182-187.

Bowen, H. J. M. (1966) Trace elements in biochemistry, Academic Press, San Diego.

Chau, Y. K. and Wong, P. T. S., Luxon, P. L. and bengert, G. A. (1976) Methylation of selenium in the aquatic environment, Science (Washington, DC), 192, 1130-1131.

Coleman, L., L.J. Bragg and R.B. Finkelman (1993) Distribution and mode of occurrence of selenium in US coals. Environmental Geochemistry and Health, 15(4), 215-227.

Combs, G. F. and Combs, S. B. (1986) Effects of selenium excesses, In: The Role of Selenium in Nutrition Academic Press, New York.

Cornell, R. M. and Schwertmann, U. (2003) The iron oxides: Structure, properties, reactions, occurrences and uses, 2nd Ed., Wiley-VCH Verlag GmbH\&Co. KGaA, Weinheim.

Crisenti, L. J. and Sverjensky, D. A. (1999) The role of electrolyte anions (ClO4-, NO3-, and $\mathrm{Cl}-$ ) in divalent metal (M2+) adsorption on oxide and hydroxide surfaces in salt solutions, American Journal of Science, 299, 828-899. 
Crittenden, J.C., Trussell, R. R., Hand, D. W., Howe, K. J. and Tchobanoglous, G. (2005) 15: Adsorption, Water Treatment: Principles and Design, John Wiley and Sons: New York.

Cutter, G. A. and Bruland, K. W. (1984) The marine biogeochemistry of selenium in seawater: A re-evaluation, Limnology and Oceanography, 29, 1179-1192.

Davis, J. A., Leckie, J. O. (1980) Surface ionization and complexation at the oxide/water interface. 3. Adsorption of ions, Journal of Colloid and Interface Science, 74, 32-43.

Del-Debbio, J.A. (1991) Sorption of strontium, selenium, cadmium and mercury in soil, Radiochima Acta, 52/53, 181-186.

Devereln, S. J., Fio, J. L. and Dubrovsky, N. M. (1994) In: Selenium in the environment, Frankenberger, W. T.; Benson, S. Eds., Marcel Dekker INC., New York, 157-183.

Eggleston, C. M. and Jordan, G. (1998) A new approach to $\mathrm{pH}$ of point of zero charge measurement: crystal-face specificity by scanning force microscopy (SFM), Geochimica et Cosmochimica Acta, 62, 1919 - 1923.

Eisler, R. (1985) Selenium hazards to fish, wildlife, and invertebrates: A synoptic review, U.S. Fish and Wildlife Service Biological Report, 85, 1.5.

Elrashidi, M. A., Adriano, D. C., Workman, S. M. and Lindsay, W. L. (1987) Chemical equilibria of selenium in soils: A theoretical development, Soil Science, 144, 141-152.

Engberg, R. A. (1999) Selenium budgets for lake powell and the upper Colorado RWER Basin, Journal of the American Water Resources Association, 35, 771 - 786.

Food and Nutrition Board- USA Institute of Medicine (2000) Dietary References Intakes for Vitamin C, Vitamin E, Selenium and Carotenoids, National Academy Press, Washington, DC.

Essington, M. E. (1988) Estimation of the standard free energy of formation of metal arsenates, selenates and selenites, Soil Science Society of America Journal, 52, 15741579.

Faraway, J. J. (2005) Linear Models with R, Chapman\&Hall/CRC, Baca Raton, FL.

Farrell, J.; Bostick, W. D.; Jarabek, R. J. and Fiedor, J. N. (1999) Uranium removal from ground water using zero valent iron media, Ground Water, 37, 618-624. 
Federal Remediation Technologies Roundtable (2002) Remediation technologies screening matrix and reference guide, $4^{\text {th }}: 2.8 .1$ Inorganics, Washington D.C. http://www.frtr.gov/matrix2/section2/2_8_1.html.

Fleming, G. A. (1962) Selenium in Irish soils and plants, Soil Science, 94, 28-35.

Fio, J. L.; Fujii, R. (1990) Selenium speciation methods and application to soil saturation extracts from San Joaquin Valley, California, Soil Science Society of America Journal, 54, 363-369.Frankenberger, W. T. Jr., Amerhein, C., Fan, T. W. M., Flaschi, D., Glater, J. Kartinen, E. Jr., Kovac, K., Lee, E., Ohlendorf, H. M., Terry, N. and Toto, A. (2004) Advanced treatment technologies in remediation of seleniferous drainage waters and sediments., Irrigation and Drainage Systems, 18, 19-41.

Gallup, D. L. (1996) In Proceedings of the 69th Water Environment Federation Conference, Dallas, TX; Water Environment Federation: Alexandria, VA, 447-453.

Garten, V., Weiss, D. and Willis, J. (1957) A newinterpretation of the acidic and basic structures in carbons, Aust. J. Chem., 10, 285.

Ghosh, M. M., Cox, C. D. and Yuan-pan, J.R. (1994) Adsorption of selenium on hydrous alumina, Environmental Progress, 13, 79-88.

Goh, K. and Lim, T. (2004) Geochemistry of inorganic arsenic and selenium in a tropical soil: effect of reaction time, $\mathrm{pH}$, and dompetitive anions on arsenic and selenium adsorption, Chemosphere, 55, 849-859.

Golder Associates, Inc. (2009) Literature review of treatment technologies to remove selenium from mining influenced water.

Goldhaber, S. B. (2003) Trace element risk assessment: essentiality vs. toxicity, Regulatory Toxicology and Pharmacology, 38, 232 - 242.

Gustafsson, J. P.; Johnsson, L. (1994) The association between selenium and humic substances in forested ecosystems - laboratory evidence, Applied Organometallic Chemistry, 8, 141-147.

Grosvenor, A. P.; Kobe, B. A.; Biesinger, M. C. and McIntyre, N. S. (2004) Investigatio of mltiplet splitting of Fe 2p XPS spectra and bonding in iron compounds, Surface and Interface Analysis, 36, 1564-1574. 
Gu, Z., Fang, J. and Deng, B. (2005) Preparation and evaluation of GAC-Based IronContaining Adsorbents for Arsenic Removal, Environmental Science and Technology, 39, 3833-3843.

Hall, K., Eagleton, L., Aerivos, A., Vermeulen, T. (1996) Pore and solid diffusion kinetics fixed bed adsorption under constant pattern conditions, Industrial and Engineering Chemistry Fundamentals, 5, 212-213.

Hamilton, S. J. and Lemly, D. A. (1999) Commentary water -sediment controversy in setting Environmental Standards for selenium, Ecotoxicology and Environmental Safety, 44, 227 - 235.

Hansen H.C.B., Koch C.B., Nancke-Krogh H., Borggaard O.K.; Sorensen J. (1996) Abiotic nitrate reduction to ammonium: key role of green rust. Environmental Science Technology 30, 2053-2056.

Harr, J. R. (1978) Biological effects of selenium, in Toxicity of heavy metal in the environment, edited by Oehme, F. W., Marcel Dekker, New York.

Harrison, J. B. and Berkheiser, V. E. (1982) Anion inter- actions with freshly prepared hydrous iron oxides, Clays and Clay Minerals, 30, 97-102.

Hayes, K. and Leckie, J. (1987) Modeling ionic strength effects on cation adsorption at hydrous oxide/solution interfaces, Journal of Colloid and Interface Science, 115, 564572.

Hayes, K., Papelis, C., and Leckie, J. (1988) Modeling ionic strength effects of anion adsorption at hydrous oxide/solution interfaces, Journal of Colloid and Interface Science, 125, 717-726.

Hiemstra, T. and Van Riemsdijk, W. (1996) A surface structural approach to ion adsorption: the charge distribution (C.D.) Model, Journal of Colloid and Interface Science, 179, 488-508.

Hiemstra, T. and Van Riemsdijk, W. (1999) Effect of differentcrystal faces on experimental interaction form and aggregation of hematite, Langmuir, 15, 8045 8051.

Hingston, F. J., Posner, A. M., and Quirk, J. P., (1974) Anion adsorption by goethite and gibbsite II. Desorption of anions from hydrous oxide surface, Journal of Soil Science. $25,16-26$. 
Hontoria-Lucas, C; Lopez-Peinado, A. J.; Lopez-Gonzalez, J. D.; Rojas-Cervantes, M. L. and Martin-Aranda, R. M. (1995) Study of oxygen-containing groups in series of graphite oxides: Physical and chemical characterization, Carbon, 33, 1585-1592.

Hoskins, J. and Karanfil T. (2002) Removal and sequestration of iodide using silverimpregnated activated carbon, Environmental Science and Technology, 36, 784-789.

Integrated Risk Information System (IRIS) (1991) Selenium and compounds (CASRN 7782-49-2), http://www.epa.gov/iris/subst/0472.htm\#reforal, last updated 09/01/1991 (accessed May, 2011)

Ishizaki, C. and Marti, I. (1981) Surface oxide structures on a commercial activated carbon, Carbon, 19 (9), 409.

Ismail, H. M.; Cadenhead, D. A.; and Zaki, M. I. (1996) Surface reactivity of iron oxide pigmentary powders toward atmospheric components: XPS, FESEM, and Gravimetry of CO and CO2 adsorption, Journal of Colloid and Interface Science, 194, 482-488.

Jacobs L.W. (1989) Selenium in Agriculture and the Environment. ed. by Jacobs et al., American Society of Agronomy, Inc., Madison, WI.

Jang, M., Chen, W. and Cannon, F. (2008) Preloading Hydrous Ferric Oxide into Granular Activated Carbon for Arsenic Removal, Environmental Science and Technology, 42, 3369-3374.

Johnston, C. T. and Sposito, G (1987) In Future Developments in Soil Science Research, Boersma, L. L., Ed.: Soil Science Society of America: Madison, WI.

Kapoor, A.; Tanjore, S. and Viraraghavan, T. (1995) Removal of selenium from water and wastewater, International Journal of Environmental Studies, 49, 137-147.

Kenward, P. A., Fowle, D. A. and Yee, N. (2006) Microbial selenate sorption and reduction in nutrient limited systems, Environmental Science and Technology, 40, 3782-3786.

Kuan, W., Lo, S. Wang, M. and Lin, C. (1998) Removal of Se (IV) and Se (VI) from water by aluminum-oxide-coated sand, Water Research, 32 (3), 915-923.

Kubota, J.; Allaway, W. H.; Carter, D. L.; Cary, E. E. and Lazar, V. A. (1967) Selenium in crops in the United States in relation to selenium-responsive diseases of animals, Journal of Agricultural and Food Chemistry, 15, 448 - 453. 
Lakin, H. W. (1948) Selenium occurrence in certain soils of the United States, with a discussion of related topics: Seventh report, USDA Technical Bulletins, 953. U. S. Govt. Print. Office, Washington, DC.

Lakin, H. W. (1973) Selenium in our environment, Advances in Chemistry Series, 123, 96-111.

Lenntech B. V., Selenium, http://www.lenntech.com/periodic/elements/se.htm, accessed May, 2011.

Lewis, D. G. and Farmer, V. C. (1986) Infrared absorption of surface hydroxyl groups and lattice vibrations in lepidocrocite $(\gamma-\mathrm{FeOOH})$ and boehmite $(\gamma$-Al-OOH). Clay Minerals, 21, 93-100.

Lindberg, P. (1968) Selenium determination in plant and animal material and in water: A methodological study, Acta Veterinaria Scandinavica Supplementum, 23.

Lo, S. L. and Chen, T. Y. (1997) Adsorption of Se (IV) and Se (VI) on an iron-coated sand from water, Chemosphere, 35 (5), 919-930.

Loeppert, R. H. and Inskeep, W. P. (1996) Method of Soil Analysis Part 3. Chemical Methods, Soil Science Society of America and American Society of Agronomy, Madison, WI.

Losi, M. E. and Frankenberger, W. T. Jr. (1997) Bioremediation of selenium in soil and water, Soil Science, 162 (10), 692-702.

$\mathrm{Lu}$, J. (1995) Comparative study on determination of iron contents in activated carbon, Linchan Hиахие Yи Congye, 15, 57-61.

Ma, X. and Pawlik, M. (2005) Effect of alkali metal cations on adsorption of guar gum onto quartz, Journal of Colloid and Interface Science, 289, 48-55.

Maiers, D. T., Wichlacz, P. L., Thompson, D. L. and Bruhn, D. F. (1988) Selenate reduction by bacteria from a selenium-rich environment, Applied and Environmental Microbiology, 54, 2591-2593.

Manceau, A. and Charlet, L. (1994) The mechanism of selenate adsorption on goethite and hydrous ferric oxide, Journal of Colloid and Interface Science, 168, 87-93.

Marinas, B. J., and Selleck, R. E. (1992) Reverse osmosis treatment of multicomponent electrolyte solutions, Journal of Membrane Science, 72, 211-229. 
Masscheleyn, P. H., Patrick, W. H., (1993) Biogeochemical prosesses affecting selenium cycling in wetlands, Environmental Toxicology and Chemistry, 12, 2235-2243.

Mavrov, V., Stamenov, S., Todorova, E., Chmiel, H., and Erwe, T. (2006) New hybrid electrocoagulation membrane process for removing selenium from industrial wastewater, Desalination, 201, 290-296.

Mayland, H. F., James, L. F., Panter, K. E. and Sonderegger, J. L. (1989) Selenium in seleniferous environments, in Selenium in Agriculture and Environment, SSSA Special Publication, no. 23.

McIntyre, N. S. and Zetaruk, D. G. (1977) X-ray photoelectron spectroscopic studies of iron oxides, Analytical Chemistry, 49, 1521 - 1529.

McKeague, J. A. and Day, J. H. (1966) Dithionite- and oxalate-extractable Fe and Al as aids in differentiating various classes of soils, Canadian Journal of Soil Science, 46, $13-22$.

McNeal, J. M. and Balistrieri, L. S. (1989) Geochemistry and occurrence of selenium: an overview, in Selenium in Agriculture and the Environment, ed. by Jacobs et al., SSSA, Inc., Madison, WI.

Monteil-Rivera, F., Fedoroff, M., Jeanjean, J., Minel, L., Barthes, M. and Dumonceau, J. (2000) Sorption of selenite $\left(\mathrm{SeO}_{3}{ }^{2-}\right)$ on hydroxyapatite: An exchange process, Journal of Colloid and Interface Science, 221, 291-300.

Moreira, R.F.P.M., Peruch, M. G. and Kuhnen, N. C. (1998) Adsorption of textile dyes on alumina equilibrium studies and contact time effects, Brazilian Journal of Chemical Engineering, 15 (1),

Moulded, J. F.; Stickle, W. F.; Sobol, P. E. and Bomben, K. D.; () Handbook of X-ray Photoelectric Spectroscopy, Published by ULVAC-PHI, Inc., Chigasaki, Japan and Physical Electronics USA, Inc., Chanhassen, MI.

Moxon, A. L. and Rhian, M. (1943) Selenium poisoning, Physiological Reviews, 23, 305 $-327$.

MSE Technology Applications, Inc. (2001) Selenium treatment/removal alternatives demonstration project: Mine waste technology program activity III, project 20.

Murphy, A. P. (1988) Removal of selenate from water by chemical reduction, Industrial and Engineering Chemistry Research, 27, 187-191. 
Nakamoto, K (2009) Infrared and Raman Spectra of Inorganic and Coordination Compounds, 6th Ed., John Wiley \& Sons, Inc., Hoboken, NJ.

National Academy of Science-National Research Council (1980) Mineral tolerance of domestic animals. Subcomm. On mineral toxicity in animals. Comm. On animal nutrition, Washington, D.C.

National Academy of Science-National Research Council (1983) Selenium in nutrition, Rev. ed. Board on Agric. NAS-NRC, Washington, D.C.

Namasivayam, C. and Prathap, K. (2006) Removal of selenite using 'waste' $\mathrm{Fe}$ (III)/Cr (III) hydroxide: Adsorption kinetics and isotherms, Toxicological and Environmental Chemistry, 88(1), 85-89.

Navarro-Alarcon, M. and Cabrera-Vique, C. (2008) Selenium in food and the human body: A review, Science of the Total Environment, 400, 115 - 141.

Neal, R. H., Sposito, G.; Holtzclaw, K. M.; Traina, S. J. (1987a) Selenite adsorption on alluvial soils: I. Soil composition and $\mathrm{pH}$ effects, Soil Science Society of America Journal, 51, 1161-1165.

Neuzil, S. G., Dulong, F. T., Cecil, C. B., Fedorko, N., Renton, J. J. and Bhumbla, D. K. (2007) Selenium concentrations in middle Pennsylvanian coal-bearing strata in the central Appalachian basin, U.S. Geological Survey Open-File Report 2007-1090.

Nishimura, T. and Hashimoto, H. (2007) Removal of selenium (VI) from aqueous solution with polyamine-type weakly basic ion exchange resin, Separation Science and Technology, 42, 3155-3167.

Nriagu, J. O. and Pacyna, J. M. (1988) Quantitative assessment of worldwide contamination of air, water and soils by trace metals, Nature, 333, 134 - 139.

Oh, S. J.; Cook, D. C. and Townsend, H. E. (1998) Characterization of iron oxides commonly formed as corrosion products on steel, Hyperfine Interactions, 112, 59-65.

Ohlendorf, H. M. (1989) Selenium in agriculture and the environment, Soil Science Society of America, 133, Madison, WI.

Öhman, L. O. (1988) In: Metal speciation: theory, analysis and application, Lewis Inc., Chelsea, 1-40. 
Olegario, J. T.; Yee, N.; Miller, M.; Sczepaniak, J. and Manning, B. (2009) Reduction of $\mathrm{Se}$ (VI) to Se (-II) by zerovalent iron nanoparticle suspensions, Journal of Nanoparticle Research.

Oremland, R. S., Hollibaugh, J. T., Maest, A. S., Presser, T. S., Miller, L. G. and Culbertson, C. W. (1989) Selenate reduction to elemental selenium by anaerobic bacteria in sediments and culture: biogeochemical significance of a novel sulfateindependent respiration, Applied and Environmental Microbiology, 55, 2333-2343.

Pakula, M.; Biniak, S.; Swiatkowski, A. (1998) Chemical and electrochemical studies of interactions between iron (III) ions and an activated carbon surface, Langmuir, 14, 3082-3089.

Palache, C.; Berman, H. and Frondel, C. (1944) The System of Mineralogy, 7th ed., John Wiley\& Sons, New York, N.Y.

Papelis, C., Brown, G. E., Parks, G. A., Leckie, J. O. (1995) X-ray adsorption spectroscopic studies of cadmium and selenite adsorption on aluminum oxides, Langmuir, 11, 2041-2048.

Papelis, C., Roberts, P. V., Leckie, J. O. (1995) Modeling the rate of cadmium and selenite adsorption on micro-and mesoporous transition aluminas, Environmental Science and Technology, 29, 1099-1108.

Parfitt, RL. (1978) Anion adsorption by soils and aoil materials, Adv. Agron., 30, 1-50.

Parida, K. M., Gorai, B., Das, N. N. and Rao, S. B. (1997) Studies on ferric oxide hydroxides: III Adsorption of selenite on different forms of iron oxyhydroxides, Journal of Colloid and Interface Science, 185, 355-362.

Peak, D. and Sparks, D. L. (2002) Mechanisms of selenate adsorption on iron oxides and hydroxides, Environmental Science and Technology, 36, 1460.

De la Puente, G.; Pis, J. J.; Menendez, J. A and Grange, P. (1997) Thermal stability of oxygenated functions in activated carbons, Journal of Analytical and Applied Pyrolysis, 43, 125-138.

Rankama, K. and Sahama, Th. G. (1950) Geochemistry, University of Chicago Press, Chicago, Ill. 
Reddy, K. J., Zhang, Z., Blaylock, M. J., Vance, G. F. (1995) Method for detecting selenium speciation in groundwater, Environmental Science and Technology, 29, 1754-1759.

Reeves, R. D. (2006) Hyperaccumulation of trace elements by plants, Phytoremediation of Metal-Contaminated Soils, 68, 25 - 52.

Reuter, D. J. (1975) Selenium in soils and plant: A review in relation to selenium deficiency in South Australia, Agricultural Record, 2, 44-50.

Rosenfeld, I. and Beath, O. A. (1964) Selenium: Geobotany, Biochemistry, Toxicity and Nutriution, Academic Press, New York.

Rovira, M.; Giménez, J.; Martínez, M.; Martínez-Lladó, X. de Pablo, J.; Martí, V. and Duro, L. (2008) Sorption of selenium (IV) and selenium (VI) onto natural iron oxides: goethite and hematite, Journal of Hazardous Materials, 150, 279-284.

Russell, J. D.; Parfitt, R. L., Fraser, A. R. and Farmer, V. C. (1974) Surface structure of gibbsite, goethite and phosphated goethite, Nature, 248, 220-221.

Saeki,K., Matsumoto, S.; Tatsukawa, R. (1995) Selenite adsorption by manganese oxides, Soil Science, 160, 265-272.

Sarathchandra, S. U. and Watkinson, J. H. (1981) Oxidation of elemental selenium to selenite by Bacillus megaterium, Science (Washington, D. C.), 21, 600-601.

Schulze, H.; Weinstock, N.; Müller, A. and Vandrish, G. (1973) Raman intensities and force constants of $\mathrm{PO}_{4}{ }^{3-}, \mathrm{SO}_{4}{ }^{3-}, \mathrm{ClO}_{4}{ }^{3-}, \mathrm{SeO}_{4}{ }^{2-}$ and $\mathrm{BrO}_{4}{ }^{-}$, Spectrochimica Acta, 29A, $1705-1709$.

Schwertmann, U. (1964) The differentiation of iron oxide in soils by a photochemical extraction with acid ammonium oxalate, Z. Pflanzenernaehr. Dueng. Bodenkund, 105, $194-201$.

Scott, M. J. and Morgan, J. J. (1996) Reactions at oxide surfaces 2. Oxidation of Se (IV) by synthetic birnessite, Environmental Science and Technology, 30, 1990-1996.

Scott, R. C. and Voegeli, P. T., Sr. (1968) Radiochemical analyses of ground and surface water in Colorado 1954-1961, Colorado Water Conservation Board Basic-Data Report No. 7.

Séby, F., Potin-Gautier, M., Lespes, G. and Astruc, M. (1997) Selenium speciation in soils after alkaline extraction, Science of the Total Environment, 207, 81-90. 
Séby, F., Potin-Gautier, M., Giffaut, E. and Donard, O. F. X. (1998) Assessing the speciation and the biogeochemical processes affecting the mobility of selenium from a geological repository of radioactive wastes to the biosphere, Analysis, 26, 193-198.

Sorg, T. J. and Logsdon, G. S. (1976) Removal of selenium from water state of art, Proceedings of the Symposium on Selenium-Tellurium in the environment, University of Notre Dame, Notre Dame, Indiana, 114-128.

Sors, T. G., Ellis, D. R. and Salt, D. E. (2005) Selenium uptake, translocation, assimilation and metabolic fate, Photosynthesis Research, 86, 373-389.

Spallholz, J. E. and Hoffman, D. J. (2002) Selenium toxicity: cause and effects in aquatic birds, Aquatic Toxicology, 57, 27 - 37.

Sparks, L. D. (2003) Environmental Soil Chemistry, Academic Press, Boston, MA.

Stumm, W., Huang, C. P., and Jenkins, S. R. (1970) Specific chemical interaction affecting the stability of dispersed systems, Croatica Chemica Acta, 42, 223.

Su, C. and Suarez, D. L. (2000) Selenate and selenite sorption on iron oxides: An infrared and electrophoretic study, Soil Science Society of America Journal, 64, 101-111.

Swaine, D. J. (1955) The trace-element content of soils, Technical Communication, 48, Bureau of Soil Science, Harpenden, England.

Swinden, L. (2007) Report on toxicity of sediments produced during channel dredging in port Phillip Bay, Department of primary industries annual report.

Tamari, Y. (1998) Methods of Analysis for the Determination of Selenium in Biological, Geological and Water Samples, Environmental Chemistry of Selenium, ed. By Frankenberger Jr., W. T. and Engberg, R. A., Marcel Dekker, Inc.

Terry, N., Zayed, A. M., de Souza, M. P. and Tarun, A. S. (2000) Selenium in Higher Plants, Annual Review of Plant Physiology and Plant Molecular Biology, 51, 401-433.

Thibeau, R. J.; Brown, C. W. and Heidersbach, R. H. (1978) Raman spectra of possible corrosion products of iron, Applied Spectroscopy, 32, 532 - 535.

Tinsley, I. J.; Harr, J. R.; Bone, J. F.; Weswig, P. H. and Yamamoto, R. S. (1967) Selenium toxicity in rats. I. Growth and longevity, In: Selenium in Biomedicine, Muth, O. H.; Oldfield, J. E. and Weswig, P. H. Ed. Proc. 1st Int. Symp., Oregon State University. 
Todini Co s.p.a. (2006) Chemical product based on selenium, http://www.todiniandco.com/products/selenium/index.html (accessed Sep. 2007)

Trelease, S. F. (1945) Geochemical survey of Missouri-Geography of soil geochemistry of Missouri agricultural soils, U.S. Geological Survey professional paper, 954-H.

U.S. Department of Agriculture (2002) Tracking the pathways and anticipating impacts of selenium, http://www.srs.fs.usda.gov/news/96

U.S. Environmental Protection Agency (USEPA) (1987) Ambient Water Quality Criteria for Selenium - 1987, Publication EPA-440/5-87-006, USEPA, Office of Water Regulations and Standards, Washington, DC.

U.S. Environmental Protection Agency (USEPA) (2006) Consumer Factsheet on: Selenium, National Primary Drinking Water Regulations, http://www.epa.gov/ogwdw/pdfs/factsheets/ioc/selenium.pdf (accessed May., 2011)

U.S. Environmental Protection Agency (USEPA) (2007) Mine Waste Technology: success stories, http://www.epa.gov/hardrockmining/ (accessed Jan, 2007)

U.S. Environmental Protection Agency (USEPA) (2003) Mountaintop Mining/Valley Fills in Appalachia: Draft Programmatic Environmental Impact Statement, U.S. Environmental Protection Agency.

U.S. Environmental Protection Agency (USEPA) (1998) Standard Methods for the Examination of Water and Wastewater, 3500-Se-C Colorimetric Method, U.S. Environmental Protection Agency. USEPA (2006) Technical Factsheet on: Selenium, National Primary Drinking Water Regulations, http://www.epa.gov/safewater/dwh/tioc/selenium.html (accessed Nov., 2006)

Vaughan Jr., R. L., Reed, B. E. (2005) Modeling As (V) removal by a iron oxide impregnated activated carbon using the surface complexation approach, Water Research, 39, 1005-1014.

Venardos, K., Harrison, G., Headrick, J. and Perkins, A (2004) Effects of dietary selenium on glutathione peroxidase and thioredoxin reductase activity and recovery from cardiac ischemia-reperfusion, Journal of Trace Elements in Medicine and Biology, 18, 81 - 89. 
Venema, P., Hiemstra, T., Weidler, P. G. and Van Riemsdijk, W. A. (1998) Intrinsic proton affinity of reactive surface groups of metal (hydr)oxides: Application to iron (hydr)oxides, Journal of Colloid and Interface Science, 198, 282 - 295.

Vesper, D. J., Bryant, G. and Ziemkiewicz, P. F. (2004) A preliminary study on the speciation of selenium in a West Virginia watershed, 2004 National Meeting of American Society of Mining and Reclamation, April 18-24, Lexington, KY.

Vesper, D. J.; Roy, M. and Rhoads, C. J. (2008) Selenium distribution and mode of occurrence in the Kanawha Formation, southern West Virginia, U. S. A., International Journal of Coal Geology, 73, 237 - 249.

Vuori, E., Vääriskoski, J., Hartikainen, H.; Kumpulainen, J.; Aarnio, T.; Niinivaara, K. (1994) A long-term study of selenate sorption in Finnish cultivated soils, Agriculture, Ecosystems \& Environment, 48, 91-98.

Watts, J. F. and Wolstenholme, J. (2003) An introduction to surface analysis by XPS and AES, John Wiley \& Sons, Ltd., West Sussex, England.

Wells, N. (1967) Selenium content of soil-forming rocks, New Zealand Journal of Geology and Geophysics, 10, 198.

White, A. F., Dubrovsky, N. M. (1994) In: Selenium in the environment, Frankenberge, W. T., Benson, S. Eds. Mareel Dekker Inc., New York, 185-221.

Wilber, C. G. (1983) Selenium. A potential environmental poison and a necessary food constituent, Charles C. Thomas, Springfield, IL.

Wijnja, H. and Schulthess, C. P. (2000) Vibrational Spectroscopy study of selenate and sulfate adsorption mechanisms on Fe and Al (hydr)oxide surfaces, Journal of Colloid and Interface Science, 229, 286-297

WV Geological and Economic Survey. Trace Elements in West Virginia Coals, http://www.wvgs.wvnet.edu/www/datastat/te/index.htm (accessed Dec., 2005)

Yang, L., Wu, S. and Chen, J. (2007) Modification of Activated Carbon by Polyaniline for Enhanced Adsorption of Aqueous Arsenate, Industrial and Engineering Chemistry Research, 46, 2133-2140.

Yantasee, W., Lin, Y., Fryxell, G., Alford, K., Busche, B. and Johnson, C. (2004) Selective removal of copper (II) from aqueous solutions using fine-grained activated 
carbon functionalized with amine, Industrial and Engineering Chemistry Research, 24, 2759-2764.

Yodnane, P.; Patelunas, G. M. and Niece, J. E. (1992) Arsenic and selenium removal from fly ash leachate, Water Environment and Technology, 4, 30 - 31 .

Zhang, N., Lin, L-S. and Gang, D. (2008) Adsorptive selenite removal from water using iron-coated GAC adsorbents, Water Research, 42, 3809-3816.

Zhang, N; Gang, D. and Lin, L-S (2010) Adsorptive removal of ppm-level selenate using iron-coated GAC adsorbents, Journal of Environmental Engineering, 136 (10), 10891095.

Zhang, P. C. and Sparks, D. L. (1990) Kinetics of selenate and selenite adsorption/desorption at the goethite/water interface, Environmental Science and Technology, 24:1848-1856. 


\section{VITA}

Ning Zhang was born in Shenyang, Liaoning Province, People's Republic of China. She enrolled in Dalian University of Technology, Dalian, China in Sep. 2000 and received her Bachelor Degree in Environmental Science and Technology in Jul. 2004. After graduation, she was admitted into West Virginia University in Aug. 2005, studying for her Master degree in Civil and Environmental Engineering. She worked under the advisement of Dr. Lian-shin Lin and her work focused on selenite removal by adsorption using iron coated granular activated carbon. She achieved her master degree in May, 2008 and continued pursuing her doctoral degree in WVU. Her Ph.D. work mainly engaged on selenate adsorptive removal, adsorbed selenate structure investigation and adsorbents characterization and preparation modifications. 